University of San Diego

Digital USD

2011-05-01

\title{
Perceptions of Leadership: An Analysis of College Students' Understandings of the Concept of Leadership
}

Paige Haber PhD

University of San Diego

Follow this and additional works at: https://digital.sandiego.edu/dissertations

Part of the Leadership Studies Commons

\section{Digital USD Citation}

Haber, Paige PhD, "Perceptions of Leadership: An Analysis of College Students' Understandings of the Concept of Leadership" (2011). Dissertations. 824.

https://digital.sandiego.edu/dissertations/824

This Dissertation: Open Access is brought to you for free and open access by the Theses and Dissertations at Digital USD. It has been accepted for inclusion in Dissertations by an authorized administrator of Digital USD. For more information, please contact digital@sandiego.edu. 
PERCEPTIONS OF LEADERSHIP:

AN ANALYSIS OF COLLEGE STUDENTS' UNDERSTANDINGS OF THE

CONCEPT OF LEADERSHIP

by

PAIGE HABER

A dissertation submitted in partial fulfillment

of the requirements for the degree of

Doctor of Philosophy

University of San Diego

May 2011

\author{
Dissertation Committee \\ Cheryl Getz, Ed.D. (Chair) \\ Steven A. Gelb, Ph.D. \\ Noriyuki Inoue, Ph.D. \\ Susan Komives, Ed.D.
}


(C) Copyright by Paige Haber 2011

All Rights Reserved 


\begin{abstract}
Colleges and universities increasingly have embraced the goal of developing students' leadership capacity. Diverse curricular and co-curricular leadership programs currently exist and continue to be developed to address leadership development outcomes. There is, however, limited understanding of how college students think about and define leadership. This study sought to fill this gap in the research by examining the ways in which college students understand the concept of leadership.

In this mixed methods study the researcher analyzed data from the MultiInstitutional Study of Leadership (MSL) project, a national research study on college student leadership and the college experience. Data for the MSL were collected through an online survey with over 91,000 undergraduate college student respondents from 101 diverse U.S. colleges and universities. For this dissertation, participants were selected through random criterion sampling from the national dataset in order to have a sample that reflected a substantial number of men and women from different racial backgrounds.

The online survey generated data about a variety of demographic and environmental variables and an open-ended response prompt, which asked participants to provide their definition of leadership. The data were analyzed qualitatively and then quantitatively. The qualitative analysis entailed thematic content analysis procedures to identify different themes of leadership definitions. The different definitional themes then served as the dependent variables in loglinear analysis and logistic regression to determine demographic and environmental variables associated with the definitions.

The study resulted in 10 leadership themes. Four of the themes reflected leader and follower/ group relationships, three reflected leader characteristics and behaviors, and
\end{abstract}


three reflected outcomes of leadership. Overall, students' themes tended to be more hierarchical and leader-centric understandings of leadership. Significant differences emerged in students' leadership themes by gender, race, and age. Additionally, a number of environmental variables emerged as significant predictors for the themes. Implications from this study suggest that administrators and faculty should clearly identify the values of leadership they wish to develop in their students and purposefully examine the leadership programs and opportunities available to students with particular attention to how leadership is presented, promoted, and modeled. 


\section{DEDICATION}

This dissertation is dedicated to the college student educators who support and challenge college students as they grow and develop and to the college students who will pursue their vocational calling to make this world a better place. 


\section{ACKNOWLEDGEMENT}

First and foremost I would like to thank the two advisors and mentors who have supported and challenged me in my professional and personal growth and development: Dr. Cheryl Getz and Dr. Susan Komives. These women are amazing role models who have inspired in me greater purpose, meaning, and confidence in my work. Additionally, I would like to recognize Dr. Steve Gelb and Dr. Nori Inoue, the other two members of my committee, for their thought-provoking contributions to this dissertation.

This research would not be possible without the leadership and hard work of Dr. Susan Komives, Dr. John Dugan, Dr. Julie Owen, and the other members of the MultiInstitutional Study of Leadership research team. I would like to thank the team for their amazing contributions to the research on college student leadership development and for the opportunity to use this vast dataset for my dissertation work.

On a personal note I would like to thank the amazing people who have supported me through my educational career as a "professional student" - my family. Thank you to my father Kai, my mother Joan, my brother Baron, and my stepmother Janet. I appreciate all of your support and interest in my work. I would also like to thank my best friend and colleague, Dan, for being an amazing sounding board, motivator, and study buddy while we spent countless hours in coffee shops writing. I would also like to thank my lovely Portuguese Water Dog, Ike, for being patient with me as I wrote this dissertation- I promise more walks in the future! Last, and not least, I would like to express my immense gratitude to my partner, Tom, for the great patience, understanding, love, and support he has provided me throughout this process. 


\section{TABLE OF CONTENTS}

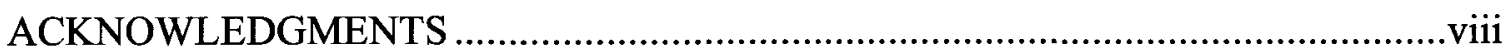

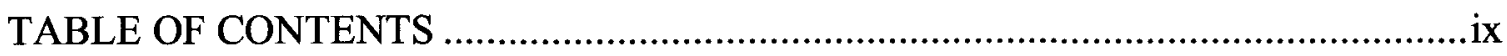

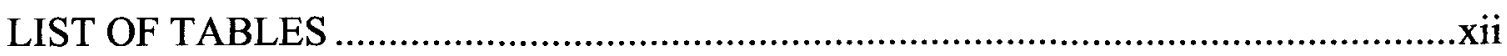

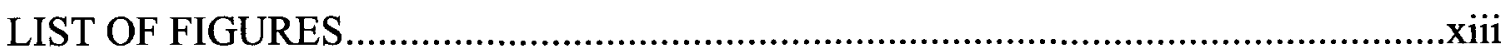

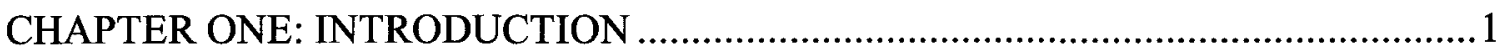

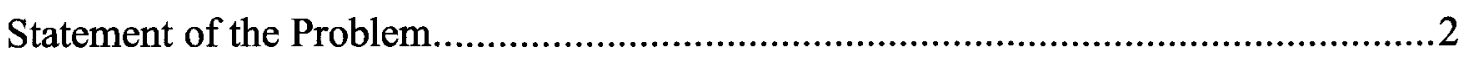

Purpose of the Study and Research Questions ............................................................5

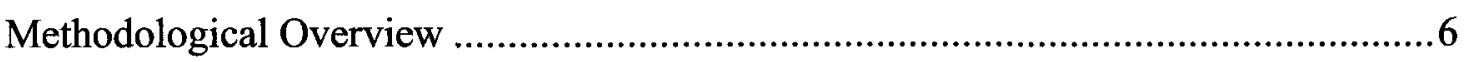

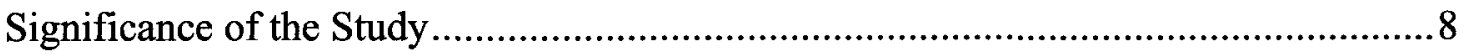

CHAPTER TWO: REVIEW OF THE LITERATURE ……………............................. 10

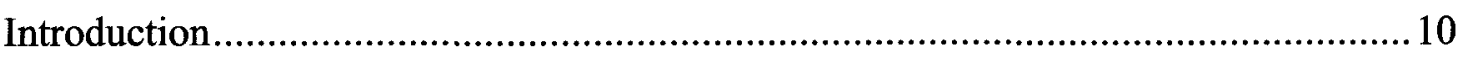

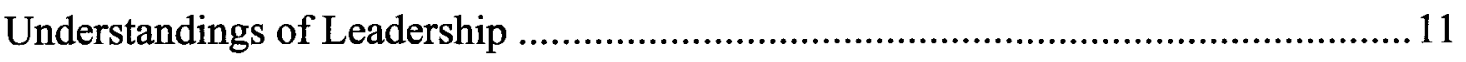

Leader-Centric Perspectives on Leadership.......................................................... 12

Relational Perspectives on Leadership .............................................................. 13

Systems Perspectives on Leadership ..............................................................23

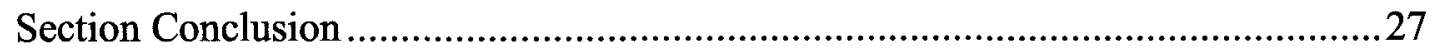

College Students' Understandings of Leadership ......................................................27

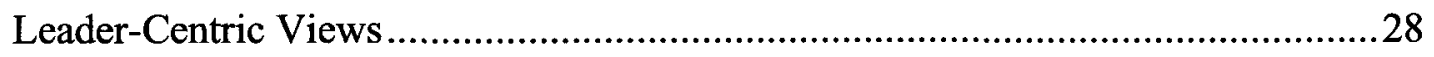

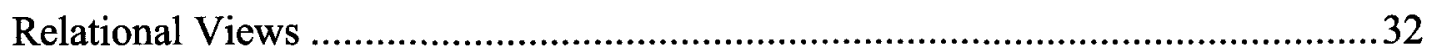

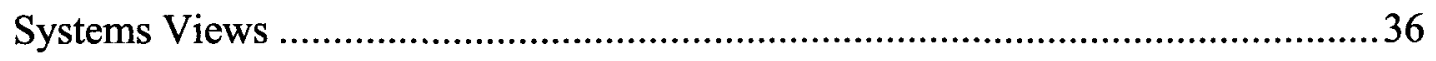

Studies Examining Leadership Definitions..........................................................38

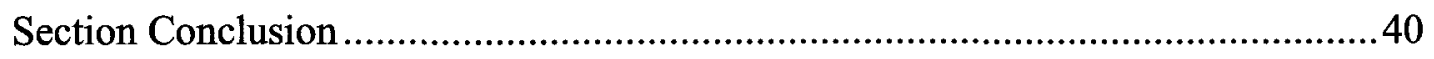

College Student Leadership Outcomes...................................................................41

Studies Focused Broadly on Leadership Outcomes ………....................................43

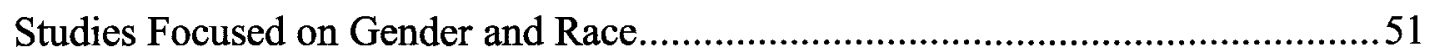

Studies Focused on Student Involvement and College Experiences.........................55

Studies Focused on Student Leadership Programs...................................................64

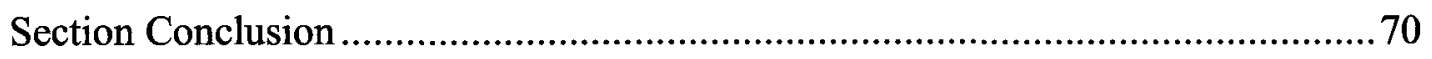

Conclusions and Discussion of Literature Review ................................................... 


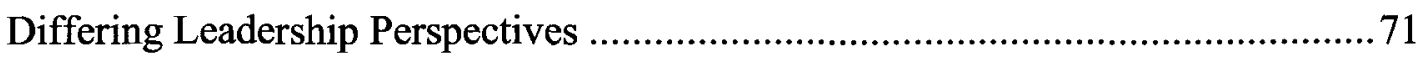

Race and Gender Matter; Might Age Also Matter? ............................................... 72

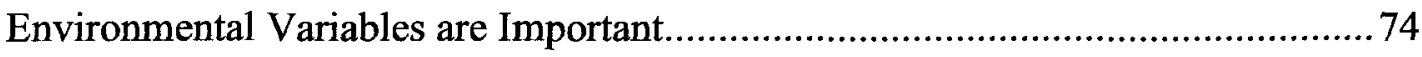

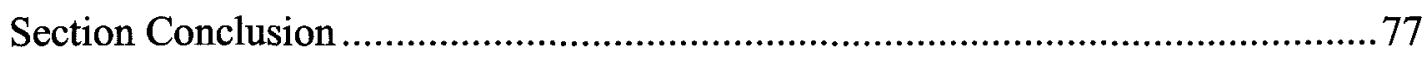

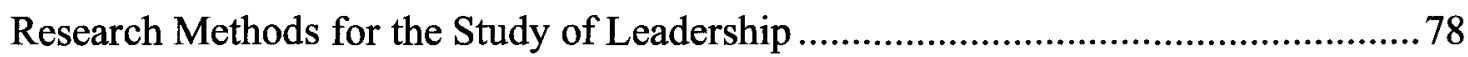

Studying Leadership Understandings and Definitions ............................................ 81

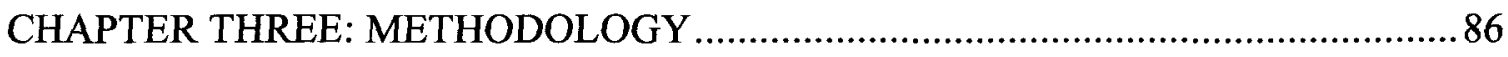

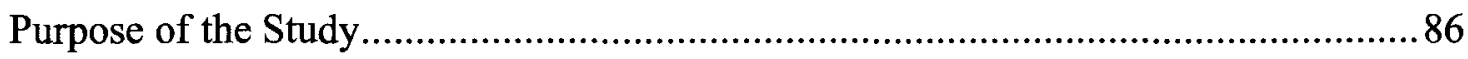

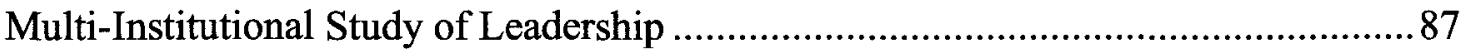

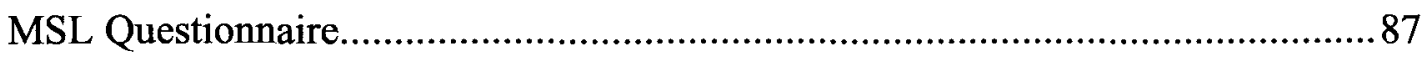

MSL Participants and Data Collection Procedures ................................................... 88

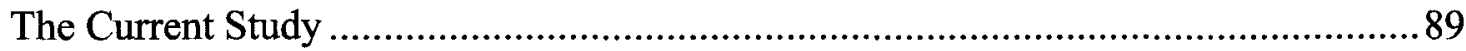

Participants in the Current Study ......................................................................90

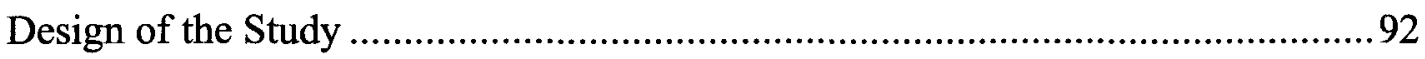

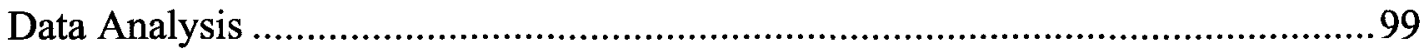

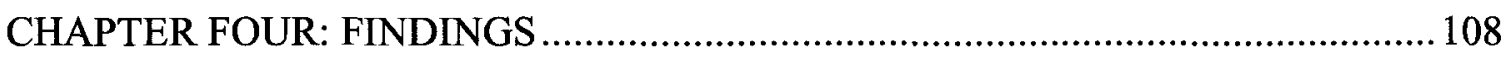

Participant Characteristics and Descriptive Findings .................................................108

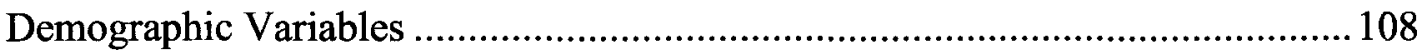

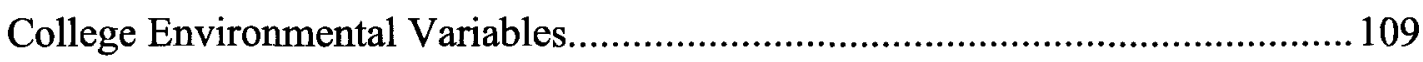

Research Question \#1: Understandings of Leadership..........................................111

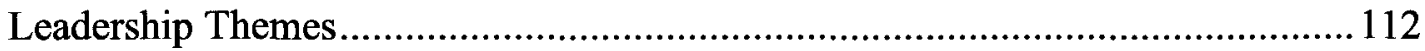

Descriptive Findings of Leadership Themes........................................................ 121

Summary of Findings for Research Question \#1 ............................................... 125

Research Question \#2: Differences by Gender, Race, and Age................................ 126

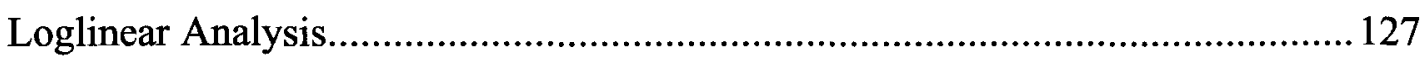

Results by Gender, Race, and Age For Leader and Follower/ Group Themes....... 128

Results by Gender, Race, and Age For Leader Characteristics and Behavior Themes

Results by Gender, Race, and Age For Leadership Outcome Themes................... 135

Summary of Findings for Research Question \#2 ................................................. 140

Research Question \#3- Predictors of Leadership Themes .......................................... 141 


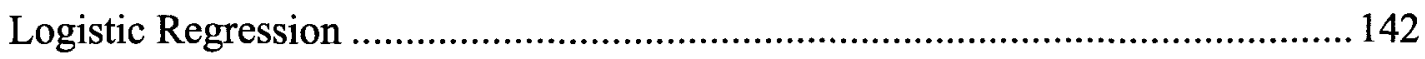

Logistic Regression Models and Variables............................................................ 142

Results for Leader and Follower/ Group Themes ................................................. 144

Results for Leader Characteristic and Behavior Themes....................................... 147

Results for Leadership Outcome Themes ............................................................ 150

Summary of Findings for Research Question \#3 …………................................. 154

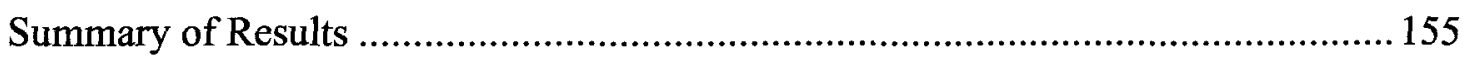

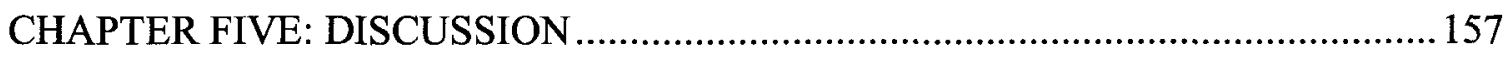

Summary and Discussion of Findings ................................................................. 157

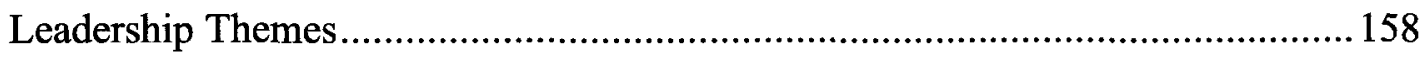

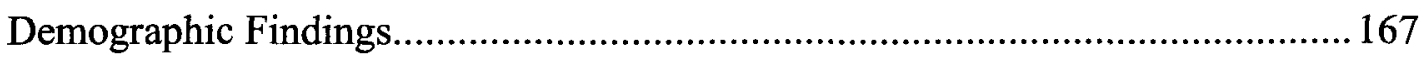

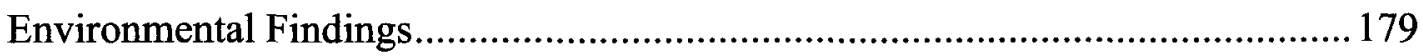

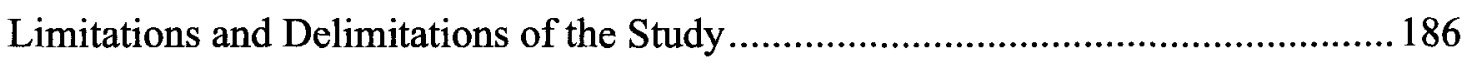

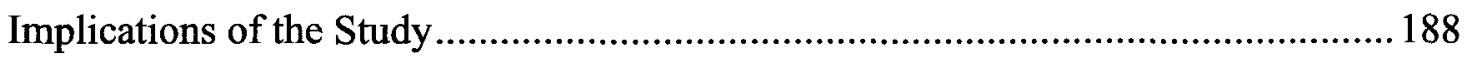

Recommendations for Further Research ............................................................ 193

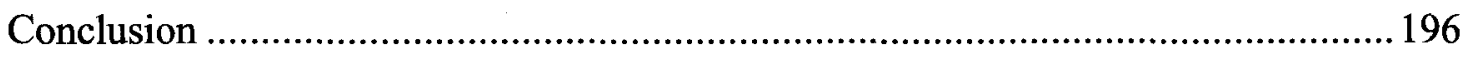

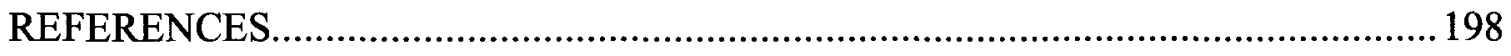

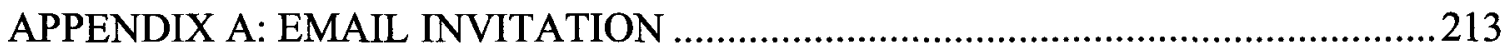

APPENDIX B: INFORMED CONSENT FORM ……….......................................214

APPENDIX C: PARTICIPANT DEMOGRAPHICS IN CURRENT STUDY AS

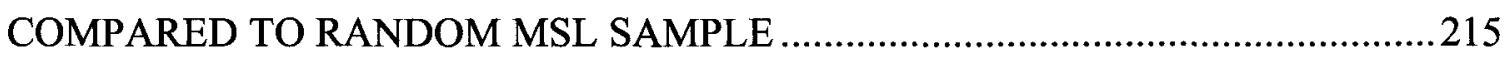

APPENDIX D: THEME CODEBOOK AND INTERRATER INSTRUCTIONS ........216

APPENDIX E: INTERCORRELATIONS OF PREDICTOR VARIABLES FOR

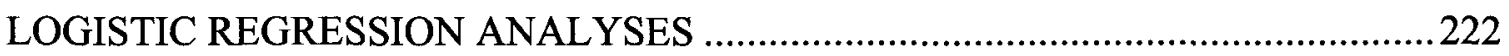




\section{LIST OF TABLES}

Table 1: Values of the Social Change Model of Leadership ............................................21

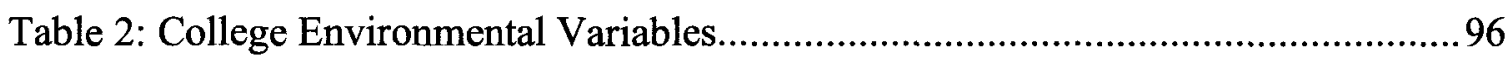

Table 3: Descriptive Findings of College Environmental Variables $(\mathrm{N}=1,100) \ldots \ldots \ldots . .110$

Table 4: Frequencies of Leadership Themes- Total, Gender, and Age.......................... 123

Table 5: Frequencies of Leadership Themes- Race ................................................... 124

Table 6: Top Leadership Theme Combinations Reflecting 2-4 Themes ....................... 126

Table 7: Summary of Observed Frequencies and Percentages for Significant Effects for

Themes 1-4 by Gender, Race, and Age ……………….................................. 129

Table 8: Summary of Loglinear Analysis of the Relation Between Leadership Themes 1-

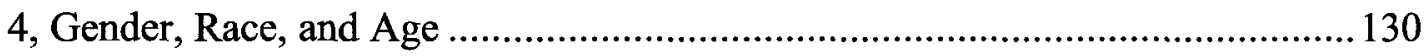

Table 9: Summary of Observed Frequencies and Percentages for Significant Effects for

Themes 5-7 by Gender, Race, and Age .............................................................. 133

Table 10: Summary of Loglinear Analysis of the Relation Between Leadership Themes

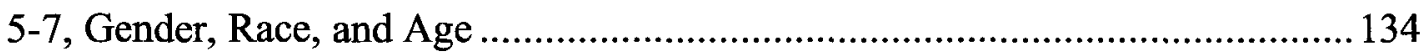

Table 11: Summary of Observed Frequencies and Percentages for Significant Effects for

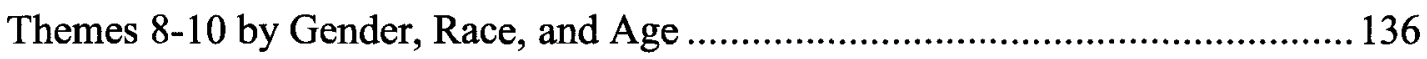

Table 12: Summary of Loglinear Analysis of the Relation Between Leadership Themes

8-10, Gender, Race, and Age .

Table 13: Summary of Logistic Regression Analysis Predicting Theme 1: Collaborate 146

Table 14: Summary of Logistic Regression Analysis Predicting Theme 4: Direct........ 147

Table 15: Summary of Logistic Regression Analysis Predicting Theme 6- Modeling .. 149 
Table 16: Summary of Logistic Regression Analysis Predicting Theme 7: Personal

Qualities.

Table 17: Summary of Logistic Regression Analysis Predicting Theme 9: Shared Goal 153

Table 18: Summary of Logistic Regression Analysis Predicting Theme 10: Task ........ 154

Table 19: Summary of Findings for Leadership Themes ............................................ 156 


\section{LIST OF FIGURES}

Figure 1: Relational Leadership Model......................................... 19

Figure 2 Social Change Model of Leadership Development.......................20

Figure 3: Prevalence of Leadership Themes Within Total Sample...................121 


\section{CHAPTER ONE: INTRODUCTION}

Leadership development as an outcome of higher education receives considerable attention at institutional and national levels (Council for the Advancement of Standards in Higher Education, 2009; Keeling, 2004). Many colleges and universities, for example, emphasize leadership in institutional mission statements and identify the development of leadership as an important outcome and goal of their educational programs (Astin \& Astin, 2000; Roberts, 2003). Institutions strive to create students who will be leaders in the larger society. This goal should not be surprising since one need only peruse bookstore shelves to know that leadership is considered a desirable quality in the workplace and society. Leadership remains necessary beyond higher education and the workplace for tackling some of the large, complex issues facing our global society (Allen, Stelzner, \& Wielkiewicz, 1998; Heifetz, 1994; Rost, 1991; Senge, Scharmer, Jaworski, \& Flowers, 2004).

Despite the strong messages about the importance of leadership in higher education and society in general—and, perhaps, because of the high demand for leadership in a variety of very different contexts-there is a lack of agreement on what leadership is and how leadership should be taught and practiced (Bass, 1990; Goethals \& Sorenson, 2007). The term leadership, for example, can be used as a kind of buzzword, i.e., as a fancier way of talking about management or success; it also has been the central concept in an emerging interdisciplinary academic field of study which tends to draw rather rigid lines between the notion of leadership and the idea of management (Goethals \& Sorenson, 2007; Rost, 1991; Sorenson, 2007). Leadership has been understood by some scholars as an inherent trait, by others as a skill set or behaviors, and yet by others 
as a process or relationship (Northouse, 2007). Leadership understandings and definitions can provide insight on one's expectations for leadership (of self and others) and inform how one engages in leadership; additionally, one's understanding of leadership could influence participation in leadership programs or opting into a leadership role.

\section{Statement of the Problem}

The field of leadership studies continues to evolve through research into the many facets of leadership and the growth of academic undergraduate, graduate, and doctoral programs (Goethals, Sorenson, \& Burns, 2004; Komives, 2011; National Clearinghouse for Leadership Programs, 2008). While a fruitful discussion and debate of differing perspectives on leadership in academia continues, there is little systematic research about the general population's understandings and definitions of leadership. Even less is known about how undergraduate students attending higher education institutions conceptualize leadership. Without an understanding of how college students view leadership, it is difficult to identify and address their leadership development needs and the desired leadership outcomes of the institutions.

While some research exists on college students' understandings of leadership, many of these studies focus on a small or narrow student population (e.g., Komives, Owen, Longerbeam, Mainella, \& Osteen, 2005; Shertzer \& Schuh, 2004) or examine students' understanding through a specified leadership framework or model (e.g., Thompson, 2006; Wielkiewicz, 2000, 2002). Additionally, a growing body of research documents college students' self-reported leadership styles and behaviors (e.g., Cress, Astin, Zimmerman-Oster, \& Burkhardt, 2001; Dugan \& Komives, 2010; Kezar \& 
Moriarty, 2000), but these studies reveal little about how students define leadership. Recent research also reveals that people's understandings of leadership, their sense of leadership identity, and their leadership behaviors reflect a developmental process (Avolio \& Gibbons, 1988; Day, 2001; Komives et al., 2005; Day, Harrison, \& Halpin, 2008; Komives, Longerbeam, Owen, Mainella, \& Osteen, 2006; Lord \& Hall, 2005). In short, people's understandings of leadership change over time and become more complex due to a variety of influences.

There is a growing body of research on different dimensions leadership, shedding light on college students' leadership development, capacity, and efficacy. The literature and research on college student leadership suggests that students' leadership behaviors tend to differ by race and gender (Dugan \& Komives, 2007; Dugan, Komives, \& Segar, 2008; Kezar \& Moriarty, 2000; Komives et al., 2005; Romano, 1996). Additionally, some research suggests that leadership is developmental, indicating that age could play a significant role in students' leadership outcomes. A larger body of research on the effect of college on students reports a similar pattern of students from different backgrounds experiencing college differently (Pascarella \& Terenzini, 2005); a one-conception-fits-all approach is not realistic or appropriate. Accordingly, researchers should anticipate group differences and should situate demographic variables such as race and gender at the forefront of their research designs (Pascarella, 2006). Thus, the social identities of race and gender should be taken into strong consideration when further studying college students' understandings of leadership. Additionally, as colleges continue to serve adult learners, age should also be a consideration. 
As the body of research on college student leadership continues to grow and provide additional understanding of how students engage in leadership, much less is known on how college students define the concept of leadership. There is some limited research on college students' understandings of leadership, yet there remains an absence of studies that directly examine how students define leadership. Consequently, it is important to expand the existing research by examining students' views and definitions of leadership in order to provide a baseline understanding of students' definitional views. Through building off of the past research that demonstrates that gender and race are significant variables in college students' views of leadership and leadership behaviors, and by examining the definitions of students across social identity groups, a more comprehensive understanding of college students' leadership views can emerge.

This understanding could then be used to design student experiences and develop programs and initiatives that help students further develop their understandings of leadership. A study of student views of leadership could also help in assessing the impact of leadership programs or other experiences on students' views of leadership. Examining the students' views and definitions of leadership in conjunction with their experiences can provide insight into how these experiences contributed to the students' perceptions of what constitutes leadership. For example, might involvement in co-curricular leadership programs or participation in community service be associated with certain beliefs or perceptions about leadership?

Additionally, by examining leadership definitions with a particular focus on gender, race, and age, there is an opportunity to understand in more depth how leadership definitions vary across these social identities. The different leadership definitions could 
also be examined alongside students' experiences in college to determine how students' understandings of leadership relate to their involvement experiences and patterns. Such knowledge would be useful for investigation of whether a student's understanding of leadership is associated positively or negatively with his or her desire to get involved in a group, run for a position in an organization, or attend a leadership workshop or event. Information about and analyses of students' understandings of leadership can also be useful in purposefully creating leadership education and development initiatives, including courses and co-curricular programs to better serve students' leadership development needs. By understanding students' typical thinking about and conceptions of leadership, leadership educators can more purposefully address what leadership is, and then perhaps expand students' more narrow or restricted views of leadership to become more empowering and enabling, reflecting some of the more emancipatory aims of higher education (Barnett, 1988). Additionally, this greater understanding can lead to a more purposeful focus on achieving articulated leadership goals and outcomes for the institution. Therefore, there is a need to systematically study college students' differing understandings of leadership.

\section{Purpose of the Study and Research Questions}

The purpose of this study was to begin to respond to the need of understanding students' views on leadership. Specifically, in this study I examined the ways in which college students understand the concept of leadership, examined potential gender, racial, and age differences within these definitions, and investigated what demographic and environmental variables were associated with the different definitions.

The purpose articulated above suggests the following research questions: 
1. What are the different ways college students understand the concept of leadership?

2. What differences, if any, exist in students' understandings of leadership based on gender, race, and age?

3. What demographic variables and college environmental variables predict the different understandings of leadership?

In this study the terms definition and understanding are often used interchangeably to mean the same thing. In this study, students provided a definition of leadership to a prompt that asked them to describe what the word leadership means to them. I have thus taken their definitions to reflect how they understand or view the concept of leadership. Literature suggests that how someone describes something most always reflects the meaning (or understanding) that someone places on something (Martin, 1987). Thus, the two words (definition and understanding) are both used in this study and mean the same thing: how students describe and define the concept of leadership.

\section{Methodological Overview}

For this study I used data from the Multi-Institutional Study of Leadership (MSL) project, a national research study examining college student leadership development and the influence of higher education on this development. A random sample of 338,732 undergraduate college students at 101 U.S. colleges and universities were surveyed in Spring 2009. Over 91,000 students responded to the survey. Data were collected through a web-based survey that included a number of demographic, pre-college, and environmental variables along with outcome measures. Demographic variables included 
variables such as race, gender, and age. Pre-college variables included experiences that occurred prior to college and participants' perceptions of certain outcome measures prior to college. Environmental variables were experiences from the college environment, such as different types of involvement on and off campus, field of study, or participation in a leadership workshop.

For this study, participants were selected from the total dataset through random criterion sampling. The total sample was made up of 1100 participants, which was made up of 220 participants from the following self-identified racial groups: White/ Caucasian, African American/ Black, American Indian/ Alaska Native, Asian American/ Asian, and Latino/ Hispanic. The 220 participants in each racial group were comprised of 110 women and 110 men. Data were analyzed using mixed-methods procedures.

Research question one was addressed qualitatively by employing thematic content analysis procedures of the free-response answers to the open-ended prompt, Please provide a brief definition of what the term leadership means to you. It is important to note that the definitions examined in this study reflect students' definitions of leadership at one point in time and do not address the developmental nature of one's understanding of leadership. Initial coding categories were determined from the literature on different understandings of leadership. Additionally, two preliminary category searches were conducted with two different samples of 50 responses to further finalize categories. Colleagues were consulted in this process of finalizing categories through helping identify the most salient categories and through an inter-rater reliability check. After the data were coded and categorized, frequencies of the themes by gender, race, and age were conducted, and the commonly grouped themes were identified. From there, the themes 
were entered into the database to allow for subsequent inferential analysis procedures to answer the second and third research questions.

Research question two was analyzed with loglinear analysis using the PASW 18 (formerly SPSS) statistical software program. Loglinear analysis allowed for examining differences in leadership definition themes based on gender, race, age, and a combination of these variables. The results from the statistical tests in research question two informed the design of the logistic regression analyses in research question three, which were also conducted using PASW 18. Logistic regression allows for the prediction of certain outcomes based on a set of independent variables. Additionally, it allows for non-linear distribution of the dependent variable (e.g. yes/ no) and multiple independent variables (Tabachnick \& Fidel1, 2001), which is fitting for the variables in this study. For each logistic regression analysis, the dependent variable was one of the leadership definition themes determined from research question one, and the independent variables were a variety of demographic and college environmental variables. The methods of this study are explained in more depth in Chapter Three.

\section{Significance of the Study}

This study resulted in a category scheme of different definitions of leadership that reflect college students' thinking about leadership. This information may help leadership scholars and educators better understand college students' thinking and serve as baseline information for creating initiatives designed to develop college students' leadership skills, knowledge, and capacity.

Additionally, demographic and environmental variables that contribute to definitional differences were found. This information can be valuable for leadership 
educators to better understand the range of students they are likely to encounter or that are likely to participate in the leadership development initiatives they design and/or implement. This improved understanding of the impact of the programs can help leadership educators tailor the education experiences to better meet the students' needs. This more comprehensive understanding can also be useful in future research to explore the relationship between students' understandings of leadership and their demonstrated leadership behaviors and provide additional insight into students' leadership development.

This research also adds to the growing but still relatively limited literature and research base of college student leadership within specific identity groups. By examining race, gender, and age upfront, we have a better understanding of students within each identity group. This information may not only provide insight into addressing leadership development needs and designing leadership programs; it may also suggest additional directions for research of these different identity groups.

To summarize, a greater understanding of students' leadership perceptions and their relationship to demographic and environmental variables can add to the conversation on college student leadership development and may inform and influence the outcome of higher education by increasing leadership capacity in students. Additionally, the study can contribute to leadership scholars' understandings of different perceptions and understandings of leadership. 


\section{CHAPTER TWO: REVIEW OF THE LITERATURE}

"Finding a more effective means for developing the leadership talents of America's young adults not only requires that new methods for teaching critical leadership skills be devised, but also that the definition of leadership itself be broadened" (Zimmerman-Oster \& Burkhardt, 1999, p. i).

\section{Introduction}

This chapter provides a context for exploring college students' understandings of leadership. There is significant literature on different leadership concepts, and college student leadership development has been well researched, but there is a gap when it comes to our understanding of how students view and define leadership. The chapter will demonstrate, among other things, the gap in research and literature on this topic. The study that was conducted is rooted in the assumption that this gap is problematic and that a more comprehensive understanding of students' views of what leadership is and variables associated with these different understandings can inform the development of leadership training and education initiatives on college campuses.

This chapter provides an overview and analysis of relevant literature with a particular focus on those findings that informed the dependent and independent variables of this study. First, as a precursor for the examination of college students' views and understandings of leadership, I will provide an overview of leadership frameworks in the leadership studies field. Next, existing research on college students' views of leadership, the topic of this dissertation, will be presented. Since this research is limited, literature and research on college student leadership development is presented in order to provide 
additional insight into college student leadership outcomes. Through the review of these three sections identified above, a number of potential variables emerge; in order to justify the variables I will use in this study, I will discuss the prominent variables reported in the past research as well as discuss variables that have not yet been researched on the topic of college student leadership but could potentially provide insight. Last, I will discuss why a mixed-methods approach is appropriate for the subject at hand, with particular focus on the concept of language and leadership, as this study examines students' written definitions of leadership.

\section{Understandings of Leadership}

We fail to grasp the essence of leadership that is relevant to the modern age and hence we cannot agree even on the standards by which to measure, recruit, and reject it....Leadership is one of the most observed and least understood phenomena on earth. (Burns, 1978, pp. 1-2)

Leadership theorists and scholars, as well as mainstream popular culture authors, present a variety of leadership theories, models, frameworks, and philosophies. I have organized literature on these different perspectives into three main categories. First, leadership is often described as a personal characteristic, trait, or ability that a person possesses; this is a leader-centric focus on leadership (Bass, 1990; Northouse, 2007). Second, leadership is also discussed as a process or relationship involving interaction with other people; this is a process-oriented or relational focus on leadership (Burns, 1978; Higher Education Research Institute [HERI] 1996; Komives, Lucas, \& McMahon, 2007; Rost, 1991). Third, leadership is also viewed as a complex organism with interconnected pieces and dynamics; this is a systems-perspective of leadership (Allen et 
al., 1998; Daloz Parks, 2005; Heifetz, 1994; Western, 2008; Wheatley, 2006). Different research and perspectives of leadership from the field of leadership studies are presented in this section within these three proposed categories.

\section{Leader-Centric Perspectives on Leadership}

Leadership is a phenomenon that can be traced back to early human existence; evidence suggests leadership was studied during the time of Plato (Bass, 1995; Burns, 1978). Much of the early study on leadership was Darwinian in nature, focusing on the best, great leaders, who were often privileged and associated with royalty (Komives et al., 2007). This view of leadership was characterized as the Great Man theory and led to the subsequent emphasis on trait theories of leadership, whereby people studied these great men (who in fact were almost all literally men) to identify their traits, which were inherent, natural qualities and characteristics (Bass, 1990; Komives et al., 2007). The trait approach received and continues to receive considerable criticism, particularly in terms of its legitimacy and usefulness because it does not consider the situation (environment and people); the research subjects were predominately White males in the military, business world, or political realm; and the findings were considered to be subjective (Bass, 1990; Northouse, 2007; Komives et al., 2007).

Additional research expanded beyond the traits of leaders toward a focus on leaders' observable behaviors, built on the assumption that there was a best way to lead and that behaviors and skills could be developed and learned (Bass, 1990; Komives et al., 2007). Additionally, a focus on situational and contingency approaches of leadership, which took into consideration the context and the capabilities of the followers, were introduced. 
Each of these different perspectives on leadership (Great Man, trait, behavioral, and situational/ contingency) focused heavily on who the leader is, what skills or abilities the leader has, or what he or she should do in a unidirectional, top-down relationship with the followers; this was referred to as an industrial paradigm of leadership by leadership scholar Joseph Rost (1991). The goals of these leadership approaches tended to focus exclusively on the desires of the leader. There are limitations in these leader-centric perspectives; trait leadership has received a great deal of criticism on its utility and the subjectivity of the research and findings (Antonakis, Cianciolo, \& Sternberg, 2004; Northouse, 2007). These leader-centric perspectives are also problematic in that they are limited to understanding leadership solely as a single person and his or her characteristics or abilities. These perspectives fail to fully take into account the role of others in a group, the mutual interactions between group members, and the larger environment or system in which leadership takes place. They also fail to consider the process of leadership. The next section highlights relational leadership perspectives, which emphasize the group and the process aspects of leadership that are absent in the leadercentric perspectives.

\section{Relational Perspectives on Leadership}

The field of leadership studies experienced a significant turning point away from these leader-centric perspectives toward a more relational focus on leadership through Burns' (1978) monumental book Leadership. Burns distinguished between the ofteninterchanged concepts of power and leadership. He argued that while leadership in some cases reflects power, it is different from power and is associated with only a few certain types of power. Leadership reflects a type of power with a focus on human nature 
through being "relational, collective, and purposeful" (p. 18), and does not encompass a type of power that strives to control. Leadership is different from power-wielding and involves a concern and recognition of followers and their goals and a focus on morality and modal values, such as honesty; Burns was one of the first scholars to introduce the concepts of morality and ethics to the leadership discussion.

Burns (1978) distinguished between two different forms of leadership: transactional and transforming. Transactional leadership reflect the leadership perspectives discussed earlier in this section; there is a leader-centric and leader-initiated focus on one person engaged in a transaction or exchange of valued things, such as goods, votes, or services. Transactional leadership does not focus on the relationship or interaction between the people (leader and followers). Transforming leadership, on the other hand, stresses these interactions and connections. Burns described transforming leadership as occurring when "one or more persons engage with others in such a way that leaders and followers raise one another to higher levels of motivation and morality" ( $\mathrm{p}$. 20). Through raising levels of motivation and morality, both leader and followers are transformed. Leadership through this perspective is purposeful, collective, and relational.

Burns' work paved the way for further scholarship in the field of leadership studies; many scholars contributed to the conversation and continued to challenge traditional notions of leadership. Rost (1991) discussed this shift in how people were viewing and studying leadership as a paradigm shift, moving from an industrial toward a post-industrial view of leadership. The industrial paradigm of leadership reflected leadership concepts that were top-down and management-oriented; the industrial paradigm focused primarily, if not exclusively, on the leader, and reflecting the leader's 
interests. The post-industrial paradigm of leadership instead emphasizes leadership as involving significant relationships that are based on mutual influence between the leaders and followers. Additionally, this paradigm of leadership reflects shared purposes among the leaders and followers, with the leaders and followers intending and working toward significant, real change that goes beyond oneself to affect the larger organization or society. This paradigm shift led to valuing inclusive leadership practices, while reframing the social construction of leadership (Komives \& Dugan, 2010). This shift helped make the concept of leadership more accessible and validates leadership approaches that are more characteristic of some marginalized groups, such as women and people of color (Komives \& Dugan, 2010).

Rost (1991) proposed his definition to capture this post-industrial leadership and advocate for leadership as "an influence relationship among leaders and followers who intend real changes that reflect their mutual purposes" (p. 102). Burns and Rost's work, among others', set the stage for relational and reciprocal conceptualizations of leadership that are more heavily emphasized in the field of leadership studies today. These perspectives opened up leadership to be more accessible and reframed leadership to focus on leadership for something beyond oneself. They also make leadership less tangible than the previous leader-centric perspectives, possibly making it more difficult for people to understand. These perspectives also did not focus much attention on the larger context or system in which leadership is enacted (which is discussed in the systems perspectives section). Some of the relational perspectives and models of leadership are: servant leadership, followership, authentic leadership, the relational leadership model, and the social change model of leadership. 
Servant leadership. Servant leadership, which was introduced around the same time that Burns (1978) introduced transformational leadership, posits that a servant leader is servant first (Greenleaf, 1977, 2002, 2008). Servant in this context means that one has a desire and motivation to put the needs of others (whether it be people or an organization or cause) before one's own needs, with a greater purpose in mind. Other people are touched and benefit from this service, encouraging them to also serve. Greenleaf stresses the importance of the relationship between leaders and followers; leaders should work to serve their followers by being in tune with their needs, supporting them, listening to them, and exercising empathy. Although much of the servant leadership focus is on the behaviors and qualities of the servant leader (which could be viewed as leader-centric), the focus on relationships and working toward a greater purpose beyond oneself reflects the leadership conceptions proposed by Burns and Rost.

Followership. Followership also is a key leadership conceptualization in the postindustrial perspectives on leadership, particularly regarding the relationship between leaders and followers. Discussions focused on followership challenge the traditional notions of leaders and followers. In this discourse followers and leaders are both considered important parts of the leadership process, and an organization's success depends both on effective leaders and effective followers (Kellerman, 2008; Kelley, 1995). In fact, from this perspective, people often move in an out of the leader and follower roles depending on the context. Furthermore, being a follower goes beyond blindly and thoughtlessly obeying orders; being an effective follower requires being an active, engaged, responsible, and contributing member who exercises critical thinking. 
Reframing the focus on followers to being a critical part of leadership and organizational success provides a more empowering focus on the role of follower (Kellerman, 2008).

Authentic leadership. With its roots in Positive Psychology, authentic leadership views leadership as something positive and involves an awareness of oneself, others, and the larger context (Avolio \& Gardner, 2005). Authentic leadership stresses awareness of one's own and others' strengths, knowledge, values, and perspectives as well as the larger environment in which leadership is taking place. Additionally, authentic leadership involves, optimism, congruence (authenticity), and morality. Similar to servant leadership, while this has a focus on the individual person and his or her abilities and awareness, it also has a strong focus having an authentic leader-follower relationship and leadership for good beyond oneself; it also reiterates the morality component stressed by Burns (1978).

Relational leadership model. The relational leadership model promotes an accessible and process-oriented conceptualization of leadership. The model, designed for college students, is based on the definition of leadership as "a relational and ethical process of people together attempting to accomplish positive change" (Komives et al., 2007, p. 74). This definition of leadership does not define the roles of leader or follower but, rather, emphasizes a process of people working together. This deemphasizing of roles brings the collaboration and purpose of the process to the forefront. The relational leadership model has five components: purpose, inclusive, empowering, ethical, and process, which are described below.

- Purpose encompasses a common vision or group goal and being committed as a group to work toward this vision, which has a positive outcome in mind. 
- Inclusive is awareness and valuing many aspects of difference and diversity, such as background experiences, identities, styles, and opinions. Additionally, the inclusive component focuses on developing the skills and capacities of the people in the leadership process and working to involve many different people and stakeholders in the process.

- Empowering encompasses shared power, whereby group members feel supported and encouraged to get involved and take the initiative to do so. This component of the model involves creating an environment that promotes ownership and involvement through reducing potential barriers.

- Ethical involves acting in line with individual and group values. It also promotes the idea of working to serve something beyond oneself and create positive change.

- Process encompasses the four components identified above, with particular focus on how the group functions. This focus on process highlights how the group works together and how decisions are made so that they are in line with the group's purpose. Being aware of this process and acting with intention also reflects this component of the model (Komives et al., 2007).

The relational leadership model diagram (Figure 1) depicts the relationships between these components of the model. Purpose is at the core of the model, and process encompasses the entirety of the model. Inclusive, empowering, and ethical are centered around purpose and exist within the larger process (Komives et al., 2007). A qualitative grounded theory study examined how students develop a leadership identity and the 
process by which they adopt a relational leadership approach (Komives et al., 2005;

Komives et al., 2006). This research is explained later in this chapter.

\section{Figure 1}

\section{Relational Leadership Model}

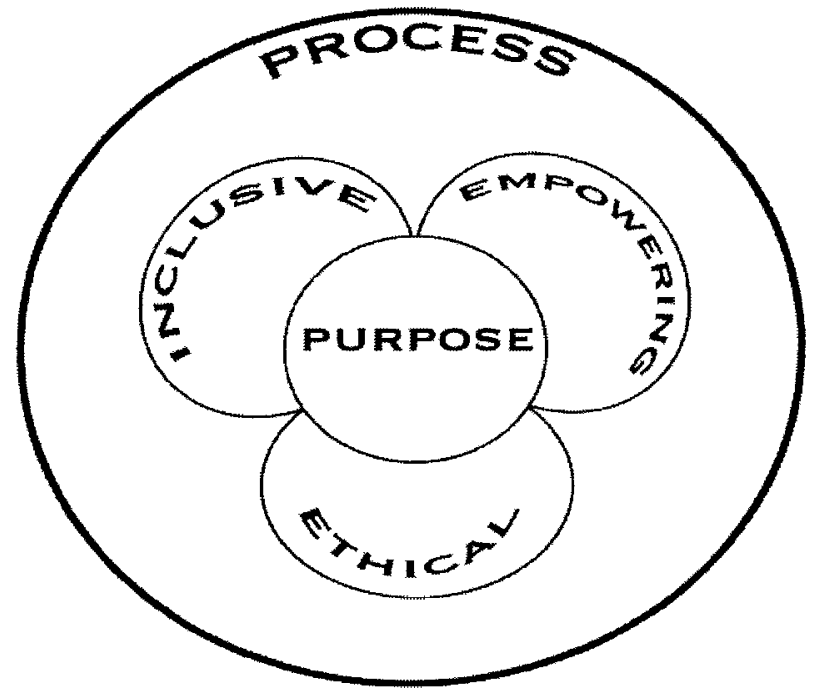

Source: Komives, S. R., Lucas, N., \& McMahon, T. R. (2007). Exploring leadership: For college students who want to make a difference (2nd ed.). San Francisco, CA: JosseyBass. Figure reprinted with permission from Jossey-Bass Inc.

Social change model of leadership. The social change model of leadership, like the relational leadership model, was designed for college students and focuses on leadership as a process and stresses the importance of the group in this process. Positive change is the goal or outcome of the model, with three dimensions of the model that contribute to this overall goal: the individual dimension, group dimension, and societal/ community dimension (HERI, 1996; Komives \& Wagner, 2009).

The individual dimension of the model focuses on the role and commitments of the people involved in the leadership process, stressing the inner-work that people must 
engage in to contribute to this process (Cilente, 2009). The group dimension focuses on how a group of people works together to accomplish their purpose. The societal/ community dimension recognizes the larger communities in which the individuals and group are involved and situated and having a commitment to serving these larger communities. Across these three dimensions are the seven values of the model. These seven values along with the outcome of change are presented in Figure 2 and Table 1 below. Recent research has been conducted on the social change model as it applies to college students through the Multi-Institutional Study of Leadership, which will be presented later in this chapter. The social change model of leadership is a prominent model on college campuses and has recently been observed to have "played a prominent role in shaping the curricula and formats of undergraduate leadership education initiatives in colleges and universities throughout the country" (Kezar, Carducci, \& ContrerasMcGavin, 2006, p. 142).

\section{Figure 2}

\section{Social Change Model of Leadership Development}

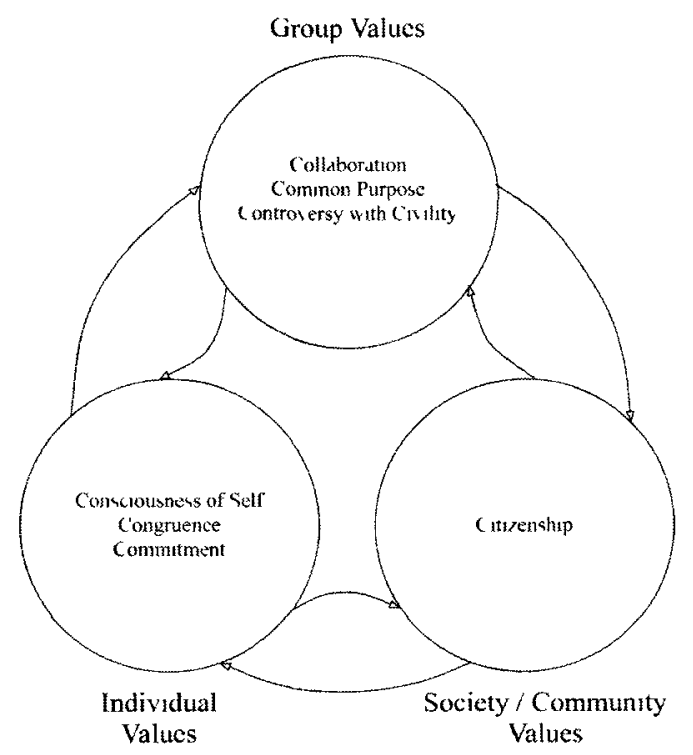


Table 1

Values of the Social Change Model of Leadership

\begin{tabular}{|c|c|}
\hline Value & Definition \\
\hline \multicolumn{2}{|r|}{ Individual } \\
\hline $\begin{array}{l}\text { Consciousness } \\
\text { of Self }\end{array}$ & $\begin{array}{l}\text { Consciousness of self requires and awareness of personal beliefs, } \\
\text { values, attitudes, and emotions. Self-awareness, conscious } \\
\text { mindfulness, introspection, and continual personal reflection are } \\
\text { foundational elements in the leadership process. }\end{array}$ \\
\hline Congruence & $\begin{array}{l}\text { Congruence requires that one has identified personal values, beliefs, } \\
\text { attitudes, and emotions and acts consistently with those values, } \\
\text { beliefs, attitudes, and emotions. A congruent individual is genuine, } \\
\text { and honest and "walks the talk." }\end{array}$ \\
\hline Commitment & $\begin{array}{l}\text { Commitment requires an intrinsic passion, energy, and purposeful } \\
\text { investment toward action. Follow-through and willing involvement } \\
\text { through commitment lead to positive social change. }\end{array}$ \\
\hline \multicolumn{2}{|r|}{ Group } \\
\hline $\begin{array}{l}\text { Common } \\
\text { Purpose }\end{array}$ & $\begin{array}{l}\text { Common purpose necessitates and contributes to a high level of group } \\
\text { trust involving all participants in shared responsibility towards } \\
\text { collective aims, values, and vision. }\end{array}$ \\
\hline Collaboration & $\begin{array}{l}\text { Collaboration multiplies a group's effort through collective } \\
\text { contributions, capitalizing on the diversity and strengths of the } \\
\text { relationships and interconnections of individuals involved in the } \\
\text { change process. Collaboration assumes that a group is working } \\
\text { towards a Common Purpose, with mutually beneficial goals, and } \\
\text { serves to generate creative salutations as a result of group diversity, } \\
\text { requiring participants to engage across difference and share authority, } \\
\text { responsibility, and accountability for its success. }\end{array}$ \\
\hline $\begin{array}{l}\text { Controversy } \\
\text { with Civility }\end{array}$ & $\begin{array}{l}\text { With a diverse group, it is inevitable that differing viewpoints will } \\
\text { exist. In order for a group to work toward positive social change, }\end{array}$ \\
\hline
\end{tabular}


open, critical, and civil discourses can lead to new, creative solutions and is an integral component of the leadership process. Multiple perspectives need to be understood, integrated, and bring value to a group.

\section{Community/ Societal}

Citizenship Citizenship occurs when one becomes responsibly connected to the community/ society in which one resides by actively working toward change to benefit others through care, service, social responsibility, and community involvement.

\begin{tabular}{ll}
\hline \multicolumn{1}{c}{ Overall Goal of the Model } \\
\hline Change & As the hub and ultimate goal of the Social Change Model, Change \\
gives meaning and purpose to the other [values]. Change means \\
improving the status quo, creating a better world, and demonstrating a \\
comfort with transition and ambiguity in the process of change.
\end{tabular}

Source: Cilente, K. (2009). An overview of the social change model of leadership. In S. R. Komives \& W. Wagner (Eds.), Leadership for a better world: Understanding the social change model of leadership development (pp. 43-77). San Francisco: Jossey-Bass. Reprinted with permission from Jossey-Bass, Inc.

Summary of relational perspectives on leadership. This section included a discussion on how relational perspectives on leadership emerged within the field of leadership studies and included an overview of some leadership models that emerged from this work. In contrast to the leader-centric approaches, relational approaches emphasize the importance of the group and relationships between different people within the group. Additionally, these models recognize leadership as a process rather than an individual's ability or a position. Relational perspectives make leadership a more accessible concept in which anyone can partake, and the purpose of leadership is to create 
positive change. These perspectives of leadership do tend to emphasize leadership as something positive, or what some might refer to as good leadership. This challenges some of the more traditional notions that leadership is a personal quality or position whereby one does something or makes others do something. This relational perspective is not as prevalent in the larger society and could be difficult for some people to grasp.

More recent work in the field of leadership studies examines leadership through a systems perspective, whereby an organization or group is viewed as an organism that is situated within a larger, complex system. This perspective emphasizes the interconnected nature of individuals, groups, and the larger system. The next section will explore some of the research and literature on these system approaches to leadership.

\section{Systems Perspectives on Leadership}

The third category of leadership perspectives present in the leadership studies literature will be referred to as systems perspectives on leadership. A systems approach to leadership recognizes organizations and groups as living systems that have "the potential to grow, learn, and evolve" (Senge et al., 2004, p. 8). Like an organism, organizations exist within the large world, or system, around them and must grow and adapt within that larger system with which it is interconnected. Some of the different leadership perspectives within the systems category of leadership are presented in this section.

Adaptive leadership. Adaptive leadership is described as "the practice of mobilizing people to tackle tough challenges and thrive" (Heifetz, Grashow, \& Linsky, 2009 , p. 14) with a particular focus on change. The word thrive describes the process by which an organism adapts to the changing conditions of the larger system in which it 
operates. This living system metaphor reflects a need for organizations to evolve and adapt in order to survive and excel. The challenges that organizations face can be classified as technical and adaptive challenges (Heifetz, 1994). Technical challenges are easily seen and understood; the problem is clear and the solution is within realm of one's capabilities and past experiences. In contrast, adaptive challenges are more ambiguous; the challenges are not as clear and the solutions are unknown. Adaptive challenges must be faced in new ways through adopting new beliefs and new behaviors to better address the needed and desired changes (Daloz Parks, 2005; Heifetz, 1994; Heifetz et al., 2009).

Learning organizations. As was noted above, adaptive leadership understands organizations as living systems that can learn and grow. This reflects Senge's (2006) work on learning organizations, which promotes the idea that organizations, like humans, can learn, grow, and enhance their capacity to innovate and perform. One of the key dimensions of a learning organization, according to Senge, is systems thinking, which is the ability to see the whole rather than the fragmented and isolated individual parts of a system. Through looking at the whole, patterns can emerge and there is a greater focus on the interconnectedness of individuals, organizations, and the larger environment. Systems thinking promotes integration of other aspects of the learning organization (personal mastery, mental models, building shared vision, and team learning), enhances the other aspects of an organization, and "reminds us that the whole can exceed the sum of its parts" (Senge, p. 12).

Networked organizations. Challenging the often hierarchical and fragmented perceptions of our world and approaches of leadership and change, Allen and Cherrey (2000) discuss the networked nature of our world and the organizations within it. A 
networked worldview requires a view of the larger, whole system and awareness of the multiple and intersecting connections within that world. Additionally, it involves a focus on the often-blurred boundaries within and among organizations, non-linear behavior, constant movement and flux within a system, a complexity that is influenced by the external world, and an absence of absolute control. The authors discuss this networked worldview in practice as systemic leadership and advocate this approach to leadership for organizations to thrive and stay current and for the people in these organizations to increase the meaning of their work (Allen \& Cherrey).

Leadership and the new science. Drawing on concepts of biology, chemistry, and quantum physics, Wheatley $(1994,2006)$ approaches leadership and organizations in a systems view that embraces chaos. Organizations are living systems that exist in a very complex and fluid world. Through looking at the system as a whole and embracing the apparent chaos, underlying order can emerge. Wheatley warns against focusing on hierarchies, tasks, and function and instead focuses on relationships. Our world is composed of "bundles of potentiality" that only manifest their potential in relationship" (Wheatley, 2006, p. 1). Interconnectedness and relationships serve as the building blocks of life.

Ecological perspective of leadership. The ecological perspective on leadership pulls from many of the conceptualizations of leadership presented above. Drawing on the ecological metaphor, organizations are viewed as complex and dynamic systems. Leadership through this perspective encompasses interdependence among and within systems, feedback loops and open systems, cycling of resources, and adaptation with a focus on continued improvement to thrive and address change (Allen et al., 1998). The 
leadership attitudes and beliefs scale (LABS) was developed to assess college students' thinking about leadership through these ecological perspectives of leadership (Wielkiewicz, 2000). The LABS instrument measures students' hierarchical and systemic thinking about leadership. Research using LABS is presented in the next section of this chapter, which overviews research on college students' understandings of leadership.

Summary of systems views of leadership. A systems view of leadership applies an organism metaphor to leadership and organizations and is captured in the concepts and models of adaptive leadership, learning organizations, networked organizations, leadership and the new science, and the ecological perspective of leadership. These perspectives go beyond the individual role of leader and beyond the group, expanding to the larger system. Additionally, it adds human qualities and abilities to organizations, such as an organization's ability to learn, grow, adapt, and address chnage (Morgan, 2006; Senge, 2006). This challenges more traditional notions of organizations as something that one can control (Morgan, 2006). Adopting a more systemic view of leadership has been captured by one researcher as a developmental process called action logics. Through a variety of experiences, human development, and other influences, a more complex and system understanding of oneself and the world can develop (Torbert, 2004).

The complex understandings of leadership and organizations through systems perspective is emergent and fairly recent in the field of leadership studies and likely is not very prominent in the larger population. Additionally, the research that suggests that a systems perspective of leadership is a part of a more complex developmental process 
could imply that systems perspectives of leadership is likely not very prominent within a population of traditionally aged college students.

\section{Section Conclusion}

The popularity and prominence of each of these different scholarly perspectives of leadership have ebbed and flowed within the field of leadership studies since they were each introduced (Antonakis et al., 2004). While current scholarship in the field of leadership studies predominately promotes and advocates for a collaborative, relational, and systemic approach to leadership that addresses desired group, social, or societal changes (Astin \& Astin, 2000), there is evidence of a parallel increased emphasis on hierarchical and trait perspectives in leadership practice (Antonakis et al., 2004). In fact, this focus on hierarchical and leader-centric leadership approaches is even strongly evident within the administration and faculty of higher education institutions (Astin \& Astin, 2000). T'1e next section will examine research on college students' differing perspectives of leadership.

\section{College Students' Understandings of Leadership}

What would a campus look like if these core principles of leadership - self-knowledge, competence, authenticity, commitment, collaboration, shared purpose, empathy, division of labor, and respectful disagreement-were to permeate the student culture and define the norms for interacting with others?

-Astin \& Astin, 2000, Leadership Reconsidered, 29

The previous section introduced three different categories of leadership perspectives in the field of leadership studies: leader-centric, relational, and systems. 
There is evidence that these three categories of leadership are also present in college students' views of leadership. The fairly limited research on college students' understandings and perceptions of leadership are presented below and organized within the three categories of leadership perspectives previously identified: (1) leader-centric, (2) relational, and (3) systems perspectives.

\section{Leader-Centric Views}

An emphasis on authority and control, reflective of the leader-centric view, is a prominent theme in the literature about students' perceptions of leadership. A focus on control was found in a study of college students' perceptions of leadership. Shertzer and Schuh's (2004) qualitative study on college students (24 students involved in student leadership roles and five students who did not hold a formal leadership role) focused on the students' perceptions of leadership. Students who held a significant role in a student organization, who were identified as student leaders by the researchers, tended to express a desire to control a group, organization, or process as a motivating factor for getting involved in a leadership position (Shertzer \& Schuh). The student leaders also reflected leader-centric perceptions of leadership; many students viewed leadership as an innate trait or ability that one is born with. Leadership was characterized as being positional and requiring possession of certain skills. The skills that resulted in this research as important favored those students who may be more extroverted, charismatic, outgoing, gregarious, and persuasive.

Shertzer and Schuh (2004) also examined the leadership beliefs of students who did not hold formal leadership roles. There is evidence of a leader-centric view of leadership in some of these students' beliefs; they “did not feel qualified for leadership, 
that they were not intelligent enough for the responsibility, and their personality limited their ability to lead" (Shertzer \& Schuh, p. 126). Although this study was relatively small and cannot be generalized to the entire college student population, it highlights that understanding leadership as a personal characteristic related to intelligence and other personality factors was present in both the student leaders' and non-student leaders' perceptions of leadership.

Leadership as a hierarchical and authoritative concept was examined through the development of the Leadership Attitudes and Beliefs Scale (LABS III) and subsequent studies that utilized this scale (Smith, 2009; Thompson, 2006; Wielkiewicz, 2000, 2002). The scale examines college students' attitudes and beliefs about leadership through two dominant frames: hierarchal thinking, which is characterized by top-down control and authority, and systemic thinking, which is characterized by an ecological and complex systems perspective (Allen et al., 1998; Heifetz, 1994; Wielkiewicz, 2000). Note that this scale is based on a specific framework and therefore limits the expression of students' perceptions of leadership to the two frameworks of hierarchical thinking and systems perspective. There are additional limitations with the use of this scale, as it relies on respondents' self-reported perceptions of leadership.

One study used this scale with 300 undergraduate students at a single campus to examine the preferred leadership attitudes and beliefs of the students; results indicated greater focus on hierarchical thinking (88\%) than systemic thinking (12\%) (Smith, 2009). Additional research indicated that men had a stronger emphasis on hierarchical thinking and a lesser emphasis on systemic thinking than women (Fischer, Overland, \& Adams, 2010; Wielkiewicz, 2000). One study found that White students demonstrated higher 
scores on hierarchical leadership beliefs than students of color (Fischer et al., 2010). The more dominant groups, men and White students, had higher hierarchical thinking of leadership than their less dominant peers.

Additional findings using this scale reveal that students from a small, liberal arts Catholic school, when compared to students at a large public institution, had significantly less emphasis on both hierarchical and systemic thinking (Wielkiewicz, 2000). Students with higher levels of hierarchical thinking tended to demonstrate less adaptability, success, and sustainability than those students who adopted more systemic thinking (Thompson, 2006; Wielkiewicz, 2000). High levels of hierarchical thinking and low levels of systemic thinking were also negatively associated with college GPAs (Thompson, 2006). Additional findings from these studies on systemic thinking are presented in the systems view section later in this paper.

Leader-centric views of leadership were also found within a stage in students' progression of developing a leadership identity (Komives et al., 2005; Komives et al., 2006). This grounded theory study examined the leadership perceptions and experiences of 13 college students who were identified by administrators and faculty as demonstrating relational leadership. Although the study's focus was on those students who are expected to already view and approach leadership as a relational concept, there was evidence that the students viewed leadership through a leader-centric perspective earlier in their lives. Note that there is research currently underway by Wendy Wagner that seeks to further examine and validate the leadership identity development model through examining the views, attitudes, and definitions of leadership from a wide range of students, not just those who view and approach leadership as a relational concept. 
The leadership identity development research resulted in a six-stage developmental model of how one develops a leadership identity and how students' understandings of leadership shift over time and through experiences. One of the prominent stages in this model is the leader identified stage, the third stage in the model, whereby leadership is viewed as positional; the leader of the group is the person who demonstrates leadership and must be in charge and "get the job done" (Komives et al., 2006, p. 407). This leader identified stage emerged as a critical and common stage for students' progression toward viewing leadership as a more relational process. As students gained confidence and increased levels of comfort in taking on leader and member roles in organizations, they experimented with trying new leadership styles and different ways of interacting with others in their organizations. Additionally, as they took on more complex roles or projects, they found "they could not do everything themselves and that the talents and skills of group members were vital for organizational success" (Komives et al., 2006, p. 409).

This realization marked an important transition in beginning to adopt more relational views and practices of leadership. The developmental experiences of peer and adult interaction, involvement, and reflection were also found to be important influences (Komives et al., 2006). This grounded theory suggests that adopting a leader-centric view of leadership is common and a natural progression, particularly for students when they arrive at college. While this leader identified stage was critical, it was in fact just a stage leading to more complex and developed ways of viewing and practicing leadership. Regardless, many people may not progress past this leader-centric stage. 
Leader-centric perspectives of leadership have gained attention in the academic and popular culture arenas of leadership over the past 30 years (Antonakis et al., 2004), and these perspectives appear to also be present for college students. Although prominent, the leader-centric view of leadership is not the only view of leadership present in the college environment. The next section examines literature and research on relational views of leadership.

\section{Relational Views}

The research on students' views of leadership also suggests that students, at times, view leadership as a process or relationship that exists between group members. The following studies highlighted in this section, all of which are qualitative, highlight the presence of relational views of leadership in college students' perceptions of leadership. Discussed in the section above, Shertzer and Schuh (2004) found that both those students with formal leadership roles and those who had not held formal leadership roles demonstrated leader-centric views of leadership. While this leader-centric perspective of leadership appeared to be the dominant perspective within the student leaders, there was evidence of relational views of leadership, or at least views that deemphasize the authoritarian role of a leader, in those students who did not hold leadership roles. In contrast to their peers in leadership roles, these students emphasized the importance of leading by example and rejected the notion that one must possess certain skills to lead, particularly those related to extroversion. Some students also believed that the need to control was a leadership myth.

A shift toward a more relational perspective on leadership was demonstrated in a qualitative dissertation study examining the apparent impact of fraternity members' 
participation in a five-day leadership program (DiPaolo, 2002). The study examined what the students learned from participation in the program and how they view leadership and their role of leader after the program. The sample was small and homogeneous, with the six total participants being White men between the ages of 20 and 22 who held formal leadership roles in their fraternities. The findings are not generalizable to a larger population, but do shed light onto the potential impact of this leadership program.

The participants reported learning about leadership from their participation in the leadership program (DiPaolo, 2002). Five of the six participants learned that leadership involves a group process as opposed to an individual. Additionally, some of the men realized that one must not be in a formal leadership role to be a leader, and one participant discussed that he learned that leadership involves relationships, communication, and mutual respect with others in the group. A cross-case analysis resulted in finding that the participants realized that core values and belief systems are central to being a leader (DiPaolo, 2002). This study demonstrates the potential impact of leadership programs on shifting students' understandings and perceptions of the concept of leadership and their role as leaders.

A more explicit example of relational leadership was evident in the leadership identity development research (Komives et al., 2005; Komives et al., 2006). It is important to note the qualitative nature of this study, small number of participants $(n=13)$, and the purposeful sampling or selecting students that reflect relational leadership, which is not reflective of the larger student body. This grounded theory is useful in further examining and understanding relational perspectives of leadership college students. Following the leader identified stage of leadership identity development, which was 
discussed in the leadership identity development findings in the previous section, reflect relational views of leadership.

The stage following the leader identified stage of leadership identity development is the leadership differentiated stage, which is reflective of more relational understandings of leadership (Komives et al., 2005). There is a key transition that exists between these two stages that is worth noting. In this transition, students begin to understand more the complexity of leadership and realize that they are not able to accomplish everything on their own. They begin to realize the value of others in the leadership process and learn a language of leadership, which ultimately leads to the leadership differentiated stage, which is the fourth stage in the model.

In this stage, students adopted an interdependent approach to leadership, whereby they found value, power, and even necessity in many people working together, regardless of leader title. These students recognized that they could engage in leadership from many levels of an organization, regardless of position, and along with a variety of people (Komives et al., 2005, 2006). In addition, in the stages following the leadership differentiated stages (which are the generativity and internalization/ synthesis stages), students' views of leadership shifted over to understanding their role of not only being a leader in an organization, but also in being a member of an organization with responsibility for the larger organization and the sustainability of the organization, (Komives et al., 2005, 2006). The students rejected their previously-held leader-centric perceptions and instead focused on the interdependent, collaborative, and processoriented nature of leadership and emphasize. 
The feeling of responsibility to a group or the larger organization was also a prominent perspective in a qualitative study of the leadership experiences of students of color (Arminio et al., 2000). When reflecting on why they took on leadership roles in their organizations, many of the students stressed the desire and feeling of responsibility to benefit the group and the organization. They were committed to the sustainability of their organization, helping others become more involved and committed, and working toward the goals of the organization (Arminio et al., 2000). Additionally, when asked about their greatest leadership accomplishments, many students stressed organizational successes as opposed to personal successes. Interestingly, many of the students in this study did not view their work and roles in the organization as leadership. Many students resented the term leadership and did not view themselves as leaders.

There is additional evidence of the rejection of the more leader-centric, authoritative, and hierarchical views of leadership that are reflective of a White and maleoriented schema of leadership by students of color (Balon, 2004). Students of color may associate leadership with power and have negative perspectives about power and how it has been used. This may be particularly the case for Asian Pacific American students; one study found that Asian American students, when compared to peers from other ethnic backgrounds, were less likely to view themselves in the leader category or view other Asian Pacific American students as prominent leaders (Balon, 2004). Additionally, leadership from a traditional American Indian perspective reflects a focus on spirituality, kindness, honor, community, leading by example, and respect (American Indian Research and Policy Institute., 1997). These findings are consistent with recent literature on 
leadership perspectives reflected in communities of color as being more relational, and concerned with values and positive change (Bordas, 2007).

In addition to the apparent role of ethnicity in students' views of leadership as relational, gender also appears to be an important variable. Research shows that college women tend to adopt relational views of leadership more often than college men (Arminio et al., 2000; Kezar \& Moriarty, 2000). When studying students of color, Arminio et al. found that along with ethnicity, gender emerged as a significant factor; women of color tended to embrace more relational views of leadership than men of color. Differences in leadership perception by social identity were also reported in the leadership identity development research, whereby women, gay males, and the students of color viewed leadership situations differently than their more dominant identity peer groups, placing additional emphasis on "including all members so that no one would feel excluded or marginalized" (Komives et al., 2005, p. 610). It can be concluded that social identities, such as ethnicity and gender, play a role in students' perceptions and views of relational leadership. Additionally, the leadership identity development research suggests students' development in how they viewed leadership over time, which could suggest the role of age in students' understandings of leadership. Research on the third perspective of leadership, a systems view, is presented below.

\section{Systems Views}

Although not as prominent in the research as the leader-centric and relational perspectives of leadership, there is some research that suggests a system-perspective view of leadership among college students. It is important to note that the presence of systems perspectives of leadership in the research primarily came from an instrument that consists 
of scales related to hierarchical and systemic thinking; the participants selected rather than named systemic thinking in their understandings of leadership. The LABS III instrument, described earlier in this paper, measures students' leadership perspectives by examining their levels of hierarchical and systemic thinking. Systemic thinking, in combination with varying levels of hierarchical thinking, is prevalent in studies using this instrument (Thompson, 2006; Wielkiewicz, 2000, 2002). Research using the LABS III instrument demonstrates that there are desirable outcomes associated with systemic thinking. Students with high levels of systemic thinking, for example, tended to be more conscientious, intellectually sophisticated, and extroverted than those students who demonstrated high levels of hierarchical thinking (Wielkiewicz, 2002). Systemic thinking was also associated with higher levels of success, adaptability, and sustainability (Thompson, 2006; Wielkiewicz, 2000). Students with higher systemic thinking believed that all members of an organization should share in the organization's success and stressed the importance of feedback loops in leadership and organizational success (Wielkiewicz, 2000).

Similar to findings from the leader-centric and relational views on leadership, the variable of gender and a variety of environmental variables emerged as significant for systemic thinking (as measured by LABS III). Gender appears to be a significant variable in differences in leadership perspective. College men tended to emphasize higher levels of hierarchical thinking and lower levels of systemic thinking than women (Wielkiewicz, 2000). Additionally, in examining what may contribute to systemic thinking, the environmental variables of experiences and interactions with faculty, staff, and peers, participation in athletics, and involvement in internships and field experiences 
emerged as significant (Thompson, 2006). Other environmental variables that were examined but did not emerge as significant factors were: participation in arts, entertainment, or music groups, coursework experiences, participation in political or social organizations, and volunteer experience. This study did not examine how race, age, participation in leadership programs, and holding leadership roles contribute to different perspectives of leadership.

A systems perspective of leadership was also evident in the leadership identity development research (Komives et al., 2006; Komives et al., 2005). The participants in the study who had progressed into later stages of their leadership identity development began to recognize the larger systems in which they operated. This new perspective "led them to see the contributions of diverse roles of stakeholders in those systems and the complexity of different groups within a system" (Komives et al., 2005, p. 604). One student recognized that he was able to view the role of university administrators in a new light, understanding how the larger system may hinder the administrators' ability to operate.

Although there is not a great deal of research examining college students' systems views of leadership, this section highlights that there is evidence of systems perspectives of leadership among college students and that there are a number of positive variables associated with this understanding of leadership.

\section{Studies Examining Leadership Definitions}

A recent undergraduate senior thesis was conducted examining themes in students' leadership definitions (Meier, 2010). The data utilized in this study came from the same dataset that will be used in this current dissertation study, the Multi-Institutional 
Study of Leadership (Dugan \& Komives, 2007). Meier used data from one of the institutions in the study and examined the leadership definitions of 696 students. The themes she identified in this study were:

1. completion of a task or goal

2. unifying the group

3. understanding of group dynamics and considering others' feelings

4. confidence

5. willingness

Meier (2010) found that definitions sometimes involved more than one theme. She also focused on gender differences, although not tested statistically for significance. Based on comparing respective percentages of men and women for the different themes, Meier concluded that women tended to define leadership with more of a focus on relationships and collaboration, while men tended to define leadership with more of a focus on task or goal attainment. Additionally, students' definitions of leadership tended to be more complex and sophisticated for seniors as compared to freshmen. Although this study was not rigorous in terms of statistical analysis, it can serve as a resource when identifying themes of different definitions of leadership, and the suggestion of potential gender and class year differences can support a more statistically sound examination of potential gender and class year (or age) differences in students' leadership definitions. Another single-campus study examined the qualitative leadership definitions from the Multi-Institutional Study of Leadership. The researcher determined themes of the definitions of leadership for 50 students' responses at DePaul University, a Catholic 
institution, and presented his findings at the International Leadership Association's annual meeting (Whitney, 2010). The seven leadership themes found in this study were:

1. Inspire others (influence)

2. Hierarchy (power, directing, positional)

3. Common goal (mutual benefits, group specific)

4. Leadership characteristics

5. Involving others (team, teamwork, collaboration)

6. Authenticity (self-confidence)

7. Common good (society, collective)

Although these two studies were limited in their scope, the findings from both studies can serve as a resource when determining themes of different definitions of leadership. Additionally, the suggestion of potential gender and class year differences from Meier's (2010) study can support a more statistically sound examination of potential gender and class year (or age) differences in students' leadership definitions.

\section{Section Conclusion}

This section included a number of findings from literature and research on how students understand and view leadership, specifically within the three categories of leader-centric, relational, and systems views of leadership. An overall conclusion from the reviewed research and literature is that various understandings of leadership exist on college campuses. There was strong evidence that leader-centric and relational views of leadership are prominent among college students, and additional evidence pointed to some students embracing systems views. Additionally, social identities such gender and race/ ethnicity appear to play a role in the differing understandings of leadership. 
Women and students of color tend to embrace more relational views of leadership than their dominant group peers. Although not directly examined, development over time suggests that age may, too, play a role in how one understands leadership.

The role of involvement in students' differing understandings of leadership is unclear. The two studies that focused on the role of involvement in students' views of leadership (Komives et al., 2005; Shertzer \& Schuh, 2004) were both small qualitative studies with fairly narrow student populations. The leadership identity development research suggests that involvement and a variety of experiences is associated with more relational and developed views of leadership (Komives et al., 2005), yet this study only selected those students who were observed to embrace a relational view of leadership. On the other hand, Shertzer and Schuh's (2004) study found that holding a formal leadership role tended to be associated with leader-centric views of leadership. The role of involvement and holding formal leadership roles in students' perceptions of leadership warrants additonal research.

While these two previous sections focused on different peceptions and understandings of leadership, the next section will expand the discussion to include research on different leadership outcomes, often behavioral, of college students. The variables of race, gender, and different types of involvement are also present in that research.

\section{College Student Leadership Outcomes}

If higher education must assume some of the responsibility for the poor quality of leadership that currently characterizes much of American society, it also has the potential to produce future generations of transformative leaders who will be able to 
devise more effective solutions to some of our most pressing social problems. (Astin \& Astin, 2000, p. 6)

The purposes of higher education are multifaceted; two of the central aims of higher education are to develop future leaders and to help students develop holistically and achieve their fullest potential (Komives, Dugan, Owen, Slack, \& Wagner, 2006; Roberts, 2007). Accordingly, there are a number of in-class and out-of-class initiatives in place to support the holistic and leadership development of college students (Komives, Dugan, Owen, Slack, \& Wagner, 2006; Roberts, 2007).

Because the development of leadership ability is often seen as a central outcome to the college experience, a number of researchers have studied college students' leadership development and the different background variables and experiences that contribute to this development. A review of these studies is presented below.

Prior to presenting the research, it is important to recognize that much of the research on student leadership outcomes is self-reported in nature, whereby students assess their own leadership ability or variety of outcomes. This is an increasingly common form of assessment and evaluation in higher education (Gonyea, 2005). In comparison to standardized measures, self-reported data often has lower fidelity, or reliability, but greater bandwidth (Gonyea, 2005). Self-reported data is attractive for studying leadership, as it allows for gathering information about behavior, attitudes, and growth, among other measures. Use of self-reported data, though, can pose challenges in assessing the role different experiences, such as leadership education or development programs, play in students' leadership behaviors (Rohs, 2002). Learning more about leadership or oneself can lead to a more accurate self-assessment of one's leadership 
capabilities, thus making it difficult to assess the impact of the experiences (Rohs, 2002). Experts note that self-reported measures should be accompanied with other forms of measurement and should not take the place of objective measures (Goneyea, 2005).

Much of the research on college student leadership outcomes and behaviors is measured through self-reported instruments. This way of measuring college students' leadership outcomes on its own may not be the best measure to capture students' leadership abilities, styles, and capacities, as greater self-awareness or understanding of the complexity of leadership may result in students providing a more realistic (or lower) self-appraisal of their leadership. This should be kept in mind when reviewing this research.

\section{Studies Focused Broadly on Leadership Outcomes}

Findings from a few studies shed light on college students' leadership outcomes more broadly. Two of these studies are large-scale in nature, examining college student leadership across many institutions (Dugan \& Komives, 2007; Wabash College, 2009). Both of these studies utilized the social change model of leadership, which was presented earlier in this chapter. Overall findings about college student leadership outcomes are presented in this section. Another study is also included in this section, which examined college student leadership through a grounded theory approach, which provided insight on how college students develop a leadership identity (Komives et al., 2005). These findings are discussed alongside other work on college student development that informs college student leadership development.

Multi-Institutional Study of Leadership. The Multi-Institutional Study of Leadership (MSL) is a national study of leadership with 52 participating institutions in 
2006 , over 100 participating institutions in 2009, and 37 institutions in 2010 . The study's theoretical framework is the social change model of leadership (HERI, 1996), which was presented earlier in this chapter (see Table 1) and approaches leadership as a relational, purposeful, collaborative, and inclusive process. The eight values of the model are: consciousness of self, commitment, congruence, collaboration, controversy with civility, common purpose, citizenship, and change. The operationalized term for the social change model of leadership is socially responsible leadership (Komives \& Wagner, 2009), and each of the eight components of the social change model serve as outcomes in the MSL research. These outcomes are measured through the Socially Responsible Leadership Scale (SRLS-R2) (Tyree, 1998). An additional outcome examined in the MSL is leadership efficacy, or one's confidence in his or her ability to lead. The study also included the examination of demographic and environmental variables from the college environment in relation to the various outcomes (Dugan \& Komives, 2007).

MSL research in the 2006 dataset found that college students tended to report relatively high levels of socially responsible leadership across the eight outcomes of socially responsible leadership assessed in the study. Students demonstrated the highest scores in commitment (mean of 4.24 on a 5-point scale) and the lowest scores in change (mean of 3.75 on a 5-point scale) (Dugan \& Komives, 2007). Additionally, students reported fairly high levels of leadership efficacy (mean of 3.13 on a 4-point scale). The study also examined changes in students' outcome measure ratings over time by using a cross sectional design. In fact, the study documented statistically significant changes across the eight assessed outcomes from pre-college perceptions and their perceptions during their senior year, ranging in effect size from trivial for a few outcomes 
(commitment and controversy with civility) to large (consciousness of self) (Dugan \& Komives, 2007).

Wabash National Study of Liberal Arts Education. Also national in scope, the Wabash National Study of Liberal Arts Education is a longitudinal mixed-methods study which began in 2006 that examines the factors that affect outcomes of liberal arts education (Wabash College, 2009). The study's seven outcomes are: (1) effective reasoning and problem solving, (2) inclination to inquire and lifelong learning, (3) integration of learning, (4) intercultural effectiveness, (5) leadership, (6) moral reasoning, and (7) well-being. Similar to the MSL work, the study focuses on the college environmental experiences that contribute to the students' development in these specific outcomes; this is done through assessing students when they begin college, at the end of their first-year, and in their fourth year of college. The socially responsible leadership scale (SRLS-R2) was also used for this study when examining the leadership outcomes.

At this point, the findings are limited since the study requires four years of longitudinal data collection. Initial findings were released that focus on approximately 3,000 students, focusing on changes from the start of college and the end of the first year (2006-2007) (Wabash College, 2009). There was not much reported student growth across the seven outcomes, which is understandable considering that this data would also reflect student growth over one year. Across the seven different outcomes examined in this study, the largest reported growth was in moral reasoning, whereby scores increased by approximately $10 \%$ over the first year. Findings on the leadership outcomes from the SRLS-R2 reflected very minimal differences; the authors explained that this was understandable considering the data were collected over the course of one year, which is 
not very long in the scheme of longitudinal data. The three outcomes that reflected significant differences had relatively small mean changes. Students' scores reflected significantly higher scores at the end of the first year, as compared to the beginning of the first year, for the outcomes of consciousness of self and change. For the outcome of commitment, the scores from the end of the first year reflected significantly lower scores than the beginning of the year (Wabash College, 2009).

Leadership identity development. Looking at one's identity of being a leader and engaging in leadership, Komives et al. (2005) used grounded theory to explore the development of college students' leadership identity and created the leadership identity development (LID) model, a six-stage developmental process. The researchers conducted a series of in-depth interviews with 13 student leaders from diverse backgrounds, seeking to understand how college students progress in viewing leadership as a relational process. Participants were selected using intensity sample meaning they they were observed to exercise relational leadership, which emphasizes leadership as a shared, ethical, inclusive, and purposeful process (Komives et al., 2007). Although participants "had different experiences, came to new awareness of themselves in a leadership context at different ages, identified a variety of ways these experiences and context had an impact on them...they engaged with the process [of developing a leadership identity] in similar ways" (Komives et al., 2007, p. 596). Six categories were found in contributing to this process: developmental influences, developing self, group influences, students' changing view of self with others, and students' broadening view of leadership. 
The first category, developmental influences, includes the properties of meaningful involvement, reflective learning, adult influences, and peer influences. Meaningful involvement tends to include team-based involvements and contributes to participants' clarification of values. Reflective learning includes critical reflection and learning a language of leadership to help assess their personal leadership development. Adult influences include parents, teachers, and advisors, and this influence is often characterized by affirmation of leadership capacity and mentoring. Peer influences includes friends and role models, and "engaging with peers gained depth and meaning as leadership identity developed" (Komives et al., 2005, p. 597). These four properties of developmental influences change across the stages of the model. For example, the way peers influence a new leader differs from how peers influence a more experienced leader.

The second category contributing to the leadership identity process is developing self. This category includes deepening self-awareness, building self-confidence, establishing interpersonal efficacy, applying new skills, and expanding motivations (Komives et al., 2005). These properties of developing self emphasize personal growth, and they change during the process of leadership identity development. For example, students' sense of self becomes more complex and includes multiple identities as they progress to higher stages of the model. Developing self interacts with the third category: group influences. Group influences includes engaging in groups, learning from membership continuity, and changing perceptions of groups.

The interaction of developing self and group influences contributes to the fourth category: changing view of self with others (Komives et al., 2005). Participants' view of self with others changes during the process of leadership identity development, shifting 
from dependence to independence to interdependence. The fifth category contributing to the leadership identity development process, a broadening view of leadership, is influenced by students' broadening view of leadership. Their view of leadership shifts from something external to self (other people are leaders), to positional (I am the leader), to also as non-positional (I can be a leader without a title; we can all engage in leadership), to leadership as a process (we are engaged in a meaningful process of leadership that should be sustained).

The interaction of these five categories informs the final and central category of the process: leadership identity. Leadership identity includes a six-stage model, which moves from a leader-focused view of leadership to higher stages that are increasingly collaborative and relational (Komives et al., 2005). The stages are: (1) awareness, (2) exploration/ engagement, (3) leader identified, (4) leadership differentiated, (5) generativity, and (6) integration/ synthesis. In the process students' progression with the other five categories also shift. In the lower stages of the model (stages one through three) students have dependent and/ or independent relationships with others, whereas in higher stages of the model (stages four to six) these relationships are interdependent. The authors draw particular attention to the transition between the third and fourth stages of the model (leader identified and leadership differentiated), which marks the crucial shift toward interdependence. This is identified as the "key transition", which develops in response to students' seeing that "the tasks become so complex... they cannot accomplish them alone and must depend on others" (Komives, Owen Casper, Longerbeam, Mainella, \& Osteen, 2004, p. 3). This shift from dependence and independence to an integrated and interdependent view of self with others reflects the trend in leadership studies of moving 
from a singular and positional view of leadership to leadership as a relational process. It also reflects other developmental research.

The shift from dependence to independence to interdependence is reflective of the broad areas of development in Kegan's (1994) orders of consciousness. The higher orders of consciousness, which reflect interdependent relationships with others, reflect more complex human development than the dependent and independent relationships characteristic of earlier orders of consciousness or stages in the LID model.

This is also reflective of Baxter Magolda's $(1999,2001)$ concept of selfauthorship, that is, the way in which one makes meaning of oneself and the larger world. Connecting knowledge to one's own experiences and making meaning from these experiences leads to adult growth and development. Self-authorship has three dimensions, "simultaneously cognitive (how one makes meaning of knowledge), interpersonal (how one views oneself in relationship to others), and intrapersonal (how one perceives one's sense of identity)" (Baxter Magolda, 1999, p. 10). Baxter Magolda (2001) conducted a longitudinal study to better understand college students' learning and intellectual development. Through studying 39 college students' developmental process, she developed a four stage model of the journey toward self-authorship. The stages are (1) following external formulas, (2) the crossroads, (3) becoming the author of one's own life, and (4) internal foundation. The journey progresses from ascribing to others' ways of being and seeking their approval toward identifying one's own beliefs and values to creating an internal belief system and a coherent sense of self. This progression reflects the move away from dependence toward interdependence demonstrated in the LID (Komives et al., 2005) and in Kegan's (1994) model and includes interpersonal and 
intrapersonal dimensions of development that emphasize the concept of identity. These studies and others (e.g. Avolio \& Gibbons, 1988; Day, 2001; Day et al., 2008; Lord \& Hall, 2005) suggest and demonstrate that leadership is a developmental process; it is therefore possible that students may demonstrate different leadership behaviors or think about leadership differently based on adult development processes and experiences. These findings support the consideration of age as a variable when examining students' leadership development.

A study that utilized the LID framework explored the leadership identity development and lesbian, gay, bisexual, transgender (LGBT) identity development. Renn and Bilodeau (2004) interviewed 15 LGBT college student leaders to examine the relationship between leadership involvement in an LGBT organization and the outcomes of leadership identity development and LGBT identity. The researchers found that involvement in LGBT student activities allowed for leadership development opportunities reflecting each of the six LID stages. Overall findings indicated that participants' leadership experiences and activism in combination with their LGBT identity contributed to students' progression through the LID stages. These experiences also contributed to their sexual identity development.

Focusing specifically on the LID findings, 13 of the 15 participants demonstrated leadership behaviors in at least the fourth stage of the LID model, reflecting a collaborative and relational view of leadership (Renn \& Bilodeau, 2004). Stage one and two leadership included exposure to involvement opportunities on campus and seeing other people in leadership positions within student organizations. Participants in stage three emphasized accomplishing tasks, enhancing skills, and holding formal leadership 
positions. Stage four leadership sometimes reflected contextual variables contributing to the need to collaborate, such as planning a large-scale event that required the work of others. Participants in stage five were characterized by passion driving their involvement and commitment. Participants reflecting stage six leadership shared a sense of a larger purpose in life, which included commitments to causes or careers. Participants operating in this sixth stage were also aware of organizational complexity and made connections across different contexts.

\section{Studies Focused on Gender and Race}

Similar to the research on college students' views of leadership reviewed earlier in this chapter, the demographic variables of gender and race emerged in research as significant as it relates to leadership outcomes. Findings regarding race and gender that relate to student involvement and experiences (Dugan \& Haber, 2007; Kezar \& Moriarty, 2000) will be presented in subsequent sections.

MSL findings. Gender and race emerged as significant demographic variables in the MSL research. Women scored significantly higher than men on seven of the eight self-reported outcomes of socially responsible leadership (Dugan, Komives, \& Segar, 2008). This finding is interesting alongside findings about students' self-reported leadership self efficacy. Men reported significantly higher levels of efficacy for leadership as compared to women (Dugan \& Komives, 2007). While this is not a measure of efficacy for socially responsible leadership, it does suggest that while women appear to have higher competence in socially responsible leadership than their male peers, they have lower confidence in their ability to engage in leadership, and vice versa for men. 
A single institution study using the MSL data reflected similar findings around gender differences in the socially responsible leadership outcomes (Haber, 2006a). Additionally, the study examined the experiences that contributed to these outcomes (which will be discussed later in this chapter). Results indicated that different experiences contributed to college women and men's leadership outcomes; while some experiences, such as involvement in community based organizations, was a significant experience for women, it was not for men. So, not only do outcome scores differ by gender, the experiences that contribute to these outcomes also appear to differ.

Race was also a significant factor emerging from the MSL research. Overall, African American students reported higher levels of socially responsible leadership than peers from other racial groups, while Asian American students reported the lowest levels of socially responsible leadership of all racial groups (Dugan, Komives, \& Segar, 2008). No significant differences existed in students' capacity for socially responsible leadership based on sexual orientation. Additionally, no findings were reported based on interaction effects of gender, race, or sexual orientation.

Differences in students' leadership involvement patterns also differed by gender and race. Men reported significantly higher involvement in leadership majors, minors, and certificate programs than women. Examining involvement by race, Asian American and African American students reported higher levels of involvement in these curricular experiences than White students (Owen \& Komives, 2007). In contrast to enrollment in solely curricular programs, women were significantly more likely than men to become involved in short-term and long-term leadership programs, which include curricular and co-curricular programs (Dugan \& Haber, 2007). This was also the case for African 
American, Asian American, Latino, and Multiracial students across all three levels (short, moderate, and long-term) of leadership programs when compared to their White peers. This research suggests that gender and race are significant variables when examining students' leadership outcomes, their involvement, and how their involvement influences their leadership development.

Gender differences in emotionally intelligent leadership. Gender differences among college students' emotionally intelligent leadership capacities were recently examined in a research study (Shankman, Haber, Facca, \& Allen, 2010). The framework of the study, emotionally intelligent leadership (EIL), combines contemporary thoughts about leadership with key concepts from the field of emotional intelligence, such as Goleman's (1995), Salovey and Mayer's (1990), and Bar-On's (1997) work on emotional intelligence. The EIL model includes three main facets of EIL: consciousness of context, consciousness of self, and consciousness of others; it also includes 21 specific EIL capacities (Shankman \& Allen, 2008). The researchers examined significant differences in students' EIL facets and capacities. Significant differences emerged for the EIL facets of consciousness of self and consciousness of others, with women reporting significantly higher scores than men. Women also had significantly higher scores than men on six of the 16 capacities reflecting consciousness of self and consciousness of others. Men had significantly higher scores than women on the capacity of capitalizing on strengths (Shankman et. al., 2010).

The researchers also examined gender differences across many different levels of involvement (ranging from involvement in one, two, three, and four or more organizations). Results closely paralleled the gender differences noted above, with the 
exception that men involved in four or more organizations reported significantly higher scores on three of the EIL capacities than women at the same involvement level (Shankman et al., 2010).

Gender differences in the five practices of leadership. A number of studies have been conducted on college students that focus on the five exemplary practices of leadership, which is a framework for effective leadership derived from research on leaders from a variety of industries and organization. These five practices are: challenge the process, model the way, inspire a shared vision, enable others to act, and encourage the heart (Kouzes \& Posner, 1987). Participants complete a self-reported assessment of their leadership practices, the Student Leadership Practices Inventory (SLPI); the instrument is designed to measure the five exemplary practices of leadership for college student populations. One study focused on Greek leaders (presidents), examining correlations between the women leaders' leadership practices and leader effectiveness (men has been researched in a past study); the study also focused on potential gender differences in the five exemplary leadership practices (Posner \& Brodsky, 1994). The participants were 96 Greek presidents, who completed the SLPI; chapter advisors as well as 389 executive board members assessed the Greek leaders' effectiveness in their roles.

Results indicated a strong, significant correlation between frequency of leadership practices and leader effectiveness for Greek women leaders. When comparing this to past similar research on male student leaders, the researchers concluded that "the practices of effective student leaders did not vary according to gender"' (Posner \& Brodsky, 1994, p. 119). Additionally, some significant differences emerged based on gender for the leadership practices; female chapter presidents' self-assessed scores on the 
leadership practices were significantly higher than their male counterparts for the practices of: enabling others to act, modeling the way, and encouraging the heart. Their executive board members' assessment of their chapter presidents, though, did not reflect differences by gender. This research finding demonstrates a difference between how the presidents self-assessed their own leadership capacities and how their peers assessed their capacities; self-assessment is only one angle through which leadership capacities can be assessed.

Studies on college women leaders. A qualitative study that provides insight to understanding how students engage in leadership focuses on the leadership styles of college student women who hold significant leadership roles in student organizations (Romano, 1996). The women, when describing the ways in which they engaged in leadership, used many descriptors that reflect relational leadership, such as "nonhierarchical, interact, accessible, one-to-one, equality and team member" (Romano, 1996, p. 679). They stressed the importance of relationships with their peers. They also shared that they developed as leaders through their leadership experiences, such as leading their organizations, and found this more effective than learning about leadership through training or education programs.

\section{Studies Focused on Student Involvement and College Experiences}

Understanding not only what leadership outcomes students develop, but also how they develop these outcomes is a topic often researched in college student leadership literature. By focusing on the experiences or other environmental variables that contribute to students' leadership development, leadership educators and practitioners can intentionally tailor experiences and provide opportunities that can facilitate this growth. 
Included in this section are findings from research studies that focus on student involvement and other college experiences and leadership outcomes. Note that studies that focused on the experience of participation in leadership programs are presented in the following section. Experiences discussed in this section will help inform the environmental variables that will be used in this research study.

Astin's involvement research. Student involvement is often noted as a significant experience for a variety of college outcomes. Astin's (1997) research on 25,000 undergraduate students focused on how the college environment and associated experiences affect students. The study found that organization involvement and holding a formal leadership role served as salient experiences for a variety of leadership outcomes. The amount of hours per week spent involved in student clubs and organizations and being elected to office was positively associated with the outcomes of self-reported growth in leadership ability and increases in public speaking ability (Astin, 1997). The number of hours per week spent involved with clubs and organizations were also positively correlated with perceived growth in interpersonal skills. Peer interaction, which is a key aspect of student organization involvement, also emerged as having a significant positive association with a variety of leadership-related outcomes.

MSL Studies. A number of significant environmental variables that contribute to socially responsible leadership emerged from the MSL research, many of which reflected different forms of student involvement. Pre-college experiences were particularly relevant; this includes in high school groups, service and volunteering, varsity sports, holding formal leadership roles, and leadership training experiences (Dugan \& Haber, 2007). Engaging in socio-cultural discussions was the environmental variable found 
most significant, explaining the most variance of all environmental variables for each of the eight socially responsible leadership outcomes and leadership efficacy (Dugan, Garland, Jacoby, \& Gasiorski, 2008); this is also reflective of research findings on the significance of interracial interactions for addressing leadership outcomes (Antonio, 2001; Wabash College, 2009).

A number of other experiences emerged as significant for students' socially responsible leadership outcomes and self-efficacy. These include: mentoring experiences (particularly from faculty and employers), involvement in student organizations, service, off-campus employment, participation in leadership programs and holding formal leadership roles (Dugan \& Komives, 2007; Dugan, Garland, Jacoby, \& Gasiorski, 2008). The one variable that emerged as a negative predictor of some of the socially responsible leadership outcomes was breadth of involvement, as measured by the number of student organizations in which students are involved.

A single-campus MSL study examined how involvement in student organizations, holding a formal leadership role in student organizations, and participation in leadership programs contributed to college student men and women's socially responsible leadership outcomes (Haber, 2006a). A number of college environment experiences emerged as significant; it is also important to note that the pre-college experiences of holding a formal leadership role in an organization and leadership training emerged as significant for many of the socially responsible leadership outcomes for men and for women.

In examining the college experiences of women, student organization involvement was the environmental variable that explained the most variance across the socially responsible leadership outcomes, and involvement in community-based 
organizations was a significant positive predictor for the four outcomes of consciousness of self, collaboration, common purpose, and citizenship (Haber, 2006a). Holding a formal leadership role in community organizations was a significant predictor for women's commitment, controversy with civility, citizenship, and change, whereby holding a formal leadership role in a student organization was only a significant predictor for women's consciousness of self(Haber, 2006a).

For men, student organization involvement was the most significant environmental variable for six of the eight outcomes (all but congruence and change, which did not result in any significant environmental predictors) (Haber, 2006a). Breadth of involvement was not a significant positive predictor for any of the outcomes for men or women and resulted as a significant negative predictor for men's commitment. Holding a formal leadership role in a college organization did not serve as a positive predictor for any of the outcomes, and was a negative predictor for men's change. Interestingly, a consistent positive predictor for men's socially responsible leadership was holding a formal leadership role prior to college (most likely in a high school organization). Last, neither community organization involvement nor holding a formal role in a community organization emerged as a predictor (positive or negative) for men's socially responsible leadership outcomes (Haber, 2006a).

Kezar and Moriarty's study on involvement and leadership ability. One study focused on a variety of independent variables as contributors of leadership ability, communication skills, self-confidence, and ability to influence others for African American and Caucasian men and women across 352 four-year institutions drawn from Cooperative Institutional Research Program (CIRP) data from 1987 and 1991, which over 
20 year old data (Kezar \& Moriarty, 2000). Differences by gender were examined, whereby men, both Caucasian and African-American, demonstrated higher self-reported scores of leadership ability, verbal communication, self-confidence, and ability to influence others than Caucasian and African American women. Since these were selfreported abilities or levels of confidence, the findings reflect that of men's higher levels of leadership efficacy found in the MSL research.

The study's primary reported outcome, self-reported leadership ability, is quite vague, without description or explanation as to what it means and how it was measured. While it is unclear what exactly the outcome of leadership ability entails and possible that respondents may not have viewed this in a consistent manner, the study does provide insight on the experiences that contribute to students' development of self-reported leadership ability. Participation in leadership courses was a significant predictor for all four groups, and the most significant predictor of all environmental variables for Caucasian men and women. In addition, for Caucasian men, election into office, participation in intramural sports, participation in ROTC, serving as an RA, and involvement in student organizations were positive predictors of leadership ability (Kezar \& Moriarty, 2000).

Volunteer work, participation in racial or cultural awareness workshops, and participation in ROTC were significant positive predictors of leadership ability for African American men. For Caucasian women, participation in student organizations, election into office, membership in a sorority, serving as an RA, and participation in intramural sports were significant experiences. Last, for African American women the experiences of election into office and participation in intramural sports were significant 
predictors (Kezar \& Moriarty, 2000). There were more environmental experiences that emerged as significant for Caucasian men and women as compared to their African American counterparts, such as the experience of socializing with people from a different racial group, which was not a significant variable for the African American men and women.

While this research is helpful in identifying possible differences in leadership outcomes by gender and race, as well as significant environmental variables that contribute to these outcomes, it is important to note that this data is nearly 20 year old. The data were collected in 1987 and 1991. The collegiate environment and the student body has changed over the past two decades, and accordingly, the number, type, and makeup of student involvement experiences may be quite different today than 20 years ago. This study does add value to the research in examining women and men separately and by race, as race and gender emerged in the literature as significant variables in students' leadership outcomes.

Astin and Sax's study on service participation. Another study utilizing CIRP data (in this case collected from 1990-1994) focuses on the impact that participation in community service has on a variety of student development outcomes (Astin \& Sax, 1998). Approximately 3,500 students participated in the study, and the researchers supplemented the CIRP data with a follow-up survey (1995 College Student Survey). The study examined the impact of service on a variety of academic and life skills outcomes. One of the life skills outcomes was leadership ability; some of the other outcomes reflect leadership, such as change during college in interpersonal skills, conflict resolution skills, and ability to work cooperatively. In examining four different types of 
service (education, human needs, public safety, and environment), each of these forms served as significant, positive predictors of students' leadership ability and growth in interpersonal skills, conflict resolution skills, and ability to work cooperatively (Astin \& Sax, 1998).

Wabash study findings. The Wabash National Study of Liberal Arts Education, which was discussed above, focuses on examining teaching practices and institutional conditions that are associated with student growth across the seven outcome measures of the study (one of which was leadership) (Wabash College, 2009). The study included six scales that reflect teaching practices and institutional conditions, which were: (1) good teaching and high quality interaction with faculty, (2) academic challenge and high expectations, (3) diversity experiences, (4) frequency of interacting with faculty and staff, (5) interactions with peers, and (6) cooperative learning (Wabash College, 2009). Initial findings from this study focused on data from first-year students in the first two phases of the study: Fall 2006 and Spring 2007. While this is a limited scope in time and does not encompass significant longitudinal scope, there were three scales found to significantly contribute to students' growth. These were: good teaching and high-quality interactions with staff, academic challenge and high expectations, and diversity experiences. In each of these cases, the outcome scores increased with time.

\section{Cooper, Healy, and Simpson's research on involvement and formal roles.}

Cooper, Healy, and Simpson (1994) conducted mixed-methods longitudinal research examining the role that student organization involvement and holding a formal leadership position have on leadership outcomes. Participants in the study (some of whom participated in student organizations and held leadership roles while others did not) 
completed a survey and interviews focused on leadership outcomes. Students involved in student organizations reported significantly higher scores in the leadership-related outcomes of developing purpose, lifestyle planning, cultural participation, and life management as compared to those students not involved in student organizations. Similarly, students who held formal leadership roles, when compared to their peers who did not, reported significantly higher levels of developing purpose, lifestyle planning, and life management (Cooper et al.).

Kuh and Lund's study on student government participation. Kuh and Lund's (1994) mixed-methods study examines college outcomes of students involved in student government. Participants were 149 college seniors, and 26 of the participants held a formal leadership position in student government. The researchers conducted interviews with the participants that focused on perceived changes while in college and experiences that they believed contributed to these differences and categorized these different outcomes into Kuh's outcomes taxonomy, which includes 14 different outcomes (Kuh, 1993 as cited in Kuh and Lund). Findings from the study indicated that of the 14 outcomes, student government was significantly correlated with one: gains in practical competence $(\mathrm{r}=.22)$. This outcome includes: decision making, understanding organizational structures and operations, communication skills, working with others in group processes, teamwork, leadership, cooperation, and followership. Participation in student governance was significantly negatively correlated with the outcome of altruism $(r=-13)$. It is unclear whether this study only focused on the students who held positional leadership roles in student governance or also focused on those students involved in student government, but not in a formal role. 


\section{Studies on student leaders and the five exemplary practices of leadership.}

Also examining the experience of holding a formal leadership role, Posner and Brodsky (1993) focused their study on examining the leadership practices of resident assistants (RAs) alongside effectiveness measures. The RAs ( $\mathrm{N}=33$ across six institutions) completed the self-reported SLPI, which measured the frequency of using the five exemplary practices of leadership; they also assessed their effectiveness in their role. Their constituents (students who lived on their floors) also assessed the RAs through a constituent version of the SLPI, while the supervisors assessed all RAs, placing them into different effectiveness categories (Posner \& Brodsky).

Results from the study suggest a positive relationship between RAs' leadership practices and their effectiveness in their role of RA (as perceived by themselves and others) (Posner \& Brodsky, 1993). A positive relationship also emerged between how constituents viewed the effectiveness of RAs and how often those RAs engaged in the five exemplary practices of leadership; this relationship was not as strong based on how the supervisors assessed the RAs. Again, this demonstrates the varied results of students' leadership capacities based on who assesses them, such as self-report or assessment by peers or supervisors.

A similar study examined the leadership practices of orientation advisors (OAs) $(\mathrm{N}=78)$ along with perceived effectiveness and satisfaction (Posner \& Rosenberger, 1997). OAs completed the SLPI and an effectiveness assessment, and the new students who were in each of the OA's groups also assessed the OAs using the constituent SLPI assessment tool along with effectiveness and satisfaction measures. The new students' assessments of the OAs' leadership practices of challenging the process and modeling the 
way were significantly higher than the OAs' self assessment of these practices; no significant differences emerged for the other three practices. The OAs and the new students who assessed them identified that enabling others to act was the practice more frequently used by the OAs, while modeling the way and challenging the process were the two practices less frequently used. Consistent positive relationships emerged between the perceived effectiveness of the OAs' and the frequency of engaging in leadership practices. Additionally, a positive relationship between the new students' satisfaction with the OAs and the frequency of leadership practices.

Although these studies do not necessarily speak to the student leadership roles of being a RA or OA and the relationship of these roles to leadership practices, they do suggest that those students who are perceived to be more effective in their role also reflect higher scores in leadership practices. Additionally, this study suggests that students' self-perceived leadership practices reflect that of their constituents (or in some cases are lower).

\section{Studies Focused on Student Leadership Programs}

One area of campus life that has greatly developed and become more prevalent in the past 20 years is the presence of leadership training, education, and development programs. This section includes research findings from studies that examine leadership programs and leadership outcomes.

Kellogg study. The W.K. Kellogg Foundation funded 31 leadership projects across the country from 1990-1998 to help create and sustain leadership development programs (Zimmerman-Oster \& Burkhardt, 1999). A number of these programs were established on college campuses. The different projects each had different objectives and 
utilized a variety of different programs and activities. An assessment of programs resulted in findings that suggest a number of perceived improvements in participants' skills, knowledge, and abilities. The assessment of each project was conducted by the project leaders, which could reflect inconsistency and/ or bias.

The assessment resulted in 21 categories of improvement observed in program participants; the items with the most perceived change were: civic/ social/ political awareness $(92.6 \%)$, commitment to service/ volunteerism (85.7\%), communication skills (85.2\%), personal/ social responsibility (78.6\%), and civic/ social/ political efficacy (78.6\%) (Zimmerman-Oster \& Burkhardt, 1999). Other items with perceived change included: self-esteem, problem solving, conflict resolution, ethics, and shared power. Cress, Astin, Zimmerman-Oster, and Burkhardt (2001) examined 10 of these projects funded by the W. K. Kellogg Foundation to conduct further analysis on how the programs enhance participants' leadership skills and knowledge; they also examined if there was a relationship between "leadership development and other educational outcomes such as multicultural awareness and civic responsibility" (p. 16). The study was longitudinal in nature, whereby the researchers collected data from a total of 875 students at their entry to college and during their senior year. This data was compared with that of a non-participant control group.

Chi-square comparison tests of these two groups (participants and nonparticipants) resulted in significant differences for 10 of the 14 outcome measures, whereby participants (as compared to non-participants) reported significantly higher reported change in the outcomes over the four years (Cress et al., 2001). Among these significant findings were reported growth on the outcomes of civic responsibility, conflict 
resolution skills, personal ethics, multicultural awareness and community orientation, personal and societal values, leadership skills, and leadership understanding and commitment. Significant differences also emerged when examining the experiences of holding an elected or appointed leadership position and level of co-curricular involvement. Those students who were involved in the leadership programs were significantly more likely to also hold an elected or appointed leadership position and had higher levels of co-curricular involvement.

It is important to note when examining these findings and other findings around leadership that students often self-select participation in leadership program. Other variables including input characteristics and other environmental factors likely account for some of the differences identified in this study, not just leadership program impact.

MSL research. A few MSL studies have examined the role of leadership programs on socially responsible leadership outcomes. One study examined students' participation in leadership minors, majors, and certificate programs; this study resulted in significantly lower scores across each of the eight outcome variables of socially responsible leadership of those students who participated in these programs (Owen \& Komives, 2007). This finding at first may seem quite perplexing, as one might imagine that enrollment in leadership programs such as these would result in higher levels of leadership competence. The researchers suggested that this outcome might be due to the fact that there could be great variety in theoretical frameworks and curriculums of these different programs; many programs may not promote or teach socially responsible leadership. Also, perhaps additional exposure to and awareness of the complexities and challenges of leadership and the multiple approaches and theories of leadership could 
make students more "aware of what they do not know" (Owen \& Komives, 2007, p. 5), thus affecting the ways in which they rate their behaviors.

It is also possible that students' understandings of the different measures may vary based on exposure to leadership education. The students involved in leadership minors, majors, or certificate programs may in fact demonstrate equal or higher levels of socially responsible leadership than their peers who were not enrolled in these programs. Leadership programs, particularly those that are long-term, tend to include a variety of different strategies to help students better understand themselves, other people, and the larger complexities of leadership and the world. Additionally, they often include opportunities for critical self-awareness and reflection (Haber, 2006b, 2011). This additional focus on self and awareness of the complexity of leadership could influence students' view of self and self-reported scores on leadership outcomes. The students may be more reflective and may have a more realistic, accurate, and in-depth understanding and assessment of themselves and their leadership; in other words, they may realize how much they do not know or how they can continue to improve. While these are just postulated reasons why this may be the case, there is clearly need for additional examination of the role of leadership programs in college students' leadership development.

Another MSL study focused on the effect of short-term, moderate-term and longterm leadership programs on students' leadership outcomes. Short-term experiences include one-time or brief leadership experiences such as leadership conferences or lectures; moderate-term experiences include participation in multiple or ongoing experiences such as workshops, retreats, or trainings, or participation in a single 
leadership course; long-term programs include experiences such as multi-semester leadership programs, certificate, major, or minor programs (Dugan \& Haber, 2007). It is important to note that this study included the leadership minor, major, and certificate programs examined in Owen and Komives' (2007) study highlighted above, resulting in some overlap of the variables. All three types of programs (short, moderate, and longterm) positively influenced students' self-reported socially responsible leadership. More specifically, involvement in short-term and moderate-term leadership programs was significant across all eight outcomes, with short-term programs having a greater effect size, or degree of impact, than moderate and long-term programs (Dugan \& Haber, 2007). Participation in long-term leadership programs resulted in significantly higher scores for the outcomes of collaboration, common purpose, citizenship, and change with a small effect size.

The smaller effect of long-term leadership programs, particularly in comparison to short-term programs, is an intriguing finding. Additionally, it is interesting that short and moderate-term programs were significant for all eight outcome measures while longterm programs were only significant for half of these. The possible explanations of why participation in leadership majors, minors, and certificate programs may lead to lower levels of self-reported socially responsible leadership may be applicable to this finding as well. Perhaps greater awareness of the complexity of leadership and greater exposure to leadership could result in recognition that there is much more to learn or know, or that there are areas for personal growth and improvement in leadership behavior. Additionally, it is possible that these leadership programs do not promote socially responsible leadership. 
Another MSL research study, which was discussed earlier in this chapter, was a single-campus study that focused on the role of involvement in student organizations, holding formal leadership roles, and participation in leadership programs on socially responsible leadership outcomes (Haber, 2006a). As has already been discussed, involvement in student organization was consistently the experience accounting for the most variance in students' leadership outcome scores. Leadership programs were significant experiences (accounting for a small amount of variance) for some of the leadership outcomes. For women, moderate-term leadership programs were significant experiences for citizenship and change, and long-term leadership programs were significant for common purpose. For men, short-term programs were significant for citizenship and common purpose, moderate-term programs were significant for collaboration and change, and long-term programs were significant for controversy with civility. Participation in leadership training and education programs prior to college (most likely in high school) was a significant experience for women in each of the eight outcomes and for men in half of the outcomes.

\section{Hobbs and Spencer's study on leadership through a stewardship course.}

Another study examined the apparent impact of a two-week outdoor stewardship course. Twelve participants participated in the course, and each student took on the role of leader for a day (Hobbs \& Spencer, 2002). In assessing students' perceived changes in their leadership skills as a result of the program, the researchers utilized the leadership skills inventory (LSI) as a pretest and posttest tool. Significant findings emerged for the outcomes of group dynamic skills, character-building skills, speech communication skills, and fundamentals of leadership. There were no significant changes in students' 
perceived skills for the outcomes of written communication skills, decision-making skills, problem-solving skills, personal development skills, or planning skills. A limitation of the study is the small sample size for a quantitative study. Additionally, long-term effects were not assessed.

\section{Section Conclusion}

This section reviewed research related to college students' leadership outcomes and behaviors. Differences in leadership styles and behaviors by gender and race were evident. Additionally, the literature in this section suggests a number of environmental variables that are significant in students' leadership development. Some of these include: curricular and co-curricular leadership programs, holding formal leadership roles, involvement in student groups, socio-cultural discussions, mentoring, and volunteer work.

Some limitations and challenges of using self reported data were discussed in the sections above. While the above studies on students' self-reported leadership outcomes and behaviors provide additional insight into the topic of college student leadership development, the studies may not sufficiently measure students' leadership capacities and how experiences contribute to their leadership behaviors. Additional measures are needed to understand students' leadership development; one angle that can provide further insight is exploring students' understandings of leadership. The next section of this chapter will provide a synthesis of the research discussed in the above sections with specific focus on demographic and environmental variables that were noted as significant in the research. 


\section{Conclusions and Discussion of Literature Review}

Thus far, this chapter explored research and literature on differing perspectives of leadership in the field of leadership studies, college students' views of leadership, and college student leadership behavioral outcomes. The research and literature provide insight into a systematic study of students' perceptions and understandings of leadership. Three main conclusions can be drawn from the above review of literature and will be summarized. These conclusions are:

1. A variety of understandings of leadership exist within the college student population.

2. Race and gender appear to be significant variables for some leadership measures and outcomes; other demographic variables, such as age, may be potentially relevant variables that have not been directly examined.

3. A number of college environment variables emerge in the research as significant in college students' leadership measures and outcomes.

\section{Differing Leadership Perspectives}

The review of the literature on college students' understandings of leadership suggests that a number of different leadership perspectives exist within the college student population. The perspectives range from leader-centric views to relational views to systems views. These three views are quite different in general assumptions of leadership, the roles of the leader and followers, and how one would exercise or demonstrate leadership.

Recognition of these differing understandings of leadership speaks to the importance of tailoring leadership training, education, and development programs to 
different students based on their respective understandings of leadership. Additionally, evidence of differing understandings of leadership being associated with a developmental process (Komives et al., 2005) supports the idea that different students have different needs, and, therefore could benefit from different experiences and interventions depending on where they exist in their developmental process of leadership, or based on their understanding of leadership.

\section{Race and Gender Matter; Might Age Also Matter?}

The above research also provides evidence that in some cases students' understandings of leadership and leadership behaviors tend to differ by gender and race. Overall, women and students of color tend to have more relational and process-oriented views and practices of leadership than their dominant group peers (Dugan, Komives, \& Segar, 2008; Haber, 2006a; Shankman et al., 2010). Additionally, women's competence in leadership exceeds that of men, while their confidence in their leadership is lower than men's confidence (Dugan \& Komives, 2007; Dugan, Komives, \& Segar, 2008). While gender seemed to be an important variable, one study did not find evidence of differences by gender within student leaders' leadership practices (Posner \& Brodsky, 1994).

Research also suggests that men and women have different involvement patterns (Dugan \& Haber, 2007) and that different experiences contribute to the leadership outcomes of men and women (Haber, 2006a). The minimal research on gender differences in students' understandings of leadership also suggests differences in how women and men view leadership (Arminio et al., 2000; Fisher et al., 2010; Kezar \& Moriarty, 2000; Wielkiewicz, 2000). 
Some differences in leadership behavior also emerged across racial groups (Dugan, Komives, \& Segar, 2008; Kezar \& Moriarty, 2000) as well as differences in involvement patterns (Owen \& Komives, 2007; Dugan \& Haber, 2007). Additionally, some students of color were found to resent the term leadership, reject the notion that they are leaders, disregard members of their own community as leaders (Arminio et al., 2000; Balon, 2004), and promote inclusivity in their leadership style (Komives et al., 2005). It is evident that race and gender should be considered for a systematic study of how students understand and view leadership.

A conclusion of the research on the overall impact of college on students reflects this similar finding that students' outcomes and experiences differ across identity groups (Pascarella \& Terenzini, 2005). A recent discussion on this trend in research provides a convincing argument that researchers should focus not just on general effects of college, but also on the conditional effects, such as the demographic variables of race and gender (Pascarella, 2006). Pascarella suggests that researchers should anticipate these possible differences by gender and race in their research designs by putting these variables at the forefront of their research. This suggestion seems particularly relevant for the study of college student leadership definitions since previous research on college student leadership development have uncovered race and gender differences.

Other demographic variables. While the variables of race and gender were two demographic variables that were often examined in the research, there appears to be a gap in the examination of other demographic variables. Two demographic variables that were not included in the identified research on college student leadership outcomes are age and socio-economic status. These variables could provide additional insight into how 
background variables can relate to students' leadership perceptions and behaviors. Research that suggests that understandings and practices of leadership are developmental (e.g. Avolio \& Gibbons, 1988; Day et al., 2008; Komives et al., 2005) and adult/student development theory that informs this development (e.g. Baxter Magolda, 1999, 2000; Kegan, 1994) can inform the study at hand; age is a variable that is not very well researched as it relates to leadership and could provide insight into how students view leadership. A gap also exists in socio-economic status and student leadership outcomes. Socioeconomic status is a variable worth exploring as there could be cultural implications regarding cultural and social capital that can be captured in this variable. Socioeconomic status could lead to differing levels of access and aspiration for certain experiences (Walpole, 2003), such as seeking out opportunities for leadership and involvement.

\section{Environmental Variables are Important}

There is limited research on if and how college student involvement and other environmental variables contribute to students' understandings of leadership. There were three qualitative studies that provide some insight on this topic. One study examined student leaders' (those holding a formal leadership role) views of leadership as compared to students who did not hold a formal role; the leaders tended to have more hierarchical views of leadership more often than their non-leader peers (Shertzer \& Schuh, 2004). The LID research, on the other hand, found that a number of environmental variables and experiences were key in students' development of a leadership identity; such experiences were peer and adult interaction, involvement in organizations and taking on roles in those organizations (Komives et al., 2006). One study examined the experience of fraternity 
men in a five-day leadership program; results were positive, indicating that the students' views of leadership shifted through the program to be more relational and inclusive (DiPaolo, 2002). While this research was limited, there was more substantial research on the students' experiences and involvement in relation to their leadership behavior and styles.

A number of different variables emerged within the literature on college student leadership outcomes. While there were few findings of negative relationships between the involvements and experience and leadership outcomes (e.g. breadth of involvement in Dugan \& Komives, 2007 and Haber, 2006a; leadership programs in Owen \& Komives, 2007) and at times the variables did not emerge as significant (e.g. across the several MSL studies), a number of significant positive relationships emerged between involvements/ experiences and leadership outcomes. These experiences include:

- pre-college involvement experiences (Dugan \& Haber, 2007; Haber, 2006a)

- socio-cultural discussions and diversity experiences (Antonio, 2001; Dugan, Garland, Jacoby, \& Gasiorski, 2008; Kezar \& Moriarty, 2000; Wabash College, 2009)

- involvement in student organizations (Astin, 1997; Cooper et al., 1994; Dugan, Garland, Jacoby, \& Gasiorski, 2008; Dugan \& Komives, 2007; Haber 2006a; Kezar \& Moriarty, 2000; Shankman et al., 2010)

- involvement in community organizations (Haber, 2006a)

- holding a formal leadership role (Astin, 1997; Cooper et al., 1994; Haber, 2006a; Dugan, Garland, Jacoby, \& Gasiorski, 2008; Dugan \& Komives, 2007; Kezar \& Moriarty, 2000; Kuh \& Lund, 1994) 
- service/ volunteering (Astin \& Sax, 1998; Dugan, Garland, Jacoby, \& Gasiorski, 2008; Dugan \& Kezar \& Moriarty, 2000; Komives, 2007)

- participation in leadership programs (Cress et al., 2001; Dugan \& Haber, 2007; Dugan \& Komives, 2007; Haber 2006a; Hobbs \& Spencer, 2002; Kezar \& Moriarty, 2000; Zimmerman-Oster \& Burkhardt, 1999)

- off-campus employment (Dugan, Garland, Jacoby, \& Gasiorski, 2008)

- mentoring experiences/ interaction with faculty (Astin, 1997; Dugan, Garland, Jacoby, \& Gasiorski, 2008; Dugan \& Komives, 2007; Wabash College, 2009) While many of these experiences resulted in consistent findings across the studies, findings on the role of leadership training, education, and development programs were quite perplexing. In some cases different types of leadership programs did not emerge as significant, and in another, longer-term programs were found to be less effective than short-term programs (Dugan \& Haber, 2007; Owen \& Komives, 2007). Still, another study reported participation in leadership programs as significant, with those students participating scoring higher than non-participants on a variety of outcomes (Cress et al., 2001). It is clear that leadership educators need a better understanding of the role of leadership programs in students' leadership development. One way this could be accomplished is by examining students' behaviors through observation or by peer or follower assessment. Another way to examine the role of leadership programs would be to study how the students view leadership; perhaps differences in leadership perceptions would emerge based on participation in a leadership program. 


\section{Section Conclusion}

This section included a synthesis of findings identified from the literature review pertaining to students' views of leadership, the role of gender and race, and the role of involvement and other experiences in a variety of student leadership outcomes.

Much of the research discussed focused on students' behavioral outcomes; studying students' understandings and views of leadership could provide additional information of value to college and university administrators and faculty. Through examining how students view leadership along with their involvement patterns, leadership educators could have a better understanding of why some students report lower levels of efficacy for leadership (i.e. women) or do not believe themselves to be leaders (i.e. students of color). This could also lead to additional exploration into if students' views of leadership are related to their levels of involvement and other experiences. Additionally, information on how students view leadership can be examined alongside their leadership behaviors to better understand students' leadership development and capacities on a more holistic level.

There is a lack of a comprehensive understanding of how college students view leadership in the literature and research on college student leadership development. Thus there is a need to understand how college students view leadership and how this relates to other environmental and demographic variables. Additional research on this topic can provide valuable information to enhance leadership education practice and to contribute to the growing research and understanding of college students' leadership development. The question of how exactly to study this naturally arises. A discussion on research methods appropriate for examining how college students understand the concept of 
leadership and variables associated with the different understandings is discussed below in the final section of this chapter.

\section{Research Methods for the Study of Leadership}

The body of research on leadership continues to grow, and with this more and more is researched on college student leadership (Dugan, 2011). Historically much of the research on leadership has been quantitative in nature, often reflecting a positivistic and logical approach to research and knowledge (Klenke, 2008). Quantitative approaches to leadership have received some criticism in recent years, whereby "quantitatively generated leadership descriptors often fail to lead to an understanding of the deeper structures of the phenomena of [leadership]" (Klenke, 2008,, p. 4). Due in part to this scrutiny, qualitative approaches to studying leadership have recently gained greater attention and have been viewed in some cases as more fitting, as qualitative methods can more appropriately address the multidisciplinary and context-dependent nature of leadership. The qualitative study of leadership has faced some resistance and difficulty in being a legitimate research approach in the academy, which is reflective of qualitative research in other social science disciplines (Klenke, 2008).

The ongoing quantitative-qualitative debate and polarization that comes from this debate exists within the academy as a whole and within leadership studies. Interestingly, these paradigm debates are "reminiscent of the many dichotomies found in leadership theory" (Klenke, 2008, p. 45), such as autocratic vs. democratic or task-oriented vs. relationship-oriented leadership. These polarizations are often viewed as false or overly simplistic (Klenke, 2008). Rather than approaching research practices with this dichotomy, they can be viewed as existing along a continuum between the two 
approaches (Creswell, 2003). There is a range of different approaches to research and quantitative and qualitative approaches can be utilized together to address research questions (Klenke, 2008; Patton, 2002).

Mixed-methods approaches to studying leadership have become more prominent in recent years (Klenke, 2008), and are used for a variety of different purposes. Mixed method research design involves philosophical assumptions and methods of inquiry that reflect a mixture of qualitative and quantitative research, the central premise being that this "combination provides a better understanding of research problems than either approach alone" (Creswell \& Plano Clark, 2007, p. 5). Creswell (2003) presented three strategies of mixed-method research:

1. Sequential procedures: the findings from one method are elaborated upon through use of the other method

2. Concurrent procedures: both forms of data are collected at the same time, whereby one form of data is nested within the other. The researcher integrates qualitative and quantitative data when interpreting the results

3. Transformative procedures: both forms of data are collected (through either sequential or concurrent procedures) and analyzed through a theoretical lens.

Bryman (2006) also examined different approaches to mixed-methods research through a qualitative content analysis study of 232 mixed-methods studies in social sciences. He found that semi-structured interviews and self-administered questionnaires were the two methods used most frequently within these studies. He also created a framework of justifications or purposes for combining quantitative and qualitative methods based on his research: 
1. Triangulation: converging results from different methods

2. Complementarity: elaborating on results through the use of another method

3. Development: using results from one method to inform or further develop another method

4. Initiation: seeking to identify paradoxes or contradictions across the different methods

5. Expansion: extending the range of the study by using different methods for different components of the study (Bryman).

The sequential approach from Creswell's (2003) framework purpose of expansion from Bryman's (2006) study reflect the use of mixed-methods research in this dissertation, which examines college students' leadership understandings and factors that relate to these understandings. Qualitative approaches were used in examining the different definitions of leadership provided by the participants, and quantitative methods were employed in order to use these thematic findings in further analysis to identify variables that are statistically significant differentiators and predictors of the various leadership understandings. While the qualitative component of this dissertation is a study in itself, the quantitative methods expand the study to utilize the findings in further exploration of the demographics and experiences of college students that are related to the different understandings of leadership. The quantitative analysis therefore is dependent on the qualitative findings. This use of qualitative and quantitative methods reflects a sequential mixed design, whereby one of the methods is conducted as a result of the findings from the other method (Creswell, 2003; Klenke, 2008). 


\section{Studying Leadership Understandings and Definitions}

This study sought to examine the ways in which college students understand the concept of leadership and identify the potential themes within these understandings. Since there is limited research on different understandings of leadership, this study sought to capture participants' different ways of expressing their own views rather than choosing their definition from a pre-existing framework. Therefore, an open-ended qualitative approach to analysis was appropriate. Qualitative inquiry is "oriented toward exploration, discovery, and inductive knowledge" (Patton, 2002, p. 55), which allows for patterns and themes to emerge from the data without making prior assumptions or using predetermined theories or frameworks. Since the purpose of this study was to inductively identify themes of leadership definitions across the individual cases and without prior categorization of the cases, qualitative research was fittings (Patton, 2002). Quantitative methods and experimental designs, on the other hand, tend to use a hypotheticaldeductive approach in which the researcher determines the potential responses.

Although the qualitative data from each participant in this study is limited to data from one open-ended response, the qualitative approach to analyzing this data allows for greater depth and identification of potential variations that cannot be predicted by the researcher. A thematic approach to coding allows for identifying manifest codes (directly observable) and latent codes (underlying the phenomenon) (Klenke, 2008). Attention to manifest codes in this case of this study relates to verbiage that may reflect a term but that term may not be directly stated. For example, the code of collaborate may be a manifest code through the direct use of the word collaborate in a definition, whereby 
working together to accomplish something could be a latent code that could be taken to mean collaborate in a definition.

Studying language is "a way of gaining insight into mind, inasmuch as language is the creation of mind" (Chomsky, 1972 as cited in Pondy, 1989, p. 231). Language provides insight into the person's understanding and meaning. Martin (1987), a scholar on the meaning of language, discussed that the same things can be described in as many different ways as the number of people describing it: "A language consists, loosely, of a pairing of meanings with sentences... [and] there are an infinite number of pairings of meanings and sentences" (Martin, 1987, p. 8).

Not only are different people likely to describe the same thing in many different ways, but meaning and understanding may also vary within an individual. In describing something, there is a speaker's (or writer's) meaning and a sentence meaning (what the sentence actually means from an outside perspective). While they often coincide, as "people nearly always mean what they say" (Martin, 1987, p. 19), differences in the two meanings could emerge based on uncertainty in use of language or if someone has a slip of the tongue. Whether or not one's understanding of the concept of leadership reflects their actual behaviors is an entirely different story and is beyond the scope of this study. Pondy (1989) suggests, "whether these different meanings of the term leadership are retained in usage will probably depend on how strong are the participants' vested interests in the current meaning" (p. 230). This reflects differences in espoused values and how one actually acts (Schein, 2004), which again is beyond the scope of this study. In focusing more specifically on definitions, Martin (1987) discusses that words can be defined in two different ways: ostensive definitions and verbal definitions. 
Ostensive definitions involves pointing out or identifying the meaning of something by providing examples (such as in defining a color), while a verbal definition involves constructing words together to portray the meaning of a word. Leadership is a concept that may, for some, be more easily defined in an ostensive manner than a verbal manner; participants may be able to more naturally and easily provide examples of what leadership is (or is not) than conceptualizing and putting into words what it is. Recognizing this, attention to the potential meaning of a participant's definitions rather than only focusing on the mere presence of a word is particularly important for examining language of defining leadership.

Pondy (1989) suggests that the number of meanings people have for the concept of leadership differs based on environments and settings; in high-variety, or more volatile, environments the concept of leadership might expand and in low-variety, or more stable, understandings of the concept of leadership might contract. He explains: "once the category exists we will try to fill it, so more and more things will be attributed to 'leadership,' especially in turbulent environments where there are a great number of unique events to make sense of' (p. 228). This supposition can support the notion that differing environments or situations can influence the ways in which the concept of leadership may be understood, which leads to the other part of this dissertation: the role that background characteristics and environmental variables play in differing understandings of leadership.

Additional literature supports the idea that contextual factors influence how one perceives or defines leadership. In examining how one might define leadership, Lord, Brown, Harvey, and Hall (2001) presented prototypes to explain how leaders are 
perceived and the factors that may influence this perception. Their work, which is based in part on advances in cognitive science, discusses the influence of the larger external environment, such as situational and contextual factors as being a key contributor to how one perceives leadership. These variables include organizational culture, leader characteristics, follower characteristics, and features of the leadership task. Additionally, the authors distinguish between the formation of masculine and feminine prototypes. The variables present in the situation then influence the leadership schema, or how one perceives the traits or qualities associated with a leader (Lord et al., 2001). This work supports the focus of the second part of the dissertation: examination of different variables that could predict different definitional themes.

While qualitative methods were discussed above as appropriate for the analysis of the leadership definitions and understandings examined in this study, quantitative methods are appropriate for examining potential experiences or other variables that are significant for variation across the different leadership definition themes. Quantitative methods allow for examining a large number of responses and the statistical aggregation of the data to conduct comparisons, ideally leading to generalizable findings (Patton, 2002). The use of statistical analysis is common in social sciences, as it allows for examining a behavior, attitude, or belief numerically and explaining the behavior, attitude, or belief in relationship to other variables, such as background variables, other behaviors, or experiences (Hinkle, Wiserma, \& Jurs, 2003).

There is limited research on the experiences related to college students' different understandings of leadership. Further, there are no identified studies that examine the relationships between college environmental variables or other experiences and students' 
understandings of leadership through a quantitative approach. The use of quantitative methods in this study builds off of the findings from the qualitative methods to examine potential variables that reflect differences in themes. This can lead to a greater, potentially generalizable understanding of the college environment and additional factors, such as demographics, that play a role in students' different understandings of leadership. This discussion on the appropriate use of research methods in examining students' leadership definitions and accompanying significant variables will be built upon in Chapter Three, which overviews the methodology of this study. 


\section{CHAPTER THREE: METHODOLOGY}

This chapter begins by reviewing both the purpose of the study and the research questions. Next, the Multi-Institutional Study of Leadership (MSL) will be described. The MSL provided the data for this study; the discussion of the MSL will include a focus on the design of the study and the procedures utilized to gather the data. The final sections of this chapter focus on the design of the study, the procedures that were used to generate a sample from the larger data set to serve as the participants in this study, the analysis procedures that were used to code and categorize the sub-sample data, and the additional analysis procedures that were used to answer this study's research questions.

\section{Purpose of the Study}

The purpose of this study was to examine the different ways in which college students define leadership, examine potential racial, gender, and age differences in the different definitional themes, and investigate what demographic and environmental variables are associated with the different definitions.

The three research questions were:

1. What are the different ways college students understand the concept of leadership?

2. What differences, if any, exist in students' understandings of leadership based on gender, race, and age?

3. What demographic variables and college environmental variables predict the different understandings of leadership? 


\section{Multi-Institutional Study of Leadership}

This study involved analysis of data from the larger Multi-Institutional Study of Leadership (MSL). MSL is a national study examining college students' leadership development and the influence of higher education on this development. MSL is a project of the National Clearinghouse for Leadership Programs and the Center for Student Studies. MSL was first conducted in 2006, and the second iteration of the study took place in Spring 2009. I was a member of the original research team at the University of Maryland that designed and conducted the MSL study in 2006. Additionally, I was part of a small team that developed the survey instrument. For the 2009 study, I was the campus investigator for one of the participating institutions.

\section{MSL Questionnaire}

The conceptual model for the MSL survey questionnaire is Astin's (1991) inputenvironment-outcome (I-E-O) model, which focuses on the impact of the input variables (e.g., race, gender, pre-college involvement) and environmental variables (e.g., college major, involvement in student organizations, mentoring) on different outcome variables. This model, combined with appropriate inferential statistic analyses, allows for controlling input variables as a way to assess the impact of the college environmental variables (Astin). Quasi pre-tests are used in the MSL instrument to reflect this I-E-O model since the survey was administered as a cross-sectional design.

The MSL survey questionnaire includes over 400 scales, variables, and composite measures that reflect participants' input/ background, environment, and outcome measures (Komives, Dugan, \& Owen, 2009). The primary outcome measures of the study are eight outcomes of the social change model of leadership (Komives \& Wagner, 
2009). These outcomes are: consciousness of self, congruence, commitment, collaboration, common purpose, controversy with civility, citizenship, and change; they are measured in the MSL survey through an adapted version of the Socially Responsible Leadership Scale (SRLS) (Tyree, 1998); see Table 1 in Chapter Two for a description of these outcomes. Additional outcome measures in the study include measures of: leadership efficacy, complex cognitive skills, and outcomes related to mentoring, spirituality, social perspective-taking, and racial esteem.

\section{MSL Participants and Data Collection Procedures}

The total number of students sampled for the national MSL in 2009 was 337,482 students who attended 101 U.S. colleges and universities. Institutions applied to participate in the study, and the participating institutions reflected diverse institutions including four-year institutions, two-year colleges, research institutions, liberal arts institutions, religiously affiliated institutions, women's colleges, historically Black colleges and universities, and Hispanic serving institutions (Komives et al., 2009). Random samples of 4000 part-time and full-time undergraduate students were drawn from each institution; in the cases where there were fewer than 4000 students, all of the undergraduate students at the institution were included in the sample. There was an overall response rate of $34 \%$, resulting in 115,582 usable surveys and 94,317 participants who completed $90 \%$ of the core survey (Dugan \& Komives, 2009).

Data collection for the national MSL study was administered by the Center for Student Studies in conjunction with members of the MSL research team and partners at the 101 participating institutions. All data collection was managed by the Center for Student Studies to ensure confidentiality of responses, with any identifiable information 
(such as student identification numbers) stored in separate files than the responses to the survey.

Data were collected from January through April 2009, with each institution selecting a three-week window in which students were invited to participate in the study. The survey was web-based, and selected students were invited to participate in the study via a personalized email, which included information about the study, confidentiality, consent, and a link to the survey questionnaire (MSL, 2009). See Appendix A for the invitation email and Appendix B for the Informed Consent Form. Participants were sent two to three reminder emails, depending on the specific institutional protocols, after the initial email.

Participants were each assigned a unique identification number to access the survey and a link to complete the survey online. Participants completed an online informed consent form before proceeding to the instrument. Participation in the study was optional, and participants could opt out of the survey at any point in time. Participant responses and unique identification numbers were stored in two different places and were unable to be linked once separated in order to maintain participants' confidentiality. Incentives for participating in the study (such as iPods and cash prizes) were provided by the national study as well as by the individual institutions. Incentive winners were drawn from those participants who completed the survey.

\section{The Current Study}

This current study uses data from the aforementioned MSL project. This section will include an overview of the participants, design, and data analysis of my study. 


\section{Participants in the Current Study}

Participants in the study were undergraduate students who were part of the 2009 MSL study. For the study 1100 participants were selected from the overall national database through random criterion sampling through the random number generator function in Microsoft Excel. The sample included 220 students from each of the groups of students who self-identified racially as White/ Caucasian, African American/ Black, American Indian/ Alaska Native, Asian American/ Asian, and Latino/ Hispanic, with 110 of the participants in each racial group being women and 110 being men. The students selected in the study were those who chose only one racial group on the survey (although the prompt on the survey allowed for identification of multiple groups), and those students who selected more than one racial group were not considered for the sample due to the immense diversity within the multiracial population (Renn \& Shang, 2008). Drawing a sample with an equal number of participants from the five identified racial groups allowed for understanding a diverse array of students as well as representing enough respondents in each group to conduct statistical analysis procedures by the variable of race. Purposefully selecting a sample that is reflective of different racial background is also in line with a recent review of research in higher education that suggests moving in a direction toward understanding different groups of students rather than utilizing a one-size-fits-all approach to researching college students (Pascarella, 2006).

While selecting a sample that reflects equal representation from multiple racial groups allows for greater opportunity examine race as a construct, it does, too, have 
limitations. The findings from this study do not reflect the college student population as a whole and the findings may reflect variability within the different racial groups rather than the variability that exists within college students as a larger population. Refer to Appendix $\mathrm{C}$ for a breakdown of the demographic makeup of the participants in this current study as it compares to the MSL respondents as a whole.

The number of participants was selected based on the number of responses required to conduct the statistical analyses in the study. Logistic regression, which was used in research question three, requires a substantial number of cases per variable to determine sample size. Research on sample size for logistic regression analysis by Peduzzi, Concato, Kemper, Holford, and Feinstein (1996) suggests criteria for determining sample size. Their research suggests that the number of events, or responses, per variable should be at least 10. The formula that considers Peduzzi et al.'s research for determining sample size takes into account the number of covariates, or independent variables $(\mathrm{k})$, in addition to the proportion of positive or negative (whichever is smaller) cases in the population for the dependent variable (p) (Hosmer \& Lemeshow, 2000; MedCalc, 2010). The formula is $\mathrm{N}=10 \mathrm{k} / \mathrm{p}$. I estimated an appropriate sample size to be 1050 based on the number of positive cases for the different themes in my initial category search of data ( 50 cases) and the number of covariates for the logistic regression analyses. To account for possible unusable data, I drew a sample of 1100 participants.

Results from research question one indicated that the proportion of positive cases in the population for the leadership definition category was 0.13 . The number of covariates used for the logistic regressions was at most 13 . Therefore, the formula 
suggests a sample size of at least 1,000 . The sample size of 1100 allowed for a sufficient number of participants to conduct the analyses.

Choosing a sample size of 1100 also allowed for a sufficient number of cases needed to conduct loglinear analysis, which was the statistical analysis procedure used in research question two. Loglinear analysis requires a minimum of five cases in at least $80 \%$ of the cells (Cohen, Manion, \& Morrison, 2007). Although a standard rule of thumb was not determined for total number of cases, through examining many websites and sources through a websearch, 30 cases per variable appeared to be a commonly used and accepted total number of cases. The sample size of 1100 participants adequately meets this requirement.

\section{Design of the Study}

Data for this study came from the $2009 \mathrm{MSL}$, pulling from one open-ended (qualitative) prompt and a number of closed-ended (quantitative) questions. The variables utilized in this study are presented below.

Variables. The first research question was examined through the responses to the following open-ended prompt: Please provide a brief definition of what the term leadership means to you (prompt \#40). For research questions two and three, a number of dependent variables and independent variables were examined. The dependent variables for research questions two and three were the 10 leadership definition themes, which were identified from research question one. The independent variables were items from the MSL instrument and included a number of demographic variables and college environmental variables, which are discussed below. Some of the variables were ordinal 
or continuous while others were nominal or dichotomous. These varying measurement formats were taken into account during the data analysis procedures.

Demographic variables. The demographic variables of gender, race, and age were examined in research question two. Gender was examined in research question two due to past research that suggests differences in students' leadership behaviors, approaches, and understandings based on gender (Dugan, Komives, \& Segar, 2008; Dugan \& Komives, 2007; Fischer et al., 2010; Kezar \& Moriarty, 2000; Wilkiewicz, 2000).

The five racial groups selected were: White/ Caucasian, African American/ Black, American Indian/ Alaska Native, Asian American/ Asian, and Latino/ Hispanic. These categories came directly from a self-report multiple-choice question from the MSL instrument. Although the prompt allowed participants to select more than one racial category, I only selected those participants who identified one category, therefore eliminating multi-racial students from the analysis. Multiracial students were not selected as a racial group for analysis due to the immense diversity within this population (Renn \& Shang, 2008); it was outside of the scope of this study to examine the within-group diversity and differences of multiracial students.

The five racial were selected in part based on research that demonstrates differences in leadership perspectives, behaviors, and involvement patterns among these groups (Bordas, 2007; Dugan \& Haber, 2007; Dugan, Komives, \& Segar, 2008; Kezar \& Moriarty, 2000) in addition to the fact that White, African American, and Latino students each make up approximately $10 \%$ or more of the total undergraduate college student population in the Untied States (The National Center for Higher Education Management 
Systems, 2009). There was no research found about American Indian student leadership outcomes; American Indian students make up a very small percentage of college students. Since there were enough American Indian students who responded to the survey $(\mathrm{N}=401)$, I examined these students as a group in order to potentially identify new information on this underrepresented and under-researched identity group.

Age was also examined in research question two. Although age was not a consistently examined variable within the research on college student leadership behaviors or understandings, some research and literature suggests that leadership understandings reflect a developmental process (Day, 2001; Komives et al., 2005; Torbert 2004), which could indicate that differences in leadership definition could vary based on age. The age measure was an open response variable; in some analyses (logistic regression) the actual stated age number was used, and in other analyses, where a distinct number of categories was needed (loglinear analysis), the categories of 18-23 and 24+ were used. Age was selected instead of class year due to the diverse array of institutional types represented in the sample and the fact that approximately $11 \%$ of the MSL respondents were non-traditionally aged college students (24 years or older). Additionally, the number of adult learners in higher education continues to increase. There was a $13 \%$ increase in enrollment of students aged 25 and older in higher education institutions from 1995-2006, and the number is project to increase by an additional 19\% from 2006-2017 (National Center for Education Statistics, 2009). Examining age allowed for the potential of expanding the knowledge base on adult learners and accounting for variance in age in higher education today. 
An additional demographic variable was examined in research question three: parents' formal education. This variable was captured with a multiple-choice question that addressed the highest level of formal education obtained by any of the participant's parents or guardians. There were eight choices ranging from less than a high school diploma or less than a GED to doctorate or professional degree and including don't know. This variable was selected because I was unable to find any research that examined students' socio-economic status in relationship to leadership outcomes. Examining if this variable is significant or not can provide additional information into how social identities play into understandings of leadership. The variable of socioeconomic status could also have cultural implications regarding cultural and social capital, which could lead to differing levels of access and aspiration for certain experiences (Walpole, 2003), such as leadership and involvement experiences.

College environmental variables. There were 11 college environmental variables examined in this study. These variables reflect a variety of involvement experiences or other experiences that take place during the college years. Some of the variables are ordinal data, yet were treated as continuous data in the analysis since they reflected a natural progression. The college environmental variables used in this study are presented below in Table 2 . 


\section{Table 2}

\section{College Environmental Variables}

\begin{tabular}{ll}
\hline Variable & Response Type \\
\hline Community Service & Likert scale: 1-4 (Never to Very Often) \\
Socio-Cultural Discussions & Composite measure comprised of six items using \\
& Likert Scale: 1-4 (Never to Very Often) \\
Work Experience - off campus & \# of hours worked per week - open response \\
Work Experience- on campus & \# of hours worked per week - open response \\
Involvement in College Org & Likert scale: $1-5$ (Never to Much of the Time) \\
Leadership position in College Org & Likert scale: $1-5$ (Never to Much of the Time) \\
Involvement in Community Org & Likert scale: 1-5 (Never to Much of the Time) \\
Leadership Program & Y/N \\
Social Fraternities or Sororities & Y/N \\
Sports- Intercollegiate & Y/N \\
Student Governance & Y/N
\end{tabular}

These variables were selected due to past research that reported these experiences as significant for college student leadership development. Community service has been consistently reported as a significant variable for college students with involvement in community service positively associated with leadership outcomes (Astin \& Sax, 1998; Dugan, Garland, Jacoby, \& Gasiorski, 2008; Dugan \& Komives, 2007). Socio-cultural discussions were also selected due to past research that found these experiences to be significant for leadership outcomes. The variable of socio-cultural discussions was a composite measure comprised of six items that were measured on a Likert scale from one to four (never to very often). A sample item from this composite measure is: During interactions with other students outside of class, how often have you held discussions with students whose religious beliefs were very different from your own in the past year? 
The reliability for this scale within the larger MSL project resulted in a Chronbach's alpha score of 0.90 (Dugan \& Komives, 2009). The calculated reliability for this scale within the current dataset resulted in a Chronbach's alpha score of 0.91 .

The MSL research found socio-cultural discussions to be the strongest environmental predictor of growth of those predictor variables examined for all of the social change model outcomes and leadership efficacy (Dugan \& Komives, 2007); additional research points to the significance of interracial interaction and diversity experiences in developing leadership skills (Antonio, 2001; Wabash College, 2009) and the impact of socializing with a different racial group on self-perception of leadership ability for White men and women (Kezar \& Moriarty, 2000).

Work experience was selected due in part to the fact that the relationship between work experience and leadership outcomes of college students has not been very well researched. Recent MSL research reported off-campus employment as a significant predictor for independent commuters (those who live on their own or with friends, as opposed to with relatives) (Dugan, Garland, Jacoby, \& Gasiorski, 2008; Dugan \& Komives, 2007). Additionally, mentoring relationships from employers, which come from work experiences, emerged as a significant experience in the MSL research for leadership efficacy (Dugan \& Komives, 2007). Work experience and how it relates to understandings of leadership has not yet been studied; including this in the study allowed for examination of if and how exposure to real-world organizations relates to perceptions of leadership.

Involvement in college organizations has consistently emerged in the literature as a significant experience for leadership outcomes (Astin, 1997; Dugan \& Komives, 2007; 
Haber, 2006a; Kezar \& Moriarty, 2000; Komives et al., 2005), and involvement in community organizations has also been found to be positively related to leadership outcomes (Dugan, Garland, Jacoby, \& Gasiorski, 2008; Haber, 2006a). Involvement in community organizations expands the opportunity to capture involvement and experience beyond the traditional campus, which may more fully capture the experiences of adult learners, commuter students, or students who are heavily involved in cultural or religious organizations. The three specific student organization types of social fraternities or sororities, intercollegiate sports, and student governance were chosen in order to more fully understand different involvement experiences. These different organizations shed light onto a more micro level of student involvement by examining different types of organizations rather than student organization involvement as a broad experience; examination of different types of student organization involvement in other research has resulted in different involvement patterns and outcomes (Dugan, 2008); examination of the specific organizational types warrants additional research to better understand these experiences.

Holding a leadership role is another variable that was examined in research question three. Positional leadership roles have been found in past research as significant experiences for leadership outcomes (Cooper, et al., 1994; Dugan \& Komives, 2007; Haber, 2006a; Kuh \& Lund, 1994; Romano, 1996; Shertzer \& Schuh, 2004). Additionally, the variable of participation in leadership programs has been researched with varying results in terms of leadership outcomes (Dugan \& Haber, 2007; Dugan \& Komives, 2007; Haber, 2006a; Owen \& Komives, 2007; Zimmerman-Oster \& Burkhardt, 1999). Further examination of the role of leadership programs for leadership outcomes 
can contribute to this research base. Refer to Chapter Two for more information about the past research of these variables on leadership outcomes.

\section{Data Analysis}

Different data analysis procedures were used to answer the different research questions. As has already been noted, analysis of research questions two and three were contingent on the results from research question one. The thematic findings from research question served as the dependent variables for research questions two and three.

Research question one. The data for research question one were the participants' typed-in responses from the dataset. Data were analyzed through content analysis procedures. Content analysis is a data analysis technique that allows for replicable, reliable, and valid conclusions or deductions to be drawn from text (Krippendorff, 2004). Content analysis enables a researcher to break down a text into more manageable themes, categories, words, or phrases (Klenke, 2008). This is particularly useful for studying leadership, of which language is a fundamental aspect (Klenke, 2008). Although the distinctions can be blurry, content analysis can take primarily quantitative or qualitative approach, whereby the quantitative approach focuses on word frequencies and the qualitative approach relies more on thematic and theorydriven approaches in analyzing the data (Krippendorff, 2004; Klenke, 2008). In this study I used an approach that pulled from both the quantitative and qualitative methods; while frequency of certain words were at times noted, I recognized that the meaning of certain words may vary for different people based on situation and other factors. Therefore, the responses were examined more thoroughly through qualitative approach, 
taking into consideration the larger context of the response including the other words in the response and considering at times the induced meaning of the response.

Krippendorff (2004) presents a categorization of six different forms of content analysis: extrapolations, standards, indices and symptoms, linguistic re-presentations, conversations, and institutional processes. Because the units of analysis for this study were small (ranging from a short phrase to a few sentences), some of the more complex and in-depth content analysis frameworks and procedures are not fully relevant for this study. Nonetheless, some of the approaches can be useful in examining the data. For example, the identification of patterns and occurrences (within Krippendorff's extrapolations category content analysis approaches) of concepts or themes across the different definitional responses was appropriate for this study. Similarly, the linguistic re-presentations categorization of content analysis speaks to the importance of recognizing the role of language and how some key words, concepts, or phrases may be connected. The content analysis procedures utilized in this study pulled from the extrapolations and linguistic re-presentations approaches in Krippendorff's typology, which in turn informed the coding procedures.

Coding. Coding involves categorizing or interpreting units of analysis, in this case the textual responses, into analyzable pieces. Thematic coding was utilized in this study in the process of analyzing the data; thematic coding involves identifying an explicit code from which the encoding can take place (Klenke, 2008). Themes are patterns "found in the information that at minimum describes and organizes the possible observations and at maximum interprets aspects of the phenomenon" (Boyatzis, 1998, p. 4). A code encompasses themes and should have five elements: a label, a definition of 
the theme, information on how to identify if and when the theme occurs, description of exclusions or qualifications for identifying the theme, and examples of both positive and negative cases of the theme (Boyatzis, 1998). The themes can be determined at the manifest level, which is directly observable, or can be determined at the latent level, whereby the theme is inferred and / or underlying the phenomenon (Boyatzis, 1998; Klenke, 2008).

The process of developing themes and codes involves three steps: "generating a code, reviewing and revising the code in the context of the nature of the raw information, and determining the reliability of the coders and therefore the code" (Boyatzis, 1998, p. 35-36). The first step draws from past research, theory, and literature; in some cases when there are not clear themes in the literature data-driven codes can be inductively derived. The second step involves examining these codes alongside the raw data for compatibility. Finally, the third step involves examining reliability of the coding, which can be done with the use of additional coders (Boyatzis, 1998). An initial pilot study included aspects of the first and second steps discussed above to determine potential initial codes.

Pilot study. The process and the results from the pilot study are presented here, as the results influenced the data analysis design of research questions two and three. I conducted a preliminary category search with 50 responses from freshmen and junior men and women from one institution to identify initial categories and codes of leadership definitions. During the preliminary category search I began with the already determined literature-based categories (i.e., leader-centric, relational, and systems focused). Some of the responses reflected the leader-centric and relational categories, and there were 
none that reflected the systems category. Additionally, the leader-centric and relational categories seemed to be too broad; many smaller more discrete categories emerged under the umbrella of these larger categories. I organized the data through a workbook on Microsoft Excel, which allows for coherently organizing the responses.

To help confirm these identified categories, I asked three colleagues who work in college student leadership education to also analyze the same 50 preliminary responses and determine categories. The categories that emerged from examining the coding and categorizing from my analysis and my colleagues' were as follows:

1. Person/ Position(al): involves a personal quality or trait; a position of authority

2. Take Charge/ Direct: taking charge of a situation or directing others to do certain things

3. Action/ Task/ Goal: accomplishing or working toward a goal or task; taking action

4. Involving Others/ Group Focus: recognition in the role or presence of other people or the group

5. Modeling: acting as a role model; mentoring; doing the right thing

6. Influence/ Inspire/ Motivate: influencing, inspiring, or motivating others; making an impact on others

7. Common Good/ Shared Purpose: acting toward the common good or positive change; working toward a common or shared purpose

The first three categories reflect leader-centric perspectives of leadership, and the last four categories reflect relational perspectives of leadership. None of these categories 
explicitly reflect a systems perspective of leadership, which was emphasized in the literature review. Many of the responses actually encompassed more than one category, sometimes reflecting both leader-centric and relational perspectives. While this pilot study was a helpful first glance at the data, the categories were altered and finalized during the data analysis process.

Analysis. The analysis was conducted through use of Microsoft Excel, which allowed for organizing and sorting a large amount of data. Microsoft Excel also allowed for assigning multiple themes, searching for words, and relatively easy conversion of the data back to PASW 18. Qualitative software analysis programs were considered, yet recognizing the value of the larger context behind the use of a word, I chose not to use this software to conduct the content analysis because it did not seem to fit the type of analysis I was conducting. For example, when starting the data analysis, I experimented with using the HyperResearch software package with a sample of the data, and the analysis focused on identifying and labeling key words. When examining the word power, four of the cases that were identified had very different meanings:

- Leadership means someone on a power trip wanting to tell people what to do

- I believe it is the ability to lead. Having very strong leadership skills. The power of personality to dominate a group.

- Someone who can take charge while open for new idea to reach the goals of the group without abuse of power.

- Executing your agenda by empowering and enlightening others.

In each of these responses there were different uses of the word power with different assumptions and connotations. Using this software package would require individually 
examine each response for accuracy and proper categorization. This reason, along with the challenge I saw in converting the data back into Excel or PASW 18, were the two main reasons why I chose to instead conduct the analysis using Excel.

Once the sample was drawn, I began the analysis by reading and initially coding 100 of the responses to immerse myself in the data and obtain a sense of the responses as a whole (Klenke, 2008). By taking note of the words, themes, and concepts that repeatedly came up and comparing them to the categories found in the pilot study, I noted differences that should be further examined or taken into consideration when coding. Through this process I confirmed some of the previously identified themes from the pilot study, I narrowed down some of the previously identified themes, and I determined new themes. This resulted in 12 themes, some involving only a few cases, and some involving more than half of the cases.

Prior to continuing the analysis, I met with two colleagues for a two-hour work and brainstorm session. In the session we focused on the first 50 cases. I shared with them my identified themes, and they discussed how they would code the definitions in accordance with these themes. We discussed any discrepancies in coding and together re-examined the themes, further clarified, renamed, collapsed, and removed some of the themes. In this process they also agreed with the cases that I had coded as unusable, including definitions such as: the act or an instance of leading and (my favorite) $a$ special bubbly feeling deep inside like a warm bath. This work and brainstorm session resulted in identification of eight themes:

1. Others/ group focus- Relational

2. Others/ group focus- Transactional 
3. Providing support

4. Modeling behavior

5. Admirable personal qualities

6. Positive difference

7. Shared goal

8. Task/goal

Using these eight themes, I then created a codebook informed by Boyatzis' (1998) framework. The codebook included a label for the theme, a description of the theme, key descriptors, any exclusions or qualifications for identifying the themes, and examples of positive cases. Using this codebook, I coded 50 additional cases and selected two independent raters (different from the two colleagues already involved) to analyze the data as a means of assessing inter-rater reliability and agreement. The two raters independently coded the same 50 responses using the codebook. I then compared the independent raters' codes to my codes. I sought to have agreement with the raters' coding at least $80 \%$ of the time. I accomplished this goal with $81 \%$ reliability with one rater and $84 \%$ with the other. In examining where discrepancies in coding existed across the three rates (myself and the two raters), I noticed that many of the discrepancies existed within the first two categories: Other/ group focus-relational and Other/group focus-transactional. Additionally, a large number of cases were included in each of these two themes. I decided to further clarify the first two themes and broke them each into two themes. The four themes were then:

1. Collaborate/ work together

2. Inspire/ motivate 
3. Influence/guide/ lead/ others follow you

4. Direct/ control/ in charge

The first two themes reflect the initial relational theme and the last two reflect the transactional theme. The final theme codebook, which describes the 10 final themes, is included in Appendix D. The final ten themes are:

1. Collaborate/ work together

2. Inspire/ motivate

3. Influence/ guide/ lead/ others follow you

4. Direct/ control/ in charge

5. Providing support

6. Modeling behavior

7. Admirable personal qualities

8. Positive difference

9. Shared goal

10. Task/goal

The 10 themes identified in this qualitative analysis will be discussed and described in more depth as findings in Chapter 4. The 10 themes served as the dependent variables for research questions two and three. During the qualitative data analysis process each response was attached to a participant ID number to allow for entering the appropriate themes into database as numbers. I then conducted frequency analyses of each of the different definitions as a whole and based on gender, race, and age to examine the prominence of the categories across these groups. Additionally, frequencies of commonly paired themes were calculated. 
Research question two. As has been previously discussed, the 10 themes from the analysis of research question one served as the dependent variables for the inferential statistics used to answer research question two. These 10 dependent variables are dichotomously coded (0 and 1). Statistical analysis for both research questions two and three were conducted using PASW 18 statistical software package, which is formerly SPSS.

To examine significant differences by gender, race, and age, loglinear analysis procedures were employed. Loglinear analysis is a nonparametric statistical test that allows for examination of multiple categorical and dichotomous variables (Field, 2009). Loglinear analysis allows for the examination of main effects (such as the variable of gender) as well as the interaction and cross-over interaction effects (such as gender and race together). The significant findings from research question two by gender, race, and age were included in subsequent analyses for research question three.

Research question three. Logistic regression analyses were used to analyze the data to address research question three. Logistic regression predicts the probability of certain outcomes based on a set of independent variables. Additionally, it allows for nonlinear distribution of the dependent variable and multiple independent variables (Tabachnick \& Fidell, 2001), which was fitting for the variables in this study. The ordinal and continuous demographic and environmental variables discussed earlier in this chapter served as the independent variables for the logistic regression analysis. More information on the statistical procedures and the assumptions of these tests used to address research questions two and three are presented in Chapter Four. 


\section{CHAPTER FOUR: FINDINGS}

The purpose of this dissertation was to examine the ways in which college students understand the concept of leadership, examine potential gender, racial, and age differences within these definitions, and investigate additional demographic and environmental variables associated with the different definitions. This chapter presents the findings from this study. First, participant characteristics and descriptive findings from the study are presented. Next, results from each of the research questions are presented. The chapter concludes with a summary of the findings.

\section{Participant Characteristics and Descriptive Findings}

As was described in the previous chapter, the participants selected for this study were a sub-sample of 1100 undergraduate students from the larger MSL database drawn through random criterion sampling. Because the participants were drawn from the larger MSL database through random criterion sampling, the participants do not reflect the demographics of the larger database, which were a combination of random samples drawn from 101 colleges and universities. The participant demographic characteristics and descriptive findings of the environmental variables are described below.

\section{Demographic Variables}

There were a total of 1100 participants included in the sample, split evenly between men and women ( $\mathrm{n}=550,50 \%$ each). Additionally, the participants were split evenly among the five racial groups of White/ Caucasian, Black/ African American, American Indian/ Alaska Native, Asian American/ Asian, and Latino/ Hispanic (n=220, 20\% each). As was discussed in Chapter Three, participants who identified with more 
than one racial group or selected Multiracial were not included in this study. International students were included in the sample. In examining this population alongside race, there were a large number of Asian students who identified as international students (23\%, $n=$ 50). This demographic is important to note, as it may skew students' responses based on cultural and language factors.

The average age of the participants was 22.55 years $(\mathrm{SD}=6.45)$, the median age was 21 , and ages ranged from 18 to 59 . When divided into two groups of traditionally aged and non-traditionally aged students, $80.5 \%(\mathrm{n}=886)$ of the participants were between the ages of $18-23$ and $19.5 \%(n=214)$ were 24 years and older. A breakdown of the gender, race, and age of the students in this study and that of the larger MSL are included in Appendix C.

Participants' socio-economic status, a variable used for the third research question, was measured through the variable of highest level of formal education obtained by a parent or guardian. These results were: $8.1 \%$ less than a high school diploma or GED ( $\mathrm{n}=89), 20.0 \%$ high school diploma or GED $(\mathrm{n}=220), 14.0 \%$ some college $(n=154), 6.3 \%$ associates degree $(n=69), 22.2 \%$ bachelors degree $(n=244), 18.5 \%$ master's degree $(n=204), 8.1 \%$ doctorate or professional degree $(n=89)$, and $2.8 \%$ don't know $(\mathrm{n}=31)$.

\section{College Environmental Variables}

A total of 11 college environmental variables were examined in this study in research question three. Frequencies, means, and standard deviations of the participants' involvement in these environmental variables are presented below in Table 3. 
Table 3

Descriptive Findings of College Environmental Variables $(\mathrm{N}=1,100)$

\begin{tabular}{|c|c|c|c|c|}
\hline Variable & $n$ & $\%$ & $M$ & $S D$ \\
\hline Community Service & & & 2.59 & 1.02 \\
\hline Never (1) & 234 & 21 & & \\
\hline Once (2) & 193 & 18 & & \\
\hline Sometimes (3) & 465 & 42 & & \\
\hline Often (4) & 208 & 19 & & \\
\hline College Organization Involvement & & & 2.99 & 1.47 \\
\hline Never (1) & 282 & 26 & & \\
\hline Once (2) & 115 & 11 & & \\
\hline Sometimes (3) & 265 & 24 & & \\
\hline Many Times (4) & 209 & 19 & & \\
\hline Much of the Time (5) & 229 & 21 & & \\
\hline Leadership Position in College Org & & & 2.08 & 1.48 \\
\hline Never (1) & 664 & 59 & & \\
\hline Once (2) & 96 & 9 & & \\
\hline Sometimes (3) & 132 & 12 & & \\
\hline Many Times (4) & 86 & 8 & & \\
\hline Much of the Time (5) & 142 & 13 & & \\
\hline Community Org Involvement & & & 2.10 & 1.42 \\
\hline Never (1) & 619 & 56 & & \\
\hline Once (2) & 80 & 7 & & \\
\hline Sometimes (3) & 175 & 16 & & \\
\hline Many Times (4) & 119 & 11 & & \\
\hline Much of the Time (5) & 107 & 10 & & \\
\hline \multicolumn{5}{|l|}{ Participation in Leadership Prog } \\
\hline Yes & 320 & 30 & & \\
\hline No & 780 & 71 & & \\
\hline
\end{tabular}




\begin{tabular}{|c|c|c|c|c|}
\hline Social Fraternities/ Sororities & 142 & 13 & & \\
\hline Yes & 958 & 87 & & \\
\hline \multicolumn{5}{|l|}{ No } \\
\hline \multicolumn{5}{|l|}{ Intercollegiate/ Varsity Sports } \\
\hline Yes & 114 & 10 & & \\
\hline No & 958 & 90 & & \\
\hline \multicolumn{5}{|l|}{ Student Governance } \\
\hline Yes & 127 & 12 & & \\
\hline No & 973 & 89 & & \\
\hline $\begin{array}{l}\text { Socio-Cultural Conversations- } \\
\text { composite measure ranging } \\
\text { from } 1 \text { (never) }-4 \text { (often) }\end{array}$ & & & 2.68 & 0.81 \\
\hline Off-Campus Work- \# hrs per wk & & & 7.83 & 13.14 \\
\hline On-Campus Work- \# hrs per wk & & & 3.36 & 6.63 \\
\hline
\end{tabular}

Note. Totals of percentages are not 100 for every characteristic because of rounding. Missing cases are not noted.

\section{Research Question \#1: Understandings of Leadership}

The first research question in this study read: What are the different ways college students understand the concept of leadership? This research question was addressed qualitatively through thematic content analysis, as was discussed in Chapter Three. This analysis resulted in 10 overall themes of leadership understandings, which are described below in this section. Then from the coded leadership definition themes, basic descriptive statistic analyses were calculated across the different gender, race, and age groups. Additionally, frequencies were calculated for the patterns of certain themes to be selected together since participants' definitions could reflect multiple themes if 
applicable. These findings, beginning with the qualitative analysis findings of the 10 leadership themes, are presented in this section.

\section{Leadership Themes}

The thematic content analysis procedures used in this study resulted in identification of 10 themes of students' understandings of leadership, which came from participants' qualitative responses to the survey question: Please provide a brief definition of what the term leadership means to you. The responses were ultimately coded using these 10 finalized themes, which were determined through a pilot study, initial analysis of the data, feedback and brainstorming from colleagues, and independent inter-rater check. This process was discussed in full in Chapter Three, and the Theme Codebook is located in Appendix D. The ten themes are:

1. Collaborate/ work together

2. Inspire/ motivate

3. Influence/ guide/ lead/ others follow you

4. Direct/ control/ in charge

5. Providing support

6. Modeling behavior

7. Admirable personal qualities

8. Positive difference

9. Shared goal

10. Task/goal

Each response was coded using these identified themes, and the number of themes associated with the participants' response ranged from one to five themes. Additionally, 
33 definitions were coded as unusable, meaning that they were insubstantial or did not fall into one of the 10 identified themes. Independent inter-raters and/ or colleagues confirmed the label of unusable for each of these responses. Examples of some of the unusable responses are: leadership to me is a major role that we as humans play in one area or other, at different point in our lives and the key to success. These two examples and the other unusable responses broad generalizations, abstract thoughts, and commentary about leadership without saying what it is. Additionally, some of the responses were coded as unusable because they did not fit into any of the 10 identified leadership themes.

Of the total 10 themes, the first four relate to leader and follower or group interaction and the nature of the leader and follower relationship. These themes are labeled collaborate, inspire, influence, and direct. The fifth, sixth, and seventh themes relate to leader characteristics or behaviors, and these themes are labeled support, modeling, and personal qualities. The last three themes relate to outcomes of leadership. These themes are labeled positive difference, shared goal, and task. Each of these themes is presented below with a description of the theme and examples of positive cases of these themes. After the 10 leadership themes are described, the frequencies of the themes are presented by gender, race, and age, and commonly grouped themes are presented (Tables 4-6).

Leader and follower/ group themes. These first four themes reflect relationships and interaction between leaders and members or followers in a group setting. As was discussed in Chapter Three, initially this category consisted of two themes: others/group focus- relational and others/group focus- transactional. In 
comparing my coding with that of the two independent raters, I determined that there were a large number of responses associated with these two themes, meaning that they may be too broad and not distinct enough. Additionally, I determined that there were a number of discrepancies across the three of us (myself and the two raters) in coding definitions based on these two categories; the distinctions were not clear enough. Consequently, I divided these two original themes into a total of four themes. The relational theme was split into collaborate and inspire, and the transactional theme was split into influence and direct. The current set of four themes can be viewed on a continuum of leader-follower relations, ranging from relational to transactional: collaborate, inspire, influence, and direct.

Theme 1: Collaborate. This theme relates to collaboration and working together. The theme emphasizes including others' ideas, and knowing that one must follow as well as lead. While there may still be mention of leader and follower as distinct roles, the nature of interaction involves collaboration. Some of the key descriptors related to this theme are: collaborating, working together, sharing tasks and responsibilities, and following as well as leading. A total of 177 participant responses reflected this theme (16\%). Some examples of positive cases of this theme (with the part of the case related to the theme bolded) are:

- It means leading the team to perform as best they can, taking into account each individual members assets and what they can contribute to the group.

- Leadership is the act of bringing people together to work on a common goal. 
- Combining one's personal insight with others' knowledge to move collectively towards a beneficial outcome.

Theme 2: Inspire. The inspire theme involves an emphasis on the interaction between a leader and others in the group through getting people involved, activated, and engaged in the process. This goes beyond being in charge of people or influencing them. There is some evidence of motivating, empowering, or inspiring others. More so than theme one, this theme is about a leader's ability- in this case to motive or inspire- rather than an action or a process. Key descriptors of this theme are: inspire, motivate, empower, and teach. A total of 144 participant responses reflected this theme (13\%). Some examples of positive cases of this theme (with the part of the case related to the theme bolded) are:

- Leadership means to be able to inspire others, and to be able to put ideas into motion.

- Leadership is the ability to motivate others towards a common goal.

- The ability to encourage others to follow in a particular direction.

Theme 3: Influence. This theme involves mention of a leader and other people or a group in a transactional or top-down manner, whereby the leader leads, influences, or guides others. The emphasis is on having others follow a leader in a transactional way. This theme emphasizes a top-down relationship, but not with a negative or controlling focus. Key descriptors of this theme are: influence, lead, guide a group, and have others follow you. A total of 467 participant responses reflected this theme (43\%). Some examples of positive cases of this theme (with the part of the case related to the theme bolded) are: 
- Being able to guide others in the group in a positive and effective path toward a collective goal.

- A person who can impact people lives and have them to follow your suggestions or directions.

- Leadership means that you can actually lead a group of people into accomplishing a goal or task.

Theme 4: Direct. The final theme in this category, direct, involves mention of other people or a group in a strictly transactional or top- down manner, which may or may not have a negative connotation or focus. The emphasis is on controlling, directing, exerting authority, or using power. Key descriptors of this theme are: directing, dictating, being in charge, taking charge of a person, group, or situation, having control, power, and an emphasis on the role or authority. A total of 218 participant responses reflected this theme (20\%). Some examples of positive cases of this theme (with the part of the case related to the theme bolded) are:

- Leadership means that there is some form of authority/or leader that takes charge of whatever a task may be.

- Leadership is the ability and action of directing others towards a common goal or purpose.

- Leadership means to me that someone is in charge of other people in order to achieve some goal.

- Leadership means someone on a power trip wanting to tell people what to do. 
Although these four themes (collaborate, inspire, influence, and direct) seem quite distinct, participants' definitions sometimes reflect more than one of these themes. In fact, 169 participant definitions reflected two or more of these first four themes (658 reflected one of these themes). Interestingly, 25 participant definitions encompassed leadership themes one and four (collaborate and direct), which reflect quite different assumptions about the relationship between the leader and followers or within the group. Patterns such as these are further explored later in this section.

Leader characteristics and behavior themes. The next group of themes reflects characteristics, qualities, or behaviors of a leader. The fifth theme, support, relates to how a leader helps or supports others. The sixth theme, modeling, emphasizes being a role model and morality. The seventh theme, admirable personal qualities, captures the many positive traits, qualities, or characteristics of a leader. These three themes are described below.

Theme 5: Support. The support theme focuses on the leader helping, supporting or giving advice to an individual. It also relates to putting others needs before one's own and helping people be their best. While the influence theme relates to guiding a group to a goal or outcome, this theme relates more to providing guidance or help to an individual. Key descriptors of this theme are: helping, giving advice, supporting, mentoring, caring for people, providing guidance, putting others before oneself, serving others, and concern for the wellbeing of others. A total of 151 participant responses reflected this theme (14\%). Some examples of positive cases of this theme (with the part of the case related to the theme bolded) are:

- Being able to give thoughtful advice to others. 
- Leadership is to take charge and help others get through situations. To be a guide and a mentor to others. To put others before yourself.

- Leadership is providing someone with positive information and encouragement to help their situation.

Theme 6: Modeling. This theme involves someone setting a positive example or being a role model in their actions or overall sense of being. It also relates to leading with morality and ethics. Key descriptors of this theme are: look up to, modeling, role model, set example, positive example, morals, ethics, and lead through actions (not just words). A total of 160 participant responses reflected this theme (15\%). Some examples of positive cases of this theme (with the part of the case related to the theme bolded) are:

- A true leader is someone who influences and directs others by their actions. It is someone who sets the example for others to follow.

- Leadership means being able to take on a position that represents my beliefs, integrity, and morals that will enhance my community and surrounding community.

- As a leader, one is responsible to uphold one's image and be a role model to those around them, demonstrating moral choices and living to out his or her personal value code.

Theme 7: Admirable personal qualities. This final theme in the group emphasizes the qualities of the leader. This theme involves mention of positive or admirable personal qualities that an individual has or demonstrates. Key descriptors of this theme include: respected, likeability, passion, problem solving ability, intelligent, charismatic, ambitious, confident, wisdom, successful, strong, and stands out. A total of 
219 participant responses reflected this theme (20\%). Some examples of positive cases of this theme (with the part of the case related to the theme bolded) are:

- Leadership is someone standing out and taking a stand for something.

- Leadership is decision that a person makes to take upon themselves to succeed through their determination.

- To me, leadership describes a person that is self-motivated, has set goals, good influence, great spirit and a great leader.

Leadership outcome themes. The last three themes relate to the outcome of leadership. Theme eight is positive difference, theme nine is shared goal, and theme ten is task. They are each described below.

Theme 8: Positive Difference. This theme involves leadership for a greater good, making a positive difference, caring about the larger community, or affecting something beyond the group or individual. Key descriptors for this theme include: make a difference, positive difference, common good, community focus, greater good, making things better, caring about the larger community/ bigger picture, responsibility to a cause or purpose, best interest. A total of 161 participant responses reflected this theme (15\%). Some examples of positive cases of this theme (with the part of the case related to the theme bolded) are:

- To be outspoken and a person who makes a difference.

- Leadership means having ambition, the drive to have a purpose in your personal space, in your living area, your community, and your world.

- A leader is someone who can embody the message of the group, engage others and inspire respect within the community. 
Theme 9: Shared Goal. The theme of shared goal involves recognition of a common or shared goal or purpose within a group. Key descriptors for this theme are: common/ shared goal, common/ shared purpose, and agreed upon goal or direction. A total of 260 participant responses reflected this theme (24\%). Some examples of positive cases of this theme (with the part of the case related to the theme bolded) are:

- Leadership is to motivate a group of people with a common goal to complete a certain task.

- Ability to take others in a direction agreed upon by the entire group.

- Leadership is the ability to put the goal of the group first without compromising the people in it, being able to balance the group versus the person.

Theme 10: Task. The final theme, task, involves accomplishing a goal or engaging in a task or action. It can also involve stepping up and taking initiative. This theme does not include the presence of a shared goal or purpose, as that related instead to theme nine. Key descriptors of this theme are: complete a task, accomplish a goal, take action, take initiative on accomplishing a task, step up, get things done, outcome, output, and objective. A total of 267 participant responses reflected this theme (24\%). Some examples of positive cases of this theme (with the part of the case related to the theme bolded) are:

- Pulling together a group and getting stuff done.

- Knowing when it is appropriate to take initiative in taking charge.

- Leadership is the ability influence others to accomplish an objective. 
Conclusion of leadership themes. These ten leadership themes were the most salient themes that emerged from the thematic content analysis. The themes can be viewed in three larger umbrella categories of (1) the leader and follower/ group relationship and interaction, (2) the qualities, characteristics, and behaviors of a leader, and (3) the outcome of leadership. Descriptive finding relates to these ten themes are presented next.

\section{Descriptive Findings of Leadership Themes}

In examining how the prevalence of the leadership themes among the participants as a whole, the percentages ranged from $13 \%$ (inspire, $n=114$ ) to $43 \%$ (influence, $n=467$ ). A graph of the total responses per theme is presented in Figure 3. A breakdown of the themes by the total participants, by gender, and by age is presented below in Table 4, and a breakdown of the themes by race is presented in Table 5 .

\section{Figure 3}

\section{Prevalence of Leadership Themes Within Total Sample}

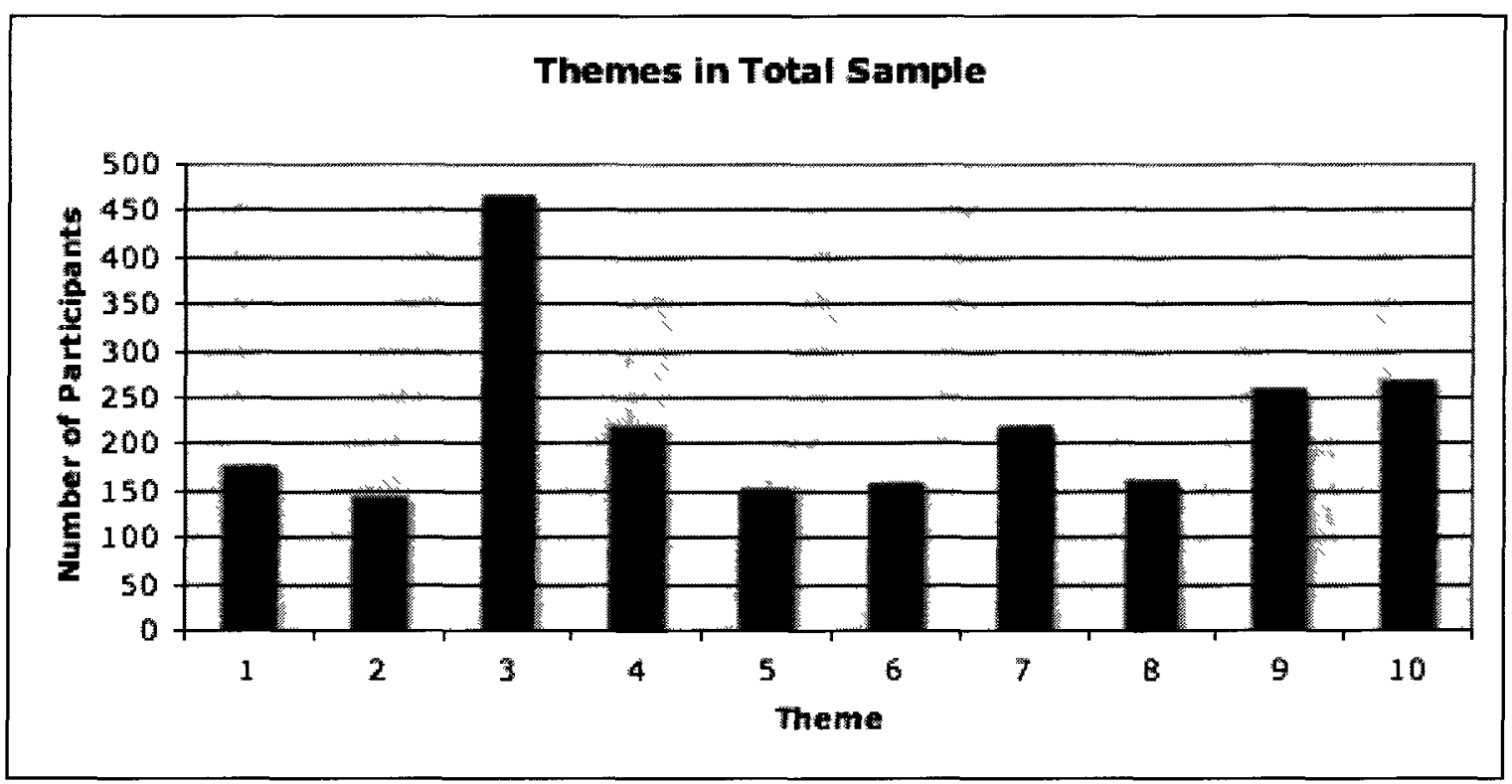


In looking at the total participants, the most prevalent themes are influence (theme 3), task (theme 10), shared goal (theme 9), personal qualities (theme 7), and direct (theme 4). The influence theme, which was the most prevalent, included the descriptor of leading or lead, which likely contributed to why this percentage was so high. The least prevalent themes are inspire, support, modeling, positive difference, and collaborate.

The three most prevalent themes for both women and men were influence, task, and shared goal. These were also the same most prevalent themes for students age 1823. For students age 24 and older, the most prevalent themes (in order) were influence, shared goal, and direct. The top three themes of influence, task, and shared goal were also the most prevalent for White/ Caucasian, African American/ Black, and Asian American/ Asian participants. For American Indian/ Alaska Native participants, the top three themes were influence, task, and personal qualities. For Latino/ Hispanic participants, the top three themes were influence, shared goal, and personal qualities. Refer to Tables 4 and 5 for more information on the breakdown of the themes. Research question two, which is the next section in this chapter, will examine significant differences in the number of participants whose definitions reflected the themes by gender, race, and age. 
Table 4

Frequencies of Leadership Themes- Total, Gender, and Age

\begin{tabular}{|c|c|c|c|c|c|c|c|c|c|c|}
\hline \multirow[b]{2}{*}{ Theme } & \multicolumn{2}{|c|}{$\begin{array}{c}\text { Total } \\
(\mathrm{n}=1100)\end{array}$} & \multicolumn{2}{|c|}{$\begin{array}{l}\text { Female } \\
(\mathrm{n}=550)\end{array}$} & \multicolumn{2}{|c|}{$\begin{array}{c}\text { Male } \\
(\mathrm{n}=550)\end{array}$} & \multicolumn{2}{|c|}{$\begin{array}{l}\text { Age: } 18-23 \\
(\mathrm{n}=886)\end{array}$} & \multicolumn{2}{|c|}{$\begin{array}{l}\text { Age: } 24+ \\
(n=214)\end{array}$} \\
\hline & $\mathrm{n}$ & $\%$ & $\mathrm{n}$ & $\%$ & $\mathrm{n}$ & $\%$ & $\mathbf{n}$ & $\%$ & $\mathrm{n}$ & $\%$ \\
\hline 1-Collaborate & 177 & 16 & 105 & 19 & 72 & 13 & 145 & 16 & 32 & 15 \\
\hline 2-Inspire & 144 & 13 & 72 & 13 & 72 & 13 & 116 & 13 & 28 & 13 \\
\hline 3-Influence & 467 & 43 & 241 & 44 & 226 & 41 & 370 & 42 & 97 & 45 \\
\hline 4-Direct & 218 & 20 & 104 & 19 & 114 & 21 & 166 & 19 & 52 & 24 \\
\hline 5-Support & 151 & 14 & 78 & 14 & 73 & 13 & 125 & 14 & 26 & 12 \\
\hline 6-Modeling & 160 & 15 & 81 & 15 & 79 & 14 & 136 & 15 & 24 & 11 \\
\hline 7-Pers. Qualities & 219 & 20 & 128 & 23 & 91 & 17 & 174 & 20 & 45 & 21 \\
\hline 8-Positive Diff & 161 & 15 & 93 & 17 & 68 & 12 & 125 & 14 & 36 & 17 \\
\hline 9-Shared Goal & 260 & 24 & 132 & 24 & 128 & 23 & 204 & 23 & 56 & 26 \\
\hline 10-Task & 267 & 24 & 136 & 25 & 131 & 24 & 218 & 25 & 49 & 23 \\
\hline
\end{tabular}

Note. Total of percentages do not equal 100 because participants' responses could fall into more than one theme. Additionally, percentages were rounded. 
Table 5

Frequencies of Leadership Themes- Race

\begin{tabular}{|c|c|c|c|c|c|c|c|c|c|c|c|c|}
\hline \multirow[b]{2}{*}{ Theme } & \multicolumn{2}{|c|}{$\begin{array}{c}\text { Total } \\
(n=1100)\end{array}$} & \multicolumn{2}{|c|}{$\begin{array}{l}\text { White } \\
(n=220)\end{array}$} & \multicolumn{2}{|c|}{$\begin{array}{c}\text { African } \\
\text { American } \\
(\mathrm{n}=220)\end{array}$} & \multicolumn{2}{|c|}{$\begin{array}{l}\text { American } \\
\text { Indian } \\
(\mathrm{n}=220)\end{array}$} & \multicolumn{2}{|c|}{$\begin{array}{c}\text { Asian } \\
\text { American } \\
(\mathrm{n}=220)\end{array}$} & \multicolumn{2}{|c|}{$\begin{array}{c}\text { Latino } \\
(\mathrm{n}=220)\end{array}$} \\
\hline & $\mathrm{n}$ & $\%$ & $\mathrm{n}$ & $\%$ & $\mathrm{n}$ & $\%$ & $\mathrm{n}$ & $\%$ & $\mathrm{n}$ & $\%$ & $\mathrm{n}$ & $\%$ \\
\hline 1-Collaborate & 177 & 16 & 41 & 19 & 32 & 15 & 30 & 14 & 40 & 18 & 32 & 15 \\
\hline 2-Inspire & 144 & 13 & 32 & 15 & 22 & 10 & 26 & 12 & 32 & 15 & 32 & 15 \\
\hline 3-Influence & 467 & 43 & 84 & 38 & 105 & 48 & 86 & 39 & 99 & 45 & 93 & 42 \\
\hline 4-Direct & 218 & 20 & 50 & 23 & 45 & 20 & 49 & 22 & 41 & 19 & 33 & 15 \\
\hline 5-Support & 151 & 14 & 24 & 11 & 25 & 11 & 28 & 13 & 37 & 17 & 37 & 17 \\
\hline 6-Modeling & 160 & 15 & 33 & 15 & 28 & 13 & 35 & 16 & 30 & 14 & 34 & 15 \\
\hline 7-Pers. Qualities & 219 & 20 & 33 & 15 & 45 & 20 & 49 & 22 & 43 & 20 & 49 & 22 \\
\hline 8-Positive Diff & 161 & 15 & 27 & 12 & 29 & 13 & 38 & 17 & 28 & 13 & 39 & 18 \\
\hline 9-Shared Goal & 260 & 24 & 64 & 29 & 50 & 23 & 40 & 18 & 48 & 22 & 58 & 26 \\
\hline 10-Task & 267 & 24 & 65 & 30 & 59 & 27 & 53 & 24 & 49 & 22 & 41 & 19 \\
\hline
\end{tabular}

Note. Total of percentages do not equal 100 because participants' responses could fall into more than one theme. Additionally, percentages were rounded.

Since many of the participants' responses reflected more than one leadership theme, I sought to identify patterns within the themes when more than one theme was selected. Typically, factor analysis is used for grouping of multiple variables into fewer variables. However, factor analysis requires data that is measured at an interval level and with roughly a normal distribution (Field, 2009). Furthermore, since the dependent variables are dichotomous (coded as 0 and 1 to reflect no and yes) and do not reflect a normal distribution, factor analysis is not appropriate. Due to this limitation, I instead sought out common grouping through a more intuitive and less complex approach. 
Through Microsoft Word in conjunction with Microsoft Excel, I used the merge data function to group together the leadership themes in each definition that reflected two, three, or four different themes $(n=792)$. For each of these definitions I printed on labels the theme that were represented (i.e. 1 \& 3) and then grouped each of the common pairings together. This approach was used because there was not a way to coherently do this through Microsoft Excel that I could determine. Through arranging each of these theme combinations and grouping them together, I counted the number of most commonly-paired themes. These themes and their associated frequencies and percentages are presented below in Table 6 . In addition to the pairs noted below, there were 16 definitions that included the three-theme combination or collaborate-influence-shared goal (2\%). Each of the four leader-follower/ group themes (collaborate, inspire, influence, and direct) were often paired with the shared goal theme. The task theme was often paired with the influence and direct themes, which are the two hierarchicallyfocused leader-follower/ group themes.

\section{Summary of Findings for Research Question \#1}

This section included the findings from the qualitative thematic content analysis of the themes prevalent in the participants open response answers to the question: What are the different ways college students understand the concept of leadership?

Additionally, frequencies of the different themes were presented for the total participants and for participants by gender, age, and race. The most common pairings of themes were also presented. The next section will present findings from research question two, which examined significant differences within each of the themes by gender, race, and age. 
Table 6

Top Leadership Theme Combinations Reflecting 2-4 Themes (n=972)

\begin{tabular}{lll}
\hline \multicolumn{1}{c}{ Theme Combination } & $\mathrm{n}$ & $\%$ \\
\hline Influence- Shared Goal & 117 & 15 \\
Influence- Task & 105 & 13 \\
Collaborate- Shared Goal & 67 & 8 \\
Direct- Task & 63 & 8 \\
Influence- Personal Qualities & 62 & 8 \\
Inspire- Shared Goal & 47 & 6 \\
Collaborate- Influence & 43 & 5 \\
Influence- Modeling & 41 & 5 \\
Modeling- Personal Qualities & 35 & 4 \\
Influence- Positive Difference & 34 & 4 \\
Support- Personal Qualities & 31 & 4 \\
Direct- Shared Goal & 29 & 4 \\
Positive Difference- Shared Goal & 24 & 3 \\
\hline
\end{tabular}

\section{Research Question \#2: Differences by Gender, Race, and Age}

The second research question examined in this dissertation was: What differences, if any, exist in students' understandings of leadership based on gender, race, and age? Loglinear analysis was used to examine this research question. In this section an explanation of loglinear analysis and the assumptions of this statistical procedure are presented. Next, the results from the statistical analyses by theme are presented by group of leadership themes: (1) the nature of leader and follower/ group relationships, (2) the qualities, characteristics, and behaviors of a leader, and (3) the outcome of leadership. 


\section{Loglinear Analysis}

Loglinear analysis is a nonparametric linear statistical analysis procedure that allows for analysis of multiple categorical variables (Field, 2009). Loglinear analysis tests main effects of the different categorical variables as well as all of the possible effects, which are known as interaction effects and cross-over interaction effects (Field, 2009; Tabachnick \& Fidell, 2001). Through loglinear analysis, observed frequencies in the data are compared to the expected frequencies of the model (Field, 2009).

Loglinear analysis is an "extension of the chi-square test" (Field, 2009, p. 710) and thus has many of the same assumptions of chi-square analysis. First, there is the assumption of the independence of cases, which means that each participant contributes to only one cell of each contingency table (Hinkle et al., 2003). This assumption is met through the way in which data were collected; each participant was only in one gender, race, or age category, and their leadership definition themes were each coded as either no or yes. Loglinear analysis also has similar assumptions as chi-square in terms of the number of cases per cell (Field, 2009). There must be a substantial number of cases per cell; some researchers suggest the expected frequency of each cell to be at least five; others suggest that at least $80 \%$ of the cells should have at least five cases (Pallant, 2005). As was discussed in Chapter Three, this rule was accounted for when determining the number of participants for this dissertation. The results from this study met the requirement of at least five cases per cell across all the cells with the exception of the support theme, whereby $78 \%$ of the cells (instead of $80 \%$ ) had at least five cases. The least number of cases per cell was zero for five of the total 400 cells across the 10 analyses. 
Findings were determined at the statistical significance levels of $10 \%(p<.10)$, $5 \%(p<.05)$, and $1 \%(p<.01)$. These are standard significance levels used in statistical analysis, with the significance levels of $5 \%$ and $1 \%$ being more rigorous and preferred (Cohen, 1992). The 10\% level is more appropriate for exploratory studies; since this is the first study of its kind, I opted to also include the $10 \%$ significance level to identify potential areas for further analysis or exploration. Due to the large number of analyses run in this study and the fairly liberal significance level of $10 \%$, strong conclusions should not be drawn from these findings. Rather, these findings should be viewed as areas for future study that may confirm significance or provide additional insight to the phenomena being studied.

\section{Results by Gender, Race, and Age For Leader and Follower/ Group Themes}

The results from the loglinear analyses for the leader and follower/ group themes by gender, race, and age resulted in significant findings for three of the four themes (collaborate, influence, and direct). The observed frequencies and percentages for the significant effects are presented in Table 7 , and the results from the loglinear analyses are presented in Table 8. 
Table 7

Summary of Observed Frequencies and Percentages for Significant Effects for Themes 1-4 by Gender, Race, and Age

\begin{tabular}{|c|c|c|c|}
\hline \multicolumn{4}{|c|}{ Theme 1: Collaborate } \\
\hline & & Yes & No \\
\hline Women & & $105(20)$ & $445(80)$ \\
\hline Men & & $72(13)$ & $478(87)$ \\
\hline \multicolumn{4}{|c|}{ Theme 3: Influence } \\
\hline Age & Gender & Yes & No \\
\hline \multirow[t]{2}{*}{$18-23$} & Women & $188(42)$ & $261(58)$ \\
\hline & Men & $182(42)$ & $255(58)$ \\
\hline \multirow[t]{2}{*}{$24+$} & Women & $53(53)$ & $48(47)$ \\
\hline & Men & $44(39)$ & $69(61)$ \\
\hline \multicolumn{4}{|c|}{ Theme 4: Direct } \\
\hline Age & Gender & Yes & No \\
\hline \multirow[t]{2}{*}{$18-23$} & Women & $85(19)$ & $364(81)$ \\
\hline & Men & $81(19)$ & $356(81)$ \\
\hline \multirow[t]{2}{*}{$24+$} & Women & $19(19)$ & $82(81)$ \\
\hline & Men & $33(29)$ & $80(71)$ \\
\hline
\end{tabular}

Note. Percentages appear in parentheses. 


\section{Table 8}

Summary of Loglinear Analysis of the Relation Between Leadership Themes 1-4,

Gender, Race, and Age

\begin{tabular}{|c|c|c|c|}
\hline Theme & Association & $\mathrm{df}$ & $x^{2}$ \\
\hline \multirow[t]{7}{*}{$\mathrm{T}=$ Theme 1: Collaborate } & $T \times G \times R \times A$ & 4 & 1.50 \\
\hline & $T \times G \times R$ & 4 & 1.56 \\
\hline & $\mathrm{T} \times \mathrm{G} \times \mathrm{A}$ & 1 & 0.02 \\
\hline & $\mathrm{T} \times \mathrm{R} \times \mathrm{A}$ & 4 & 1.01 \\
\hline & $\mathrm{T} \times \mathrm{G}$ & 1 & $7.38 * * *$ \\
\hline & $\mathrm{T} \times \mathrm{R}$ & 4 & 3.03 \\
\hline & $\mathrm{T} \times \mathrm{A}$ & 1 & 0.00 \\
\hline \multirow[t]{7}{*}{$\mathrm{T}=$ Theme $2:$ Inspire } & $\mathrm{T} \times \mathrm{G} \times \mathrm{R} \times \mathrm{A}$ & 4 & 2.59 \\
\hline & $\mathrm{T} \times \mathrm{G} \times \mathrm{R}$ & 4 & 1.35 \\
\hline & $\mathrm{T} \times \mathrm{G} \times \mathrm{A}$ & 1 & 0.03 \\
\hline & $\mathrm{T} \times \mathrm{R} \times \mathrm{A}$ & 4 & 6.87 \\
\hline & $\mathrm{T} \times \mathrm{G}$ & 1 & 0.00 \\
\hline & $\mathrm{T} \times \mathrm{R}$ & 4 & 3.68 \\
\hline & $\mathrm{T} \times \mathrm{A}$ & 1 & 0.17 \\
\hline \multirow[t]{7}{*}{$\mathrm{T}=$ Theme 3: Influence } & $\mathrm{T} \times \mathrm{G} \times \mathrm{R} \times \mathrm{A}$ & 4 & 2.95 \\
\hline & $\mathrm{T} \times \mathrm{G} \times \mathrm{R}$ & 4 & 2.72 \\
\hline & $\mathrm{T} \times \mathrm{G} \times \mathrm{A}$ & 1 & $2.75^{*}$ \\
\hline & $\mathrm{T} \times \mathrm{R} \times \mathrm{A}$ & 4 & 2.98 \\
\hline & $\mathrm{T} \times \mathrm{G}$ & 1 & 0.89 \\
\hline & $\mathrm{T} \times \mathrm{R}$ & 4 & 5.76 \\
\hline & $\mathrm{T} \times \mathrm{A}$ & 1 & 0.95 \\
\hline \multirow[t]{5}{*}{$T=$ Theme 4: Direct } & $T \times G \times R \times A$ & 4 & 4.72 \\
\hline & $\mathrm{T} \times \mathrm{G} \times \mathrm{R}$ & 4 & 5.23 \\
\hline & $\mathrm{T} \times \mathrm{G} \times \mathrm{A}$ & 1 & $3.80^{*}$ \\
\hline & $\mathrm{T} \times \mathrm{R} \times \mathrm{A}$ & 4 & 7.05 \\
\hline & $\mathrm{T} \times \mathrm{G}$ & 1 & 0.51 \\
\hline
\end{tabular}




\begin{tabular}{rll}
\hline T X R & 4 & 5.09 \\
Tx A & 1 & 2.61 \\
\hline
\end{tabular}

Note: $\mathrm{T}=$ Leadership Theme, $\mathrm{G}=$ Gender, $\mathrm{R}=$ Race, $\mathrm{A}=$ Age. ${ }^{*} p<0.10,{ }^{* *} p<0.05$, $* * * p<0.01$

For the collaborate theme there was a significant finding based on gender $\left(\chi^{2}=\right.$ $7.38, p<.01$ ). Based on the odds ratio (which is calculated by dividing the odds that men's definitions reflect this theme by the odds that women's definitions reflect this theme), this finding seems to represent the fact that the odds of women's leadership definitions reflecting collaborate were 1.53 times higher than that of men, with an effect of $r=.17$, which is a relatively small effect size.

There were no significant differences based on gender, race, age, or a combination of these variables for the theme of inspire. For the influence theme, there was a significant association between the theme, gender, and age $\left(\chi^{2}=2.75, p<.10\right)$. Since the main effects of gender and age were not significant, this finding can be understood a cross-over interaction effect, detecting a pattern that could draw meaning in better understanding the influence theme. Looking at the frequencies and associated percentages of this theme based on gender and age (Table 7), it appears as if women in the 24 and older age group tend to view leadership as involving influencing more so than the men and women aged 18-23 and men aged 24 and older. Based on the odds ratio, this finding seems to represent the fact that the odds of women aged 24 and older viewing leadership as involving influencing were 1.72 times higher than men aged 24 and older $(r$ $=.21), 1.55$ times higher than men aged 18-23 $(r=.17)$, and 1.53 times higher than women aged 18-23 $(r=.17)$. Each of these differences reflects small effect sizes. 
A cross-over interaction effect was also identified for the direct theme.

Significant associations emerged between the theme, gender, and age $\left(\chi^{2}=3.80, p<.10\right)$. By examining the frequencies and associated percentages of this theme based on gender and age (Table 7), it appears as if men aged 24 and older tend to view leadership involving directing more so than men and women aged 18-23 and women aged 24 and older. Based on the odds ratio, this finding seems to represent the fact that the odds of men aged 24 and older viewing leadership as involving directing were 1.78 times higher than the men and women in the other age groups $(r=.22)$, reflecting a small effect size.

\section{Results by Gender, Race, and Age For Leader Characteristics and Behavior Themes}

The results from the loglinear analyses for the leader characteristic and behavior themes by gender, race, and age resulted in significant findings for each of the three themes (support, modeling, and personal qualities). The observed frequencies and percentages for the significant effects are presented in Table 9, and the results from the loglinear analyses are presented in Table 10. 
Table 9

Summary of Observed Frequencies and Percentages for Significant Effects for Themes 5-7 by Gender, Race, and Age

\begin{tabular}{|c|c|c|c|}
\hline \multicolumn{4}{|c|}{ Theme 5: Support } \\
\hline Age & Gender & Yes & No \\
\hline \multirow[t]{2}{*}{$18-23$} & Women & $69(15)$ & $380(85)$ \\
\hline & Men & $56(13)$ & $381(87)$ \\
\hline \multirow[t]{2}{*}{$24+$} & Women & $9(9)$ & $92(91)$ \\
\hline & Men & $17(15)$ & $96(85)$ \\
\hline \multicolumn{4}{|c|}{ Theme 6: Modeling } \\
\hline & & Yes & No \\
\hline $18-23$ & & $136(15)$ & $750(85)$ \\
\hline $24+$ & & $24(11)$ & $190(89)$ \\
\hline \multicolumn{4}{|c|}{ Theme 7: Personal Qualities } \\
\hline & der & Yes & No \\
\hline Women & & $128(23)$ & $422(77)$ \\
\hline Men & & $91(17)$ & $459(83)$ \\
\hline
\end{tabular}

Note. Percentages appear in parentheses. 


\section{Table 10}

Summary of Loglinear Analysis of the Relation Between Leadership Themes 5-7,

Gender, Race, and Age

\begin{tabular}{|c|c|c|c|}
\hline Theme & Association & $\mathrm{df}$ & $\chi^{2}$ \\
\hline \multirow[t]{7}{*}{$T=$ Theme 5: Support } & $T \times G \times R \times A$ & 4 & 1.81 \\
\hline & $T \times G \times R$ & 4 & 1.98 \\
\hline & $T \times G \times A$ & 1 & $2.78^{*}$ \\
\hline & $\mathrm{T} \times \mathrm{R} \times \mathrm{A}$ & 4 & 2.02 \\
\hline & $\mathrm{T} \times \mathrm{G}$ & 1 & 0.18 \\
\hline & $\mathrm{T} \times \mathrm{R}$ & 4 & 5.93 \\
\hline & $\mathrm{T} \times \mathrm{A}$ & 1 & 0.28 \\
\hline \multirow[t]{7}{*}{$\mathrm{T}=$ Theme 6 : Modeling } & $T \times G \times R \times A$ & 4 & 3.19 \\
\hline & $T \times G \times R$ & 4 & 2.55 \\
\hline & $T \times G \times A$ & 1 & 0.22 \\
\hline & $\mathrm{T} \times \mathrm{R} \times \mathrm{A}$ & 4 & 3.50 \\
\hline & $\mathrm{T} \times \mathrm{G}$ & 1 & 0.02 \\
\hline & $\mathrm{T} \times \mathrm{R}$ & 4 & 1.53 \\
\hline & $\mathrm{T} \times \mathrm{A}$ & 1 & $2.76^{*}$ \\
\hline \multirow[t]{7}{*}{$\mathrm{T}=$ Theme 7: Personal Qualities } & $\mathrm{T} \times \mathrm{G} \times \mathrm{R} \times \mathrm{A}$ & 4 & 1.97 \\
\hline & $T \times G \times R$ & 4 & 3.06 \\
\hline & $\mathrm{T} \times \mathrm{G} \times \mathrm{A}$ & 1 & 0.41 \\
\hline & $\mathrm{T} \times \mathrm{R} \times \mathrm{A}$ & 4 & 2.92 \\
\hline & $\mathrm{T} \times \mathrm{G}$ & 1 & $7.90 * * *$ \\
\hline & $\mathrm{T} \times \mathrm{R}$ & 4 & 4.91 \\
\hline & $\mathrm{T} \times \mathrm{A}$ & 1 & 0.04 \\
\hline
\end{tabular}

Note: $\mathrm{T}=$ Leadership Theme, $\mathrm{G}=$ Gender, $\mathrm{R}=$ Race, $\mathrm{A}=$ Age. ${ }^{*} p<0.10,{ }^{*} p<0.05$, $* * * p<0.01$ 
For the support theme, there was a significant cross-over interaction effect between the theme, gender, and age variables $\left(\chi^{2}=2.78, p<.10\right)$. By looking at the frequencies and associated percentages of these theme based on gender and age (Table 9), it appears as if women in the 24 and older age are less likely than men and women aged 18-23 and men aged 24 and older to view leadership as involving support. Based on the odds ratio, this finding seems to represent the fact that the odds of women aged 24 and older viewing leadership as involving support were 1.8 times lower than men aged 24 and older and women aged 18-23 $(r=.23)$. The odds of women aged 24 and older viewing leadership as involving support were also 1.5 times lower than men aged 18-23 $(r=$ .16). Each of these differences reflects relatively small effect sizes.

For the modeling theme a significant main effect emerged for age $\left(\chi^{2}=2.76, p<\right.$ .10). Based on the odds ratio, this finding seems to represent the fact that the odds of students aged 18-23 viewing leadership as involving modeling were 1.43 times higher than that of students 24 years and older, with an effect of $r=.14$, which is a relatively small effect size.

For the personal qualities theme there was a significant main effect for gender $\left(\chi^{2}=7.90, p<.01\right)$. Based on the odds ratio, this finding seems to represent the fact that the odds of women's leadership definitions reflecting personal qualities were 1.50 times higher than that of men, with an effect of $r=.16$, which is a relatively small effect size.

\section{Results by Gender, Race, and Age For Leadership Outcome Themes}

The results from the loglinear analyses for the leadership outcome themes by gender, race, and age resulted in significant findings for each of the three themes (positive difference, shared goal, and task). The observed frequencies and percentages for the 
significant effects are presented in Table 11, and the results from the loglinear analyses are presented in Table 12.

Table 11

Summary of Observed Frequencies and Percentages for Significant Effects for Themes 8-10 by Gender, Race, and Age

Theme 8: Positive Difference

\begin{tabular}{|c|c|c|c|}
\hline \multicolumn{2}{|r|}{ Gender } & Yes & No \\
\hline \multicolumn{2}{|c|}{ Women } & $93(17)$ & $457(83)$ \\
\hline \multicolumn{2}{|l|}{ Men } & $68(12)$ & $482(88)$ \\
\hline \multicolumn{4}{|c|}{ Theme 9: Shared Goal } \\
\hline & Race & Yes & No \\
\hline \multicolumn{2}{|c|}{ White/ Caucasian } & $64(29)$ & $156(71)$ \\
\hline \multicolumn{2}{|c|}{ African American/ Black } & $50(23)$ & $170(77)$ \\
\hline \multicolumn{2}{|c|}{ American Indian/ Alaska Native } & $40(18)$ & $180(82)$ \\
\hline \multicolumn{2}{|c|}{ Asian American/ Asian } & $48(22)$ & $172(78)$ \\
\hline \multicolumn{2}{|c|}{ Latino/ Hispanic } & $58(26)$ & $162(74)$ \\
\hline \multicolumn{2}{|r|}{ Age } & Yes & No \\
\hline \multicolumn{2}{|l|}{$18-23$} & $204(23)$ & $682(77)$ \\
\hline \multicolumn{2}{|l|}{$24+$} & $56(26)$ & $158(74)$ \\
\hline \multicolumn{4}{|c|}{ Women } \\
\hline Age & Race & Yes & No \\
\hline \multirow[t]{5}{*}{$18-23$} & White/ Caucasian & $23(23)$ & $79(77)$ \\
\hline & African American/ Black & $19(25)$ & $60(75)$ \\
\hline & Amer Indian/ Alaska Native & $10(14)$ & $60(86)$ \\
\hline & Asian American/ Asian & $28(27)$ & $74(73)$ \\
\hline & Latino/ Hispanic & $25(26)$ & $71(74)$ \\
\hline \multirow[t]{3}{*}{$24+$} & White/ Caucasian & $5(63)$ & $3(37)$ \\
\hline & African American/ Black & $8(26)$ & $23(74)$ \\
\hline & Amer Indian/ Alaska Native & $9(23)$ & $31(77)$ \\
\hline
\end{tabular}




\begin{tabular}{|c|c|c|c|}
\hline & Asian American/ Asian & $1(13)$ & $7(87)$ \\
\hline & Latino/ Hispanic & $4(29)$ & $10(71)$ \\
\hline \multicolumn{4}{|c|}{ Men } \\
\hline Age & Race & Yes & No \\
\hline \multirow[t]{5}{*}{$18-23$} & White/ Caucasian & $33(34)$ & $65(66)$ \\
\hline & African American/ Black & $16(20)$ & $65(80)$ \\
\hline & Amer Indian/ Alaska Native & $14(20)$ & $57(80)$ \\
\hline & Asian American/ Asian & $14(15)$ & $79(85)$ \\
\hline & Latino/ Hispanic & $22(23)$ & $72(77)$ \\
\hline \multirow[t]{5}{*}{$24+$} & White/ Caucasian & $3(25)$ & $9(75)$ \\
\hline & African American/ Black & $7(24)$ & $22(76)$ \\
\hline & Amer Indian/ Alaska Native & $7(18)$ & $32(82)$ \\
\hline & Asian American/ Asian & $5(29)$ & $12(71)$ \\
\hline & Latino/ Hispanic & $7(44)$ & $9(56)$ \\
\hline \multicolumn{4}{|c|}{ Theme 10: Task } \\
\hline & Race & Yes & No \\
\hline \multicolumn{2}{|c|}{ White/ Caucasian } & $65(30)$ & $155(70)$ \\
\hline \multicolumn{2}{|c|}{ African American/ Black } & $59(27)$ & $161(73)$ \\
\hline \multicolumn{2}{|c|}{ American Indian/ Alaska Native } & $53(24)$ & $167(76)$ \\
\hline \multicolumn{2}{|c|}{ Asian American/ Asian } & $49(22)$ & $171(78)$ \\
\hline \multicolumn{2}{|c|}{ Latino/ Hispanic } & $41(19)$ & $179(81)$ \\
\hline
\end{tabular}

Note. Percentages appear in parentheses. 
Table 12

Summary of Loglinear Analysis of the Relation Between Leadership Themes 8-10, Gender, Race, and Age

\begin{tabular}{|c|c|c|c|}
\hline Theme & Association & $\mathrm{df}$ & $\chi^{2}$ \\
\hline \multirow[t]{7}{*}{$\mathrm{T}=$ Theme 8: Positive Difference } & $\mathrm{T} \times \mathrm{G} \times \mathrm{R} \times \mathrm{A}$ & 4 & 5.13 \\
\hline & $T \times G \times R$ & 4 & 4.34 \\
\hline & $\mathrm{T} \times \mathrm{G} \times \mathrm{A}$ & 1 & 0.08 \\
\hline & $\mathrm{T} \times \mathrm{R} \times \mathrm{A}$ & 4 & 3.54 \\
\hline & $\mathrm{T} \times \mathrm{G}$ & 1 & $4.69^{* *}$ \\
\hline & $\mathrm{T} \times \mathrm{R}$ & 4 & 4.44 \\
\hline & $\mathrm{T} \times \mathrm{A}$ & 1 & 0.69 \\
\hline \multirow[t]{7}{*}{$\mathrm{T}=$ Theme 9: Shared Goal } & $\mathrm{T} \times \mathrm{G} \times \mathrm{R} \times \mathrm{A}$ & 4 & $9.05^{*}$ \\
\hline & $\mathrm{T} \times \mathrm{G} \times \mathrm{R}$ & 4 & 4.54 \\
\hline & $\mathrm{T} \times \mathrm{G} \times \mathrm{A}$ & 1 & 0.03 \\
\hline & $\mathrm{T} \times \mathrm{R} \times \mathrm{A}$ & 4 & 0.79 \\
\hline & $\mathrm{T} \times \mathrm{G}$ & 1 & 0.11 \\
\hline & $\mathrm{T} \times \mathrm{R}$ & 4 & $10.51^{* *}$ \\
\hline & $\mathrm{T} \times \mathrm{A}$ & 1 & $2.76^{*}$ \\
\hline \multirow[t]{7}{*}{$\mathrm{T}=$ Theme 10: Task } & $\mathrm{T} \times \mathrm{G} \times \mathrm{R} \times \mathrm{A}$ & 4 & 5.06 \\
\hline & $T \times G \times R$ & 4 & 1.66 \\
\hline & $\mathrm{T} \times \mathrm{G} \times \mathrm{A}$ & 1 & 0.39 \\
\hline & $\mathrm{T} \times \mathrm{R} \times \mathrm{A}$ & 4 & 2.29 \\
\hline & $\mathrm{T} \times \mathrm{G}$ & 1 & 0.11 \\
\hline & $\mathrm{T} \times \mathbf{R}$ & 4 & $8.54^{*}$ \\
\hline & $\mathrm{T} \times \mathrm{A}$ & 1 & 0.34 \\
\hline
\end{tabular}

Note: $\mathrm{T}=$ Leadership Theme, $\mathrm{G}=$ Gender, $\mathrm{R}=$ Race, $\mathrm{A}=$ Age. ${ }^{*} p<0.10,{ }^{* *} p<0.05$, $* * * p<0.01$ 
For the positive difference theme there was a significant main effect for gender $\left(\chi^{2}=4.69, p<.05\right)$. Based on the odds ratio, this finding seems to represent the fact that the odds of women's leadership definitions reflecting positive difference were 1.43 times higher than that of men, with an effect of $r=.14$, which is a relatively small effect size.

For the shared goal theme three associations were significant. The variable of race resulted in significant main effect finding for the shared goal theme $\left(\chi^{2}=10.51, p<\right.$ $.05)$. Through examining the standardized residuals of the observed and expected frequencies for each racial group (which is an output of the logistic regression PASW analysis), it appears as if the significant findings lie with the White/ Caucasian students and the American Indian/ Alaska Native students. The standardized residual for the White/ Caucasian students was 1.66 , which is a $z$-score reflecting significance at the $p<$ .10 level. This indicates that White/ Caucasian students were overrepresented in this theme as compared to the expected frequency. For American Indian/ Alaska Native students the standardized residual was -1.66 , which is a $z$-score reflecting significance at the $p<.10$ level. This indicates that American Indian/ Alaska Native students were underrepresented in this theme as compared to the expected frequency.

There was also a significant main effect for age $\left(\chi^{2}=2.76, p<.10\right)$. Based on the odds ratio, this finding seems to represent the fact that the odds of students aged 24 and older viewing leadership as involving a shared goal were 1.18 times higher than that of students aged 18-23, with an effect of $r=.06$, which is an extremely small, if not negligible, effect size. Last, there was also the significant three-way cross-over interaction effect for gender, race, and age $\left(\chi^{2}=9.05, p<.10\right)$. It is difficult to interpret this complex interaction without the ability to graphically depict this cross-over 
interaction effect. Due to this negligible effect size, low significance level, and complexity of these two findings, they will not be discussed further in this chapter or in Chapter 5.

The final leadership theme is the task theme. For this theme a significant main

effect emerged for the variable of race $\left(\chi^{2}=8.54, p<.10\right)$. Through examining the standardized residuals of the observed and expected frequencies for each racial group, it appears as if the significant finding is for the Latino/ Hispanic students. The standardized residual for the Latino/ Hispanic students was -1.70 , which is a $z$-score reflecting significance at the $p<.10$ level. This indicates that Latino/ Hispanic students were underrepresented in this theme as compared to the expected frequency.

\section{Summary of Findings for Research Question \#2}

To address research question two, above, loglinear analyses were conducted to examine significant differences across and within the gender, race, and age groups. A number of significant findings emerged from these analyses (summarized and presented at the end of this chapter in Table 19).

First, gender emerged as a significant variable for the leadership themes of collaborate, personal qualities, and positive difference, with women reporting significantly higher frequencies of these themes than men. The cross-over interaction effects of gender and age were significant for three of the themes. For the influence theme, women aged 24 and older appeared to have higher frequency of this theme as compared to the other groups. For the direct theme, men aged 24 and older appeared to have higher frequency of this theme than the other groups, and for the support theme, 
women aged 24 and older appeared to have lower frequency of this theme than the other groups.

Age was a significant variable for the modeling theme, with students aged 18-23 reporting higher frequency than students aged 24 and older. Race was a significant variable for the shared goal and task themes, with White/ Caucasian students reflecting overrepresentation for the shared goal theme, American Indian/ Alaska Native students reflecting underrepresentation for the shared goal theme and Latino/ Hispanic students reflecting underrepresentation for the task theme as compared to the expected frequencies.

In the third and final research question of this study I further examined each of the 10 leadership definition themes through logistic regression to determine predictor variables for the themes. The significant main effects of gender, race, and age found from the analyses above were included in the regression models along with additional predictor variables. Results from these logistic regression analyses are presented in the next section.

\section{Research Question \#3- Predictors of Leadership Themes}

The third research question of this dissertation was: What demographic variables and college environmental variables predict the different understandings of leadership? This question was addressed through 10 logistic regression analyses, one for each of the 10 leadership themes. This section includes an explanation of logistic regression and its assumptions. This is followed by an explanation of the regression models and results of the significant models. 


\section{Logistic Regression}

Logistic regression allows for examining significance of non-linear predictive variables, either continuous or categorical, for a dichotomous dependent variable (in this case, the individual leadership themes) (Tabachnick \& Fidell, 2001). There are two main assumptions that exist for logistic regression, each of which sufficiently addressed in this dissertation. First, there is an assumption of the independence of errors (Field, 2009). The independence of errors assumption was met by the sampling technique; each case was independent and not related (i.e. not the same person at different points in time). Logistic regression also requires complete information from the predictors (Field, 2009). Thus, the cases that had missing data for any of the predictor variables were removed for the analysis.

Multicollinearity is another assumption, meaning that the predictor variables should not be too strongly related to each other (Field, 2009; Pallant, 2005). Logistic regression is "prone to the biasing effect of collinearity" (Field, 2009, p. 297), and thus multi-collinearity must be examined. Through running the collinearity diagnostics through PASW, I was able to examine the intercorrelations of the predictor variables (see Appendix E for the correlation matrix). None of the variables are highly correlated (they are all less than 0.80 ), meaning that there should not be any issues of multi-collinearity (Field, 2009). Below are the results from the significant logistic regression models presented by leadership theme.

\section{Logistic Regression Models and Variables}

For each logistic regression analysis, the dependent variable was the leadership theme, which was dichotomously coded (yes, no), and there were a number of 
independent predictor variables that were entered into the regression as one block using forced-entry method (Field, 2009). For some of the models, the covariates of gender, race, and age were included in the model; this was the case when these variables were previously found to have a significant main effect from the results of research question two. This was done to account for this potential significance when examining the significance of other variables as well as to examine if the demographic variables remained significant when other predictors were considered. The themes in which these demographic variables were not reported as significant main effects were not included in the analysis. This approach of using the demographic variables as covariates in the logistic regression analyses (rather than analyses by racial and gender groups) is due in part to the limited significant findings from research question two and the small effect size of the significant findings. Further analysis could examine the predictors by racial and gender groups in another study.

The additional demographic variable of parent's level of formal education was included in each analysis. The remaining variables are the college environmental variables of: community service, socio-cultural conversations, off-campus and on-campus work, college organization involvement, holding a leadership position in a college organization, community organization involvement, participation in leadership programs, and participation in three different types of student groups: social fraternities/ sororities, intercollegiate/ varsity sports, and student governance. The descriptive statistics of these predictor variables were presented earlier in this chapter in Table 3 . The results from the logistic regression analyses are presented below. Six of the 10 models were significant, 
and four were not. For the significant models, the summary of the analysis is presented to identify the significant predictor variables.

\section{Results for Leader and Follower/ Group Themes}

Two of the four logistic regression models within the leader and follower/ group themes (Theme 1: Collaborate and Theme 4: Direct) were significant. The models for these two themes are discussed below and presented in Tables 13 and 14. The models for the inspire and influence themes were not significant according to the chi-square statistic (Inspire: $\chi^{2}=13.25, \mathrm{df}=12, p=.351 ;$ Influence: $\chi^{2}=9.04, \mathrm{df}=12, p=.699$ ) and thus are not included.

Theme 1: Collaborate. The logistic regression analysis model for the collaborate theme (Table 13) model was significant at the .001 level according to the model chisquare statistic $\left(\chi^{2}=37.54, \mathrm{df}=13\right)$. Within the model, there were four significant predictor variables: on-campus work, gender, social fraternities/ sororities, and intercollegiate/ varsity sports. In examining on-campus work, the greater the number of hours one works on campus, the more likely his/ her definition of leadership is to reflect the collaborate theme (Wald statistic $=3.15, p<.10$ ). Being a woman was also a positive predictor for this theme, which is consistent with the aforementioned loglinear analysis (Wald statistic $=5.23, p<.05)$. This finding suggests that even when other variables are examined, the gender variable was still significant for the collaborate theme. The two student group involvements of social fraternities/ sororities and intercollegiate/ varsity sports were also predictors, but they emerged as negative predictors (each coded 1 for yes and 2 for no). Students who were involved in these student groups were less likely to include the collaborate theme in their definitions of 
leadership (social fraternities/ sororities: Wald statistic $=4.68, p<.05$; intercollegiate/ varsity sports: Wald statistic $=3.79, p<.10$ ).

Theme 4: Direct. The logistic regression analysis model for the direct theme (Table 14) was significant at the $p<.05$ level according to the model chi-square statistic $(\chi 2=$ 24.01, $\mathrm{df}=12$ ). Within the model there were three significant predictor variables: parent's formal education, community service, and participation in leadership programs. For the variable of parent's formal education, the higher the education, the more likely the participant's definition of leadership was to reflect the direct theme (Wald statistic $=$ $3.14, \mathrm{p}<.10$ ). Participation in community service was also a positive predictor of the direct theme, whereby the more community service the participant engages in, the more likely his/ her leadership definition was to reflect the direct theme (Wald statistic $=4.51$, $\mathrm{p}<.05$ ). Participation in a leadership program (coded 0 for no and 1 for yes) was negatively associated with this theme, meaning that participants involved in leadership programs were less likely to have leadership definitions that reflect the direct theme than participants who were not involved in leadership programs (Wald statistic $=6.87, \mathrm{p}<$ $.01)$. 


\section{Table 13}

Summary of Logistic Regression Analysis Predicting Theme 1: Collaborate

\begin{tabular}{lcccccc}
\hline \multicolumn{1}{c}{ Variable } & & & & & 'Wald \\
& $B$ & $S E$ & $O R$ & $95 \% \mathrm{CI}$ & Statistic & $p$ \\
\hline Parent's Formal Education & 0.07 & 0.05 & 1.08 & {$[0.98,1.18]$} & 2.33 & .127 \\
Community Service & 0.06 & 0.10 & 1.06 & {$[0.87,1.30]$} & 0.37 & .542 \\
Socio-cultural Conversations & 0.16 & 1.11 & 1.18 & {$[0.95,1.46]$} & 2.13 & .144 \\
Off-Campus Work & 0.00 & 0.01 & 1.00 & {$[0.98,1.01]$} & 0.21 & .651 \\
On-Campus Work & 0.02 & 0.01 & 1.02 & {$[1.00,1.05]$} & 3.15 & .076 \\
College Org Involvement & -0.02 & 0.09 & 0.98 & {$[0.83,1.16]$} & 0.04 & .851 \\
Leadership Position & 0.10 & 0.08 & 1.10 & {$[0.94,1.29]$} & 1.51 & .220 \\
Community Org Involvement & -0.06 & 0.06 & 0.95 & {$[0.83,1.07]$} & 0.75 & .387 \\
Leadership Program & 0.15 & 0.21 & 1.16 & {$[0.77,1.74]$} & 0.49 & .482 \\
Gender & -0.40 & 0.18 & 0.67 & {$[0.48,0.95]$} & 5.23 & .022 \\
Social Fraternities/ Sororities & 0.64 & 0.30 & 1.89 & {$[1.06,3.38]$} & 4.68 & .030 \\
Intercollegiate/ Yarsity Sports & 0.66 & 0.34 & 1.93 & {$[1.00,3.74]$} & 3.79 & .052 \\
Student Governance & -0.36 & 0.26 & 0.70 & {$[0.42,1.15]$} & 1.99 & .159 \\
\hline
\end{tabular}

Note. $R^{2}=.04$ (Hosmer \& Lemeshow), .04 (Cox \& Snell), 06 (Nagelkerke). Model $\chi^{2}(13)=37.54, p=.000 . \mathrm{CI}=$ confidence interval for odds ratio $(O R)$. 
Table 14

Summary of Logistic Regression Analysis Predicting Theme 4: Direct

\begin{tabular}{lcccccc}
\hline \multicolumn{1}{c}{ Variable } & & & & \multicolumn{4}{c}{ Wald } \\
& $B$ & $S E$ & $O R$ & $95 \% \mathrm{CI}$ & Statistic & $p$ \\
\hline Parent's Formal Education & 0.08 & 0.04 & 1.08 & {$[0.99,1.18]$} & 3.14 & .076 \\
Community Service & 0.19 & 0.09 & 1.21 & {$[1.02,1.45]$} & 4.51 & .034 \\
Socio-cultural Conversations & -0.07 & 0.10 & 0.93 & {$[0.77,1.14]$} & 0.47 & .493 \\
Off-Campus Work & 0.00 & 0.01 & 1.00 & {$[0.99,1.02]$} & 0.22 & .637 \\
On-Campus Work & 0.01 & 0.01 & 1.01 & {$[0.98,1.03]$} & 0.40 & .526 \\
College Org Involvement & -0.10 & 0.08 & 0.91 & {$[0.78,1.05]$} & 1.70 & .193 \\
Leadership Position & -0.08 & 0.08 & 0.92 & {$[0.79,1.08]$} & 1.00 & .316 \\
Community Org Involvement & -0.06 & 0.06 & 0.94 & {$[0.83,1.06]$} & 1.08 & .298 \\
Leadership Program & -0.56 & 0.21 & 0.57 & {$[0.38,0.87]$} & 6.87 & .009 \\
Social Fraternities/ Sororities & 0.03 & 0.25 & 1.03 & {$[0.62,1.68]$} & 0.01 & .921 \\
Intercollegiate/ Varsity Sports & 0.12 & 0.27 & 1.12 & {$[0.66,1.89]$} & 0.18 & .668 \\
Student Governance & -0.17 & 0.28 & 0.84 & {$[0.49,1.46]$} & 0.38 & .539 \\
\hline
\end{tabular}

Note. $R^{2}=.02$ (Hosmer \& Lemeshow), .02 (Cox \& Snell), .04 (Nagelkerke). Model $\chi^{2}(12)=24.01, p=.020 . \mathrm{CI}=$ confidence interval for odds ratio $(O R)$.

\section{Results for Leader Characteristic and Behavior Themes}

Two of the three logistic regression models within the leader characteristic and behavior themes (Theme 6: Modeling and Theme 7: Personal Qualities) were significant. The models for these two themes are discussed below and presented in Tables 15 and 16 . The model for the support theme was not significant according to the chi-square statistic $\left(\chi^{2}=10.59, \mathrm{df}=12, p=.564\right)$ and thus is not included. 
Theme 6: Modeling. The logistic regression analysis model for the modeling theme (Table 15) was significant at the $p<.05$ level according to the model chi-square statistic $\left(\chi^{2}=27.29, \mathrm{df}=13\right)$. Within the model there were three significant predictor variables: community service, socio-cultural conversations, and intercollegiate/ varsity sports. Participation in community service was a positive predictor of the modeling theme, whereby the more community service the participant engages in, the more likely he/ she was to have a leadership definition that reflects the modeling theme (Wald statistic $=3.67, p<.10$ ). The variable of socio-cultural conversations was negatively associated with this theme, meaning that the more one participates in socio-cultural conversations, the less likely he or she was to have a leadership definition that reflects the modeling theme (Wald statistic $=3.21, p<.10$ ). Last, findings on intercollegiate/ varsity sports (coded 1 for yes and 2 for no) indicate that participants' involved intercollegiate/ varsity sports were more likely to have a leadership definition that reflects the modeling theme than participants not involved in these sports (Wald statistic $=10.01, p<.01$ ). Note that when these other predictor variables are included in model, age, which was significant in the loglinear analysis, is not a significant predictor for the modeling theme.

Theme 7: Personal qualities. The logistic regression analysis model for the personal qualities theme (Table 16) was significant at the .05 level according to the model chi-square statistic $\left(\chi^{2}=25.96, \mathrm{df}=13\right)$. Within this model there were three significant predictor variables: parent's formal education, on-campus work, and gender. For the variable of parent's formal education, the higher the education, the less likely the participant was have a leadership definition that reflects the personal qualities theme (Wald statistic $=4.27, p<.05$ ). On-campus work was also negatively associated with the 
personal qualities theme, whereby the more hours a participant worked on campus, the less likely he/ she was to have a leadership definition that reflects the personal qualities theme $($ Wald statistic $=5.49, p<.05)$. Last, gender was also a significant predictor, whereby women were more likely to define leadership with a focus on personal qualities than men (Wald statistic $=8.05, p<.01)$. This finding suggests that even when other variables are examined, the gender variable was still significant for the personal qualities theme.

\section{Table 15}

Summary of Logistic Regression Analysis Predicting Theme 6- Modeling

\begin{tabular}{lccccccc}
\hline \multicolumn{1}{c}{ Variable } & & & & & \multicolumn{3}{c}{ Wald } \\
& $B$ & $S E$ & $O R$ & $95 \%$ CI & Statistic & $p$ \\
\hline Parent's Formal Education & 0.02 & 0.05 & 1.02 & {$[0.93,1.13]$} & 0.17 & .680 \\
Community Service & 0.21 & 0.11 & 1.23 & {$[1.00,1.52]$} & 3.67 & .056 \\
Socio-cultural Conversations & -0.21 & 0.12 & 0.81 & {$[0.64,1.02]$} & 3.21 & .073 \\
Off-Campus Work & 0.00 & 0.01 & 1.00 & {$[0.99,1.02]$} & 0.18 & .669 \\
On-Campus Work & -0.01 & 0.02 & 0.99 & {$[0.96,1.02]$} & 0.30 & .582 \\
College Org Involvement & 0.02 & 0.09 & 1.02 & {$[0.86,1.21]$} & 0.04 & .840 \\
Leadership Position & 0.06 & 0.08 & 1.06 & {$[0.90,1.25]$} & 0.54 & .464 \\
Community Org Involvement & -0.03 & 0.07 & 0.97 & {$[0.85,1.11]$} & 0.18 & .676 \\
Leadership Program & 0.16 & 0.22 & 1.17 & {$[0.77,1.79]$} & 0.54 & .462 \\
Social Fraternities/ Sororities & -0.24 & 0.25 & 0.79 & {$[0.48,1.28]$} & 0.95 & .331 \\
Intercollegiate/ Varsity Sports & -0.77 & 0.24 & 0.47 & {$[0.29,0.75]$} & 10.01 & .002 \\
Student Governance & 0.48 & 0.32 & 1.62 & {$[0.87,2.99]$} & 2.27 & .132 \\
Age & -0.01 & 0.02 & 0.99 & {$[0.96,1.02]$} & 0.55 & .459 \\
\hline
\end{tabular}

Note. $R^{2}=.03$ (Hosmer \& Lemeshow), .03 (Cox \& Snell), .05 (Nagelkerke). Model $\chi^{2}(13)=27.29, p=.011$. CI $=$ confidence interval for odds ratio $(O R)$. 
Table 16

Summary of Logistic Regression Analysis Predicting Theme 7: Personal Qualities

\begin{tabular}{lcccccc}
\hline \multicolumn{1}{c}{ Variable } & & & & & Wald \\
& $B$ & $S E$ & OR & $95 \% \mathrm{CI}$ & Statistic & $p$ \\
\hline Parent's Formal Education & -0.09 & 0.04 & 0.91 & {$[0.84,1.00]$} & 4.27 & .039 \\
Community Service & -0.07 & 0.09 & 0.94 & {$[0.78,1.12]$} & 0.52 & .471 \\
Socio-cultural Conversations & 0.11 & 0.10 & 1.11 & {$[0.91,1.36]$} & 1.13 & .288 \\
Off-Campus Work & 0.00 & 0.01 & 1.00 & {$[0.99,1.01]$} & 0.17 & .681 \\
On-Campus Work & -0.03 & 0.02 & 0.97 & {$[0.94,0.99]$} & 5.49 & .019 \\
College Org Involvement & 0.08 & 0.08 & 1.08 & {$[0.93,1.25]$} & 0.99 & .321 \\
Leadership Position & -0.04 & 0.08 & 0.96 & {$[0.83,1.12]$} & 0.27 & .603 \\
Community Org Involvement & 0.08 & 0.06 & 1.08 & {$[0.96,1.21]$} & 1.77 & .183 \\
Leadership Program & 0.24 & 0.19 & 1.27 & {$[0.87,1.85]$} & 1.55 & .213 \\
Social Fraternities/ Sororities & -0.20 & 0.23 & 0.82 & {$[0.52,1.30]$} & 0.70 & .402 \\
Intercollegiate/ Varsity Sports & 0.05 & 0.27 & 1.05 & {$[0.62,1.80]$} & 0.04 & .848 \\
Student Governance & 0.23 & 0.27 & 1.25 & {$[0.74,2.14]$} & 0.68 & .410 \\
Gender & -0.46 & 0.16 & 0.63 & {$[0.46,0.87]$} & 8.05 & .005 \\
\hline
\end{tabular}

Note. $R^{2}=.03$ (Hosmer \& Lemeshow), .03 (Cox \& Snell), .04 (Nagelkerke). Model $\chi^{2}(13)=25.96, p=.017 . \mathrm{CI}=$ confidence interval for odds ratio $(O R)$.

\section{Results for Leadership Outcome Themes}

Two of the three logistic regression models within the leadership outcome themes (Theme 9: Shared Goal and Theme 10: Task) were significant. The models for these two themes are discussed below and presented in Tables 17 and 18. The model for the positive difference theme was not significant according to the chi-square $\left(\chi^{2}=18.85, \mathrm{df}=\right.$ $13, p=.128)$ and thus is not included. 
Theme 9: Shared goal. The logistic regression analysis model for the shared goal theme (Table 17) was significant at the .10 level according to the model chi-square statistic $\left(\chi^{2}=24.10, \mathrm{df}=16\right)$. The logistic regression analysis model for the shared goal theme resulted in three significant predictor variables: socio-cultural conversations, holding a leadership position, and race. Within the race variable, three of the specific racial categories also emerged as predictors. Participation in socio-cultural conversations was a positive predictor of the shared goal theme, whereby the more a participant engaged in socio-cultural conversations, the more likely he/ she was to have a leadership definition that reflects the shared goal theme (Wald statistic $=4.69, p<.05$ ). Holding a leadership position was negatively associated with this theme, meaning that the more often a participant held a formal leadership role in a student organization, the less likely he or she was to have a leadership definition that reflected the shared goal theme (Wald statistic $=3.13, p<.10)$. Race was the final predictor category for this model and identified that as compared to the excluded variable in the analysis (White/ Caucasian participants), Black $($ Wald statistic $=3.65, p<.10)$, American Indian $($ Wald Statistic $=$ $7.50, p<.01$ ), and Asian (Wald Statistic $=3.20, p<.10$ ) participants were less likely to have a definition of leadership that reflected the shared goal theme. This finding suggests that even when other variables were examined, the race variable was still significant for the shared goal theme. The variable of age was not included in this analysis due to the negligible effect size found for age and the shared goal theme in research question two.

Theme 10: Task. The logistic regression analysis model for the last theme, task, (Table 18) was significant at the .10 level according to the model chi-square statistic $\left(\chi^{2}=\right.$ 
24.66, $\mathrm{df}=16$ ). Within the model there were two significant predictor variables: intercollegiate/ varsity sports and race. Within the race variable, three of the specific racial categories were also identified as predictors. Participation in intercollegiate/ varsity sports was a positive predictor variable for this model, meaning that participants involved in intercollegiate/ varsity sports were more likely to have a definition of leadership that reflects the task theme than students who were not involved in intercollegiate/ varsity sports (Wald statistic $=4.86, p<.05$ ). Race was the final predictor category for this model; the model resulted in a significant difference whereby when compared to the excluded variable in the analysis (White/ Caucasian participants) Asian (Wald Statistic $=3.52, p<.10)$ and Latino (Wald Statistic $=5.45, p<.05)$ participants were less likely to have a definition of leadership that reflects the task theme. This finding suggests that even when other variables were examined, the race variable was still significant for the task theme. 
Table 17

Summary of Logistic Regression Analysis Predicting Theme 9: Shared Goal

\begin{tabular}{lcccccc}
\hline \multicolumn{1}{c}{ Variable } & & & & & Wald \\
& $B$ & $S E$ & $O R$ & $95 \% \mathrm{CI}$ & Statistic & $p$ \\
\hline Parent's Formal Education & -0.06 & 0.04 & 0.94 & {$[0.87,1.02]$} & 2.01 & .156 \\
Community Service & 0.10 & 0.09 & 1.10 & {$[0.94,1.31]$} & 1.41 & .235 \\
Socio-cultural Conversations & 0.21 & 0.10 & 1.34 & {$[1.02,1.49]$} & 4.69 & .030 \\
Off-Campus Work & 0.01 & 0.01 & 1.01 & {$[0.99,1.02]$} & 0.74 & .391 \\
On-Campus Work & 0.01 & 0.01 & 1.01 & {$[0.99,1.03]$} & 0.63 & .428 \\
College Org Involvement & 0.11 & 0.07 & 1.11 & {$[0.97,1.28]$} & 2.48 & .116 \\
Leadership Position & -0.12 & 0.07 & 0.89 & {$[0.77,1.01]$} & 3.13 & .077 \\
Community Org Involvement & -0.07 & 0.06 & 0.93 & {$[0.84,1.05]$} & 1.43 & .232 \\
Leadership Program & -0.08 & 0.18 & 0.92 & {$[0.65,1.33]$} & 0.17 & .680 \\
Social Fraternities/ Sororities & 0.17 & 0.23 & 1.18 & {$[0.76,1.86]$} & 0.56 & .453 \\
Intercollegiate/ Varsity Sports & -0.10 & 0.24 & 0.89 & {$[0.57,1.44]$} & 0.19 & .662 \\
Student Governance & -0.08 & 0.24 & 0.93 & {$[0.57,1.49]$} & 0.11 & .737 \\
Race & & & & & 8.39 & .078 \\
Race- Black & -0.45 & 0.23 & 0.63 & {$[0.41,1.01]$} & 3.65 & .056 \\
Race- Am Indian & -0.68 & 0.25 & 0.51 & {$[0.31,0.83]$} & 7.50 & .006 \\
Race- Asian & -0.41 & 0.23 & 0.66 & {$[0.42,1.04]$} & 3.20 & .073 \\
Race-Latino & -0.30 & 0.23 & 0.73 & {$[0.47,1.17]$} & 1.68 & .195 \\
\hline
\end{tabular}

Note. $R^{2}=.02$ (Hosmer \& Lemeshow), .02 (Cox \& Snell), 03 (Nagelkerke). Model $\chi^{2}(16)=24.10, p=.087 . C I=$ confidence interval for odds ratio $(O R)$. 


\section{Table 18}

Summary of Logistic Regression Analysis Predicting Theme 10: Task

\begin{tabular}{|c|c|c|c|c|c|c|}
\hline \multicolumn{7}{|c|}{ Wald } \\
\hline Variable & $B$ & $S E$ & $O R$ & $95 \% \mathrm{CI}$ & Statistic & $p$ \\
\hline Parent's Formal Education & 0.04 & 0.04 & 1.04 & {$[0.96,1.13]$} & 0.76 & .348 \\
\hline Community Service & 0.02 & 0.08 & 1.02 & {$[0.87,1.20]$} & 0.06 & .810 \\
\hline Socio-cultural Conversations & -0.15 & 0.10 & 0.91 & {$[0.71,1.03]$} & 2.64 & .104 \\
\hline Off-Campus Work & -0.01 & 0.01 & 0.99 & {$[0.98,1.00]$} & 2.38 & .123 \\
\hline On-Campus Work & -0.01 & 0.01 & 0.99 & {$[0.97,1.01]$} & 0.69 & .407 \\
\hline College Org Involvement & 0.01 & 0.07 & 1.01 & {$[0.88,1.16]$} & 0.02 & .898 \\
\hline Leadership Position & -0.07 & 0.07 & 0.93 & {$[0.81,1.07]$} & 0.96 & .327 \\
\hline Community Org Involvement & -0.05 & 0.06 & 0.95 & {$[0.85,1.06]$} & 0.77 & .381 \\
\hline Leadership Program & 0.12 & 0.19 & 1.12 & {$[0.78,1.62]$} & 0.41 & .523 \\
\hline Social Fraternities/ Sororities & 0.11 & 0.23 & 1.12 & {$[0.71,1.76]$} & 0.21 & .644 \\
\hline Intercollegiate/ Varsity Sports & 0.60 & 0.27 & 1.81 & {$[1.07,3.09]$} & 4.86 & .027 \\
\hline Student Governance & 0.22 & 0.26 & 1.27 & {$[0.74,2.09]$} & 0.70 & .404 \\
\hline Race & & & & & 9.18 & .057 \\
\hline Race- Black & 0.00 & 0.23 & 0.99 & {$[0.64,1.56]$} & 0.00 & .999 \\
\hline Race- Am Indian & -0.18 & 0.23 & 0.84 & {$[0.53,1.33]$} & 0.57 & .451 \\
\hline Race- Asian & -0.43 & 0.23 & 0.65 & {$[0.41,1.02]$} & 3.52 & .061 \\
\hline Race-Latino & -0.57 & 0.25 & 0.56 & {$[0.35,0.91]$} & 5.45 & .020 \\
\hline
\end{tabular}

Note. $R^{2}=.02$ (Hosmer \& Lemeshow), .02 (Cox \& Snell), .04 (Nagelkerke). Model $\chi^{2}(16)=24.66, p=.076 . \mathrm{CI}=$ confidence interval for odds ratio $(O R)$.

\section{Summary of Findings for Research Question \#3}

This section included the results of the logistic regression analyses for the six leadership themes that resulted in significant models. For each model, predictor variables 
(both demographic and environmental variables) were examined. A summary of these findings along with the findings from research question two are presented below, in the summary section of this chapter as well as in Tables 19.

\section{Summary of Results}

This chapter presented the findings from the research questions of this study. The qualitative data analysis for research question one resulted in 10 leadership themes. These themes were then examined for differences based on the demographic variables of gender, race, and age as well as associations among these variables. Last, significant demographic and environmental predictors were examined. A summary of the results from this study is presented below in Table 19. The next chapter will discuss these findings through connections to the literature as well as discuss implications for practice and future research. 


\section{Table 19}

Summary of Findings for Leadership Themes

\begin{tabular}{|c|c|c|}
\hline Theme & Loglinear Analysis & Logistic Regression \\
\hline \multirow[t]{4}{*}{1 - Collaborate } & Gender & Gender \\
\hline & & On-campus work \\
\hline & & Fraternities/sororities* \\
\hline & & Intercollegiate sports* \\
\hline \multicolumn{3}{|l|}{2 - Inspire } \\
\hline 3 - Influence & Gender x Age & \\
\hline \multirow[t]{3}{*}{4 - Direct } & Gender x Age & Parents' formal education \\
\hline & & Community service \\
\hline & & Leadership program* \\
\hline 5 - Support & Gender x Age & \\
\hline \multirow{3}{*}{6 - Modeling } & Age & Community service \\
\hline & & Socio-cultural conversation* \\
\hline & & Intercollegiate sports \\
\hline \multirow[t]{3}{*}{7 - Personal Qualities } & Gender & Gender \\
\hline & & Parents' formal education* \\
\hline & & On-campus work* \\
\hline 8 - Positive Difference & Gender & \\
\hline \multirow[t]{2}{*}{9 - Shared Goal } & Race & Race \\
\hline & & Socio-cultural conversations \\
\hline \multirow[t]{2}{*}{10 - Task } & Race & Race \\
\hline & & Intercollegiate sports \\
\hline
\end{tabular}

Note. ${ }^{*}$ negative predictors of theme for continuous and interval variables. 


\section{CHAPTER FIVE: DISCUSSION}

In this mixed-methods study I examined the ways in which college students understand the concept of leadership. Additionally, I examined the different thematic understandings of leadership for differences by gender, race, and age. Last, I investigated additional demographic and environmental variables that were associated with the different understandings of leadership. Data for this study came from the Multi Institutional Study of Leadership, whereby 1100 participants were selected through random criterion sampling, reflecting an equal number of men and women as well as an equal split among the five racial groups of: White/Caucasian, Black/ African American, Native American/ Alaska Native, Asian/ Asian American, and Latino/ Hispanic participants. The participants' qualitative responses from a prompt asking about their definitions of leadership were analyzed through thematic content analysis. Additionally, loglinear analysis and logistic regression analysis were conducted to address the quantitative components of this study.

This chapter includes a discussion on the findings of the study. First, the findings, which were presented in Chapter Four, are summarized and discussed alongside existing literature and research. Second, limitations of the study are presented. Third, theoretical and practical implications of the study are discussed. Last, recommendations for further research are presented.

\section{Summary and Discussion of Findings}

This section includes a summary of the main findings from this study. First, the findings on the different leadership definition themes (research question one) are 
summarized and discussed. Next, findings for each of the themes by demographic variables will be discussed. Last, findings on the environmental predictors of the themes are summarized and discussed.

\section{Leadership Themes}

This study resulted in 10 themes of leadership definitions, which reflected three main groups of themes: (1) leadership and follower/ group themes, (2) leader characteristics and behavior themes, and (3) outcomes of leadership themes:

Leader and Follower/ Group Themes

Collaborate/ Work Together

Inspire/ Motivate

Influence/ Guide/ Lead/ Others Follow You

Direct/ Control/ In Charge

Leader Characteristics and Behavior Themes

Support/ Bring Out the Best in Others

Modeling/ Set Example

Admirable Personal Qualities

Outcomes of Leadership Themes

Positive Difference/ Community Focus

Shared Goal

Task/ Goal/ Action

In examining these 10 themes, and realizing that participants' definitions in many cases spanned multiple themes, it is clear that college students define and understand 
leadership in many different ways. This is not entirely surprising, and it reflects the similar trend in society as a whole that is seen in the vast array of definitions and understandings of leadership one can identify by searching online or browsing bookstore shelves. When looking more at the individual themes, though, some conclusions can be drawn.

Leader and follower/group themes. When examining the first group of themes, there appears to be greater representation of the latter two leadership themes (influence and direct) than the first two (collaborate and inspire). In fact, nearly two-thirds of the participants had leadership definitions that reflected either the influence or direct themes, and the most common understanding of leadership across all 10 of the themes was the influence theme. This theme included a focus on influencing, guiding, or leading others, with an emphasis on someone following a leader. Considering that this theme includes the descriptor of leading, it is not surprising that this theme was the most prevalent. The direct theme was also fairly prevalent within these four themes, and this theme focuses on directing, controlling, or being in charge of others.

These two themes reflect a transactional and hierarchical approach to leadership, aligned with Rost's (1991) industrial paradigm of leadership. This is also reflective of a research study on college students involved in leadership positions who viewed leadership as positional and involving persuasion; many of these students discussed the desire to control a group, organization, or process as a motivation for getting involved in a leadership position (Shertzer \& Schuh, 2004). A strong emphasis on leadership as transactional and positional is also consistent with research on college students through the Leadership Attitudes and Beliefs Scale III, whereby students tended to reflect greater 
hierarchical thinking as compared to systems thinking about leadership (Smith, 2009). Hierarchical thinking about leadership is also reflective of the leader identified stage of the leadership identity development research, whereby students view leadership as positional, with an emphasis on leader independence and follower dependence (Komives et al., 2005).

Although the leader-centric and hierarchical views of leadership were quite prominent, some participants viewed leadership as more relational, which is captured in the collaborate and inspire themes. Together, about a third of the participants had leadership definitions that reflected one of these two themes. The collaborate theme emphasizes working together and recognizing the need to follow at times, and the inspire theme in many cases distinguishes between the roles of leader and follower, yet the relationship between the two is characterized by inspiring, motivating, and empowering the followers. More so than the first two themes, these two leadership themes reflect the more contemporary and aspirational models and concepts of leadership that have become more prominent in the last 20 years. For example, the inspire and collaborate themes reflect Rost's (1991) postindustrial paradigm of leadership, characterized by relational perspectives and approaches to leadership, which promotes leadership as involving mutual influence. Additionally, the collaborate theme is reflective of the collaboration value of the social change model of leadership (HERI, 1996) and the process and inclusive aspects of the relational leadership model, which emphasize working together and involving many people in the leadership process (Komives et al., 2007). The inspire theme is reflective of the empowering component of the relational leadership model (Komives et al., 2007). 
In research, the presence of more relational and less directive approaches of leadership was reported in three qualitative studies. In Shertzer and Schuh's (2004) study, some of the participants who did not hold formal leadership roles emphasized that needing to have control of a person or group is a leadership myth. A study on fraternity men's attitudes of leadership after a five-day leadership program resulted in findings of leadership as involving relationships and mutual respect (DiPaolo, 2002). The leadership identity development research found the presence of relational understandings and approaches to leadership in the later stages of leadership identity development, which reflected interdependence (Komives et al., 2005). These views of leadership as more relational, particularly in the collaborate theme, were confirmed in this current study.

Participants' definitions of leadership could span multiple themes, and approximately $20 \%$ of participants' definitions that were represented in these four leader and follower/ group themes actually reflected more than one theme. In fact, about $40 \%$ of these pairs reflected the collaborate theme and either the influence or direct themes. In other words, multiple theme combinations within this group of themes (leader and follower/ group themes) often reflected potentially contradictory themes, emphasizing both relational and leader-centric, hierarchical understandings of leadership. This is reflective of a key transition in the leadership identity development research, which is the transition between the leader identified and the leadership differentiated stages (Komives et al., 2004). In this transition, students begin to realize the complexity of leadership and start to value the involvement and perspectives of other people while also learning the language of leadership. Through this, participants begin to shift their perspective on leadership as being independent and positional to requiring interdependence and 
relationships (Komives et al., 2004). This transition toward greater interdependence might help explain the finding that some participants' understandings of leadership reflected more than one theme, and even contradictory themes, in this group. The key leadership identity development transition could also help explain some of the other leadership theme pairings, such as direct and shared goal or influence and shared goal.

Students' different ways of viewing the leader and follower/group relationship may also reflect students' cognitive development and how they may view the world. Perry's (1981) theory of intellectual and ethical development, which examines how students make meaning of their experiences and how they think about the world, provides insight into students' leadership development (Wagner, 2011). Viewing leadership as working collaboratively with others may be reflective of some of the later positions in Perry's theory, such as the multiplicity position, whereby students recognize the value of other perspectives and opinions (Perry; Wagner, 2011). In contrast, dualism, an earlier position in Perry's model reflects dichotomous, right-or-wrong thinking, which may be more reflective of the direct and influence theme, whereby there is a clear distinction between the roles of leader and follower. The findings around the four different ways of viewing the leader and follower/group relationship also reflect cognitive development as captured in Baxter Magolda's (1992) theory on espitemological reflection, particularly the shift from absolute knowing toward transitional knowing and independent knowing.

Psychosocial identity development also can provide insight to how students' view the leaders and the follower/ group relationship. Chickering and Reisser's (1993) theory of college student identity development includes seven vectors of development. The vector most salient to the findings in this study around the leader and follower/group 
relationship is moving through autonomy toward interdependence. This vector emphasizes a movement away from autonomy and independence toward greater connection with others and seeking interdependence (Chickering and Reisser). This vector can help explain the differences between the directing (autonomy) and collaborating (interdependence) themes found in this study. The movement toward interdependence is also reflective of the broad areas of development in Kegan's (1994) orders of consciousness. The higher and more complex orders of consciousness reflect interdependent relationships with others in contrast to the more dependent and independent relationships characteristic of earlier orders of consciousness. Again, the more complex orders of consciousness is more reflective of the collaborate theme, and the lower orders of consciousness are more reflective of the direct and influence themes.

Leader characteristics and behavior themes. The second group of themes included those that reflect certain characteristics or behaviors of leaders. The three themes in this group are supporting, modeling, and admirable personal qualities; each of these themes emphasized positive characteristics or behaviors. Viewing leadership as supporting others emphasized helping, caring for, and recognizing the needs of others as individuals, not as a group. This theme is reflective of some of the conceptual understandings of leadership. For example, supporting reflects aspects of the inclusive and empowering components of the relational leadership model, which emphasize helping others develop their skills and supporting people in their development and involvement (Komives et al., 2007). It also is consistent with servant leadership, which emphasizes serving others and putting the needs of others before one's own needs (Greenleaf, 1977). In research, the support theme reflects the focus on mentoring and 
supporting other people in the generativity stage of the leadership identity development model (Komives et al., 2005) and the enabling other to act and encouraging the heart practices from the five exemplary practices of leadership (Kouzes \& Posner, 2008).

Leadership as modeling was characterized by being a role model with an emphasis on morality and ethics. This theme, too, is reflective of the relational leadership model, specifically the component of ethical, which emphasizes acting in line with the values of the individual and group (Komives et al., 2007). Similarly, the value of congruence in the social change model of leadership reflects leading through one's actions and acting on one's values (HERI, 1996). Additional theoretical frameworks that support this theme are Burns' (1978) emphasis on morality and leadership and authenticity and congruence in the authentic leadership framework (Avolio \& Gardner, 2005). In terms of research findings, an emphasis on modeling was also evident in Shertzer and Schuh's (2002) study, whereby students not involved in formal leadership roles tended to view leadership as leading by example. It was also evident in the modeling the way practice from the five exemplary practices of leadership (Kouzes \& Posner, 2008).

The final theme in this group was viewing leadership as an individual exemplifying certain admirable personal qualities. These qualities were quite broad, including such qualities as intelligence, strength, charisma, passion, and problem solving ability. These qualities reflect the traits or characteristics of an individual leader, which is consistent with trait perspectives on leadership (Bass, 1990; Northouse, 2007). Although the trait perspective on leadership has been criticized within the leadership studies field, it has gained considerable momentum within the general public and popular 
culture over the past thirty years (Antonakis et al., 2004), and within this study $20 \%$ of the participants' definitions reflected at least one identified admirable personal trait or quality. The personal qualities theme was often identified in conjunction with other themes, such as influence, modeling, and support, indicating that participants who viewed leadership as encompassing the personal qualities of the leader often also recognized other aspects of leadership and perhaps felt that traits alone were not enough. The recognition of certain traits of a leader was evident in Shertzer and Schuh's (2002) research on student leaders, who often associated leadership as requiring certain traits or abilities that were in some cases viewed as inherent.

Outcomes of leadership themes. This final group of leadership themes includes those themes that reflect different outcomes or goals of leadership: positive difference, shared goal, and task. The positive difference theme emphasizes creating positive change and having care and concern for a larger community. This theme is consistent with the purpose and ethical components of the relational leadership model, which stress a positive outcome of the leadership process and working to serve something beyond oneself to create positive change (Komives et al., 2007). Additionally, it is consistent with the overall goal of the social change model of leadership, which is positive social change, and the value of citizenship, which emphasizes the larger community (HERI, 1996). Leadership for something beyond oneself is also consistent with authentic leadership (Avolio \& Gardner, 2005) and servant leadership (Greenleaf, 1977). This focus on positive difference in the research reflected the generativity stage of the leadership identity development model, which emphasized a desire to help improve the organization and make a positive difference for others (Komives et al., 2005). This 
feeling of responsibility toward the larger organization and making a positive difference within the organization was also evident in Arminio et al.'s (2000) qualitative study on the leadership experiences of students of color. As will be discussed later, in this research there were no significant findings based on race for the positive difference theme.

The theme of leadership involving a shared goal was one of the most prominent in this research, with approximately one in four participants' leadership definitions reflecting this theme. The most common pairing of leadership themes was the influence and shared goal themes. Additionally, a substantial number of definitions reflected both the shared goal theme and the other leader and follower/group themes: collaborate, inspire, and direct. It is evident that across each of the four understandings of leadership in terms of the leader and follower relationship, a common purpose is salient. The shared goal theme has many conceptual and theoretical connections consistent with the postindustrial paradigm and relational perspectives of leadership. For example, shared goal is consistent with Rost's (1991) emphasis on leader and followers' mutual purposes. It is also reflective of the purpose component of the relational leadership model, which emphasizes a group goal (Komives et al., 2007) and the common purpose value of the social change model of leadership (HERI, 1996).

A shared goal was evident in the leadership identity development research among the stages of the model that reflected interdependence of group members; in these stages, leadership is about a common purpose with others (Komives et al., 2005). The shared goal theme, particularly when paired with the collaborate and inspire themes, is also reflective of the inspiring a shared vision practice from the five exemplary practices of 
leadership (Kouzes \& Posner, 2008). Viewing leadership as having a commitment to organizational goals was also evident in Arminio et al.'s (2000) study of the leadership experiences of students of color. As will be discussed later, this study found that White students tended to associate leadership with the shared goal theme more so than their Black, Asian American, and American Indian peers.

The final theme identified in this study was the task theme, which reflects accomplishment of tasks and goals, taking action, and taking initiative. Like shared goal, this theme was prominent among the different leadership definitions; approximately one in four participants' definitions reflected this theme. The second most paired themes (after influence and shared goal) were influence and task. Additionally, task was frequently paired with the direct theme, but not with the other two, more relational leader and follower themes (collaborate and inspire). Therefore, when paired with other themes, the task theme tended to be paired with the more hierarchical understandings of leadership, whereas the focus on a shared goal tended to be paired with all of the different leader and follower relationship themes. Examining this theme alongside these pairings, one could assume that task is often associated with an end goal of getting things done and a more hierarchical relationship between leader and followers. This is reflective of the leader identified stage of the leadership identity development research, which is characterized by accomplishing tasks, getting a job done, individual accomplishments, and telling others what to do (Komives et al., 2005, 2006).

\section{Demographic Findings}

The 10 leadership themes were broken down and examined by gender, race, and age. For each gender, race, and age group the most prominent themes were influence, 
shared goal, talks, direct, and personal qualities. The only groups in which these were not the top five leadership themes were women, with the collaborate theme tied for the fifth most common theme along with direct; White/ Caucasian students, with the theme collaborate in lieu of personal qualities, and Latino/ Hispanic students with the theme of positive difference in lieu of direct.

Although the top leadership themes appear to be quite similar for each of the demographic groups examined in this study, there were some significant differences within these themes based on these demographic variables and a combination (interaction effect and cross-over interaction effect) of these variables. The significant findings based on demographics reflected fairly small effect sizes, indicating that some of these findings, while statistically significant, may lack some practical significance and that other variables may better explain the variability. These findings should therefore be examined with some caution, recognizing that while there may be some meaning from these findings, more research is needed in order to deem them conclusive. The significant findings are discussed in this section along with a discussion of the demographic variable of parents' formal education, which was examined in the third research question as a potential predictor for the leadership themes.

Gender. For gender, there were three themes in which significant differences emerged, with women being significantly more likely to include the theme in their definitions of leadership than men. These three themes were collaborate, personal qualities, and positive difference. It is important to note that although these themes were found to have significant differences by gender, the effect sizes of these differences were fairly low. Additional findings by gender, also with low effect sizes, were evident for the 
themes of influence, direct, and support, by which the findings were significant for the interaction of gender and age.

Gender main effects. The finding that women's understandings of leadership more often reflected collaboration than men is consistent with research both on students' understandings of leadership as well as their leadership practice. In terms of students' understandings of leadership, research on students' views of leadership using the LABSIII instrument found that men tended to have more hierarchical thinking about leadership than women, and women demonstrated greater system thinking on leadership than men (Fischer et al., 2010; Wielkiewicz, 2000). Although systems-thinking is not solely focused on collaboration, it does reflect interdependence, which can be associated with working together and operating collaboratively (Allen et al., 1998). Women also tended to adopt more relational views of leadership than men within Arminio et al.'s (2000) study on students of color; the women tended to emphasize leadership as more relational than men. This finding was also echoed in the leadership identity development research (Komives et al., 2005).

Research on students' leadership behaviors also reflect women's greater focus on collaboration as compared to men (Dugan, Komives, \& Segar, 2008; Haber 2006a) and emphasize college women leaders' emphasis on teamwork and nonhierarchical leadership (Romano, 1996). The finding that women tend to be more collaborative in their thinking of leadership than men is also reflective of the plethora of research on women's leadership outside of the college arena, which is synthesized in Eagly and Carli's (2007) work Through The Labyrinth. Eagly and Carli conclude that when compared to men, women tend to have more communal approaches to leadership. This finding by gender 
also reflects college student moral development theory; Gilligan's (1977) research identified that women make moral judgments differently than men, valuing a focus on relationships along with self as opposed to the more logical and autonomous reasoning of men (Wagner, 2011). In this current study the fact that women viewed leadership as involving collaboration more so than men may reflect these differences in moral reasoning.

The finding that women were also significantly more likely than men to understand leadership as involving admirable personal qualities is perhaps less conclusive in the research. In fact, past research suggests that men's understandings of leadership are more leader-centric, reflecting the individual leader and the skills or qualities of that leader (Fischer et al., 2010; Wielkiewicz, 2000). As was noted earlier, many of these identified leader qualities were admirable, desirable, and positive qualities that were also paired with other leadership themes including influence, modeling, and support. This could suggest that women, more so than men, view leadership as possessing positive qualities, which often accompany leadership behaviors. This finding could also suggest that women view leadership as involving very qualified, deserving, and competent leaders. It could also suggest that women view leadership as more personalized than men do.

The final gender difference that emerged was women's greater focus on leadership as involving positive difference as compared to men. This reflects similar findings around students' leadership behaviors, whereby women have significantly higher self-reported measures of citizenship than men (Dugan, Komives, \& Segar, 2008; Haber, 2006a). It also reflects a larger body of literature on women and leadership, which 
suggests that women are motivated to engage in leadership in order to make a positive impact and serve their organizations and community (Barsh, Cranston, \& Lewis, 2009; Merrill-Sands, Kickul, \& Ingols, 2005). It can also reflect women's greater focus on interdependence identified in the research using the LABS III inventory (Fischer et al., 2010; Wielkiewicz, 2000).

Gender and age cross-over interaction effects. Findings for three of the leadership themes resulted in significant cross-over interactions between the variables of gender and age. These three themes are influence, direct, and support. For each of these themes, the main effects of age and gender were not significant.

The influence theme and direct themes are both themes that reflect the leader and follower/ group relationship. The significant findings for these two themes were for the 24 and older groups. For the influence theme, women aged 24 and older were more likely to view leadership as involving influence as compared to men of all ages and women aged 18 to 23 . For the direct theme, men ages 24 and older were more likely to associate with this theme than younger men and women in general. One could conclude that for students aged 24 and older, men associate leadership more with directing and women associate it more with influencing. Both of these themes are considered the less relational and more leader-centric approaches to leadership as compared to the other two leader and follower/group themes (collaborate and inspire).

The finding related to the direct theme supports research on gender and leadership beyond the college context, which indicates that men approach leadership in more authoritative and less democratic ways than women (Eagly \& Carli, 2007). The age difference within this finding in some ways is contradictory to the research on leadership 
that suggests that it is developmental, meaning that over time people's understandings and practice of leadership and one's understanding of self with others become more complex (Avolio \& Gibbons, 1988; Baxter-Magolda, 1999, 2001; Day, 2001; Kegan, 1994; Komives et al., 2005, 2006; Lord \& Hall, 2005). In the case of men in this study, older men were more likely to view leadership more hierarchically.

Although age is often times related to development, it is not consistently the case that the older one gets, the more developed they become and the more they recognize the complexity of the world. As was suggested in the leadership identity development research, some people may stay in more of the early stages of leadership identity development, which reflect leadership as leader-centric, for much of their lives (Komives et al., 2005, 2006). The finding that older men and women tended to have more hierarchical understandings of leadership as compared to younger men and women could reflect the work and "real world" experiences that older students may have prior to or during college. Many of these experiences may involve holding front line or lower level jobs in industries such as sales, service, and manufacturing, which may have a more hierarchical organizational structure and may reward hierarchical thinking. Another way of looking at this finding is that for men, there may be a generational difference, whereby younger men may be approaching and understanding leadership less so like their older male counter parts and more like their female counter parts, with less association of leadership as directing or controlling others. This finding could also relate to the higher number of veterans returning to college, many of whom are men. With the military reflecting often more hierarchical practices of leadership, many of these older men on college campuses could have more of a directive way of understanding leadership. 
The combination of gender and age was also significant for the support theme, whereby women aged 24 and older were less likely to define leadership as involving support. This finding is a bit perplexing, as women in this age group are more often mothers and responsible for childcare and household responsibilities (i.e. supporting) than younger women and men. It could be that although women may engage in these behaviors more often, they may not view supporting behaviors as leadership.

Gender conclusion. The fact that no other leadership themes resulted in gender differences is a finding in itself that is worth noting. For example, the literature might suggest that women would have a stronger association with leadership as involving supporting, modeling, or shared goal than men (see for example Eagly \& Carli, 2007; Dugan, Komives, \& Segar, 2007). However, significant differences did not emerge in this study for these themes (with the exception of the negative association of the support theme for women aged 24 and older), meaning that women and men may tend to view leadership in these ways in equal proportions and that men and women may in fact be more alike than different in how they view leadership. This can also be supported by the fact that the significant findings reflected small effect sizes.

In examining the findings from this study alongside literature on gender differences in leadership behavior, it could be suggested that women and men may think about leadership quite similarly even though their leadership behaviors may differ, with women demonstrating a focus on serving others, acting in line with their values, and focusing on common purposes more so than men. As will be discussed in the implications for future research section, an examination of perceptions of leadership alongside leadership behaviors would provide additional insight on this topic. 
In summary, the findings by gender evident in the leadership themes for this study suggest that women and men are quite similar in how they view leadership. There is evidence, with small effect size, of women more so than men tending to view leadership as working together with others, working toward creating a positive difference or serving one's community, and involving a leader who has admirable qualities that makes them deserving as a leader. There are also findings based on older students' differing understandings of leadership, with older men viewing leadership as more directive and women viewing leadership with more of a focus on influencing and less of a focus on supporting.

Race. For the demographic variable of race, few significant findings emerged, meaning that for the most part, students think about leadership similarly, regardless of race. It is important to remember, though, that this study examined data from the prompt: Please provide a brief definition of what the term leadership means to you. The responses reflect the personal association that the participant has of the term leadership. This may not be how they think leadership should be practiced, how they would aspire to lead, or how they imagine a group or community to function or attempt to affect change. In fact, some research suggests that some students of color may not even associate with the term leadership and may not associate their organizational involvement and roles as leadership (Arminio et al., 2000). Other literature suggests that communities of color tend to approach leadership in a relational way with a focus on values and positive change (Bordas, 2007). Literature on traditional American Indian cultures suggests understanding leadership with a focus on spirituality, kindness, honor, community, leading by example, and respect (American Indian Research and Policy Institute., 1997). 
Another example suggests that Asian American students can have negative associations with the concept of leadership, viewing it more as controlling and power-driven, Whitemale schema (Balon, 2004). It is possible that a lack of major findings by race could be a reflection of perceptions on how leadership is viewed in the greater society, not necessarily how people from various racial background believe leadership should be practiced.

Although there were not a great number of findings by race, there were two main effect findings based on race for the leadership themes of shared goal and task; each of these findings reflected fairly small effect sizes. The first main effect found in this study by race was the findings that the theme shared goal was associated more with White students and less so with American Indian/ Alaska Native, Asian American, and African American students. At first, this finding can seem alarming considering that American Indian, African American, and Asian American cultures tend to be more communal and community-focused (Bordas, 2007). The discussion above about how some students of color might associate the concept of leadership as something external and associated with more dominant, White culture may shed some light on this finding. Rather than interpreting this finding as assuming that these three communities of color do not value shared goals in a leadership process, it may be more accurate to conclude that these students are less likely to associate shared or common goals with their understanding of the term leadership. It is also important to note that a large number of the Asian students in the study $(23 \%)$ identified as international students. There may, too, be issues of language and culture playing out within the students' written definitions to the term leadership. This is worth further study to examine leadership definitions within 
international populations as well as examining the leadership definitions of Asian American students who are not international students to better understand that population and any differences based on nationality and/ or residency.

The finding that White students tended to more often view leadership as involving a shared goal is also interesting, as the GLOBE research, which examined culture and leadership, found that the Anglo culture tends to be more individualized and less communal that other cultures with a greater focus on performance and accomplishment, which could be associated more with the task theme than the shared goal theme (Javidan, House, \& Dorfman, 2004). Based on this research on leadership and culture, one might assume White students, particularly men, would have a greater focus on task as compared to their peers of color rather than a greater focus on shared goal; in this current study, this was not the case. Additionally, another study focusing on college students' leadership behaviors did not report any significant differences in students' self reported scores for the leadership outcome of common purpose based on race (Dugan, Komives, \& Segar, 2008). These three different studies (GLOBE, this current study, and Dugan, Komives, \& Segar, 2008) suggest different conclusions about race and leadership as it relates to a shared goal.

The other significant finding by race was that Latino/ Hispanic students were less likely to define leadership with an emphasis on task. This supports literature that suggests students of color view leadership as a community focus with an emphasis on the goals of the organization (Arminio et al., 2000) and the Latino community in general as having a more relational and reflective concept of leadership (Bordas, 2007). The GLOBE research examined culture and leadership, reporting that the Latin America 
societal cluster has a low focus on performance orientation, which is characterized by goal attainment and performance improvement, and a high focus on in-group collectivism, which reflects cohesiveness in organizations, families, and society (Javidan et al., 2004). Additionally, the Latin America societal cluster reflected the highest focus on team-oriented leadership of all the cultures (Javidan et al., 2004). This is in contrast to a leader-centric view with an emphasis on a leader's goals, which is characteristic of the task theme. There is a lack of other research findings on Latino/ Hispanic students and leadership outcomes; MSL research on differences in socially responsible leadership did not result in any significant differences for Latino/ Hispanic students when compared to students from other racial backgrounds.

Age. In addition to the cross-over interaction effects involving age discussed above, there was one theme, modeling, in which age emerged as a significant main effect with a small effect size. For the modeling theme, students aged 18-23 were more likely to view leadership as involving modeling than their older peers. This suggests that younger students might place a greater focus on leading by example and leading ethically than their older counterparts. Seeing as these students likely have less work and real world experiences than their older peers, this could be viewed also as these younger students being more idealistic when it comes to leadership and older students seeing a lack of role modeling in their previous "real world" experiences.

With the exception of one theme, age was not a significant demographic variable in understanding students' different understandings of leadership. When it does seem to be significant, although with a small effect size, is when it is examined alongside gender. The findings by gender and age for the themes of directing and influencing, which were 
discussed above in the gender section actually suggest that older men and women tend to have more hierarchical understandings of leadership than their younger peers.

Significant findings by age for four of the themes (three of which also involve gender) could suggest potential generational differences. The older generation of students tends to view leadership as more hierarchical, while the younger generation tends to view leadership as involving a greater focus of being a role model or modeling behavior. It is unclear with this finding if this is in fact a generational change or if this is a change based on growing older; without really understanding how students from older generations viewed leadership when they were $18-23$, it is difficult to make any conclusions on this finding.

Parents' formal education. The variable of parents' formal education was a significant predictor for two of the leadership themes. For the direct theme, higher levels of parents' formal education were associated with greater likelihood of viewing leadership as involving directing or being in charge of others. This suggests a potential socioeconomic association with leadership as being more hierarchical for those students from households with more formal education (and potentially higher socioeconomic status). Parents' formal education was also a negative predictor for the personal qualities theme, suggesting that students who come from households with less formal education are more likely to view leadership as involving certain admirable personal qualities or characteristics. Together, these findings could suggest that students with parents who are more formally educated may view leadership as more associated with authority (what role or position the person holds) while students with parents who have less formal education may be more likely to view leadership as involving certain positive personal 
qualities (who the person is versus their title or authority). There is no previous research on socioeconomic status and student leadership understandings or behavioral outcomes in order to better understand this finding.

Conclusion of demographics discussion. While there were some findings related to demographic variables and the different leadership themes, many of these had low effect sizes and should therefore be considered alongside other potential variables that may be relevant in how one views leadership. There were many more themes that resulted in no differences by gender, age, and race than those that did. This suggests that while there are many ways that college students understand leadership, there are not many major differences in how these definitions vary across students' gender, race, or age. Students may be more alike than different in how they view leadership. It could also be that the broad and singular ways of capturing social identities in this research does not account for the true differences and potential multiple identities that may influence how students view leadership.

So far this discussion in this chapter has covered the different ways that college students define leadership and the differences by race, gender, and age of these definitions. The next natural question is what environmental factors might be associated with these different ways of understanding leadership? A discussion on the findings to this question is presented next.

\section{Environmental Findings}

The final research question in this study examined variables that predict the different understandings of leadership. The variables that emerged in the study as significant are discussed below. It is important to note that some of these findings 
reflected the liberal significance level of $10 \%$. As was previously discussed, these findings are reported since this the first study of its kind and this information may provide insight for future examination of the experiences and variables.

Participation in formal leadership programs. The variable of participation in formal leadership programs emerged as a significant negative predictor for the direct theme. This finding that participation in leadership programs was negatively associated with the direct theme is understandable, as there are many leadership programs that seek to help students understand leadership as involving collaboration and demonstrating more relational approaches to leadership (Komives, Dugan, Owen, Slack, \& Wagner, 2011). It is important to note, though, that there are a variety of different types of curricular and co-curricular leadership programs (e.g. community service, social change, ROTC, or management programs) with varying purposes and formats. With this being said, the findings are limited.

Socio-cultural conversations. The variable of socio-cultural conversations was included in this study because of its prominent role in the MSL research in contributing to students' socially responsible leadership outcomes. Socio-cultural conversations were significant predictors for two of the themes, one of which being a negative predictor (modeling) and one being a positive predictor (shared goal). For the modeling theme, less participation in socio-cultural conversations was associated with viewing leadership as involving being a role model. In examining the modeling theme, one might view this theme (leading by example) as quite simple understandings of the concept of leadership; this is not a particularly complex way of viewing leadership. One way of understanding this finding is that the more students engage in conversations with others about 
difference, the less simplistic their understandings of leadership become and the more one views leadership as involving other things than leading by example. It is hard to confidently draw this conclusion since some of the definitions associated with these themes were more complex than the examples provided above (such as morality and leading with one's values), but it is nonetheless one possible way of understanding this finding.

The finding that the socio-cultural conversations variable was a positive predictor for the shared goal theme is consistent with other MSL research on student leadership behaviors. The variable of socio-cultural conversations was a significant, positive contributor to the outcome variable of common purpose in the MSL research (Dugan \& Komives, 2007). Together, these findings suggest that more students have conversations with peers about socio-cultural topics, the more likely they are to view leadership as involving a shared purpose with others and approach leadership with attention to a common purpose. This focus on common purpose and shared goal can be viewed as a more complex and certainly a more relational view of leadership (Komives et al., 2005).

On-campus work. The predictor of working on-campus resulted in somewhat similar findings as participation in socio-cultural conversations. The number of hours working in an on-campus job was a positive predictor for the collaborate theme and a negative predictor for the personal qualities theme. This finding highlights that oncampus employment is associated with students being more likely to view leadership as involving working together and less likely to view leadership as involving certain personal qualities or traits. The on-campus employment category is broad and can encompass a range of positions from being a work-study student in an administrative 
office to being a resident assistant in a residence hall. One could make the assumption that viewing leadership as involving certain personal traits or qualities is a less complex, more leader-centric way of understanding leadership while viewing leadership as being collaborative may be a more complex and relational way of viewing leadership. Similar to the discussion on socio-cultural conversations above, on-campus employment appears to be a predictor for what some might consider a more complex way of viewing leadership. On-campus work was not a significant variable found in the MSL research to date, while off-campus work was found to contribute to students' leadership self-efficacy (Dugan, Garland, Jacoby, \& Gasiorski, 2008). The variable of off-campus involvement was not a significant predictor for any of the themes in this study.

Community service. Participation in community service was a significant predictor for two of the leadership themes. For the modeling theme, community service was a positive predictor, whereby the greater amount of participation in community service, the more likely students were to define leadership as involving being a role model and leading in a way that reflected ethics and morals. This could suggest that students involved in community service look to others in the community as leaders, seeing these people are role models or demonstrating actions that are line with their values. The other finding related to community service indicated that participation in community service was a positive predictor for the direct theme. This finding is perhaps more perplexing, as community service often means making a difference together as a group or without holding formal authority. It is possible that the students may not necessarily associate community service with leadership. Participation in community service can take many forms, from requirements for number of hours to carefully 
constructed service learning experiences, from individual service to group service, and from one-time experiences to longer-term service experiences. These different forms of service could contribute to this finding. This is certainly a finding worth further exploring.

Intercollegiate sports. There were three significant findings for involvement in intercollegiate/ varsity sports. First, participation in intercollegiate athletics is a negative predictor for viewing leadership as involving collaboration. At first this finding might be perplexing, seeing as teams often need to work together in order to be successful.

However, since the category of intercollegiate athletics involves individual sports and team sports, this finding is not quite as perplexing. Students involved in individual sports may be concerned more about individual performance, effort, or achievement than that of the team. It would be interesting to examine the differences in this theme for team versus individual sports in a future study.

Participation in intercollegiate sports was a positive predictor for viewing leadership as involving modeling and accomplishing a task or goal. These findings are not very surprising, as athletes may look up to prominent athletes, coaches, or captains as role models (modeling), and because athletics involves competition and seeking to accomplish a goal, whether it is personal or team (task).

Fraternities and sororities. The student group experience of involvement in fraternities and sororities was a significant negative predictor for the collaborate theme. Students involved in fraternities and sororities were less likely to define leadership as encompassing collaboration as compared to their peers who did not participate in these organizations. Fraternities and sororities often have hierarchical organizational structures 
that emphasize authority, which may influence the students' understandings of leadership as being less collaborative and more based on position. Interestingly, though, involvement in fraternities and sororities had no association (positive or negative) with the more hierarchical and directive approaches to leadership.

Leadership position. The last predictor that I will discuss is the variable of holding a formal leadership position in a student organization, which was a negative predictor for the shared goal theme. This finding suggests that the more often students hold a formal leadership role in a student organization, the more likely they are to not view leadership as involving a shared goal or common purpose. In another research study, when the variable of holding a formal leadership role was examined as contributing factor for the outcome of common purpose, the findings were not significant, meaning that holding a formal leadership role was found to neither positively nor negatively contribute the participants' self-reported scores on common purpose (Haber, 2006a).

The fact that this current study found that holding a formal leadership role was negatively associated with viewing leadership as involving a shared goal reflects more leader-centric ways of viewing leadership when holding formal roles; this is associated with the leader identified stage of the leadership identity development model, whereby the "leader" is in charge and often does not consider the needs or ideas of others in a group (Komives et al., 2005, 2006). This finding suggests those students leading student organizations may not be seeking or valuing shared goals with their group members. One way of understanding this is that some of those students in formal leadership roles 
may be operating in a more leader identified and leader-centric way, whereby they are concerned with task accomplishment and their own goals, but not the goals of the group.

Conclusion of predictors section. This section discussed some of the key findings on the environmental variables that were predictors of the different leadership themes. Many of the variables that were found to be significant predictors did not explain a great deal about the different models and leadership themes; for example, there were no significant predictors for the positive difference theme, which can be seen as a goal of colleges and universities (Association of American Colleges and Universities, 2011). Additionally, some of the variables did not emerge as significant at all for any of the leadership themes; these variables include participation in student organizations, participation in community organizations, student governance, and off-campus work. There were also four leadership themes that did not result in a significant model, meaning that there were no identified predictors for those themes.

As a whole these findings suggest that there is much more to be explained or examined to understand each of these leadership themes and what may lead to students viewing leadership in these different ways. Other college environmental variables, precollege variables, or personal characteristics and differences may shed additional light on college students' understandings of leadership. Findings from the MSL research suggested that students' pre-college experiences play a significant role in students' leadership behaviors; this may, too, be the case for students' understandings of leadership (Dugan \& Komives, 2007). 


\section{Limitations and Delimitations of the Study}

While there are a number of findings in this study, there are some limitations and delimitations worth noting. First, examining students' understandings of leadership through a free-response question on a survey has its limitations. The depth of these definitions could be limited due to the limited nature of gathering data on a potentially complex topic through a written prompt and the students' associated lack of time to reflect on and carefully consider one's definition of leadership. There could also be a disconnect between the written definitions that students provide and their actual understandings of leadership, as some students many not have the words to accurately describe their understanding of leadership. Similarly, because a participant does not mention a certain theme in his or her definition, it does not necessarily mean that he or she does not view leadership that way (i.e. although a participant may define leadership as involving modeling, he or she may not disagree with the idea that leadership involves setting an example).

In examining the survey used in this study, the item's location on the survey (the item in question was the last item on a relatively long survey) leads to additional challenges such as fatigue and resulting effort required to respond in writing rather than through other means. Additionally, many of the questions in the survey imply an approach to leadership through the values of the social change model of leadership; this could influence how students respond to the definition question, particularly since it is the last question on the survey.

There is also a potential limitation associated with utilizing content analysis procedures. Although measures were taken to accurately categorize definitions, the 
coding and quantification processes almost inevitably simplified some of the definitions. By definition, coding, like any form of data reduction, reduces the variance in the data.

While examining a diverse array of students in this study can be viewed as a strength, it can also be viewed as a limitation. Drawing a purposeful sample of students that reflect an equal proportion of racial and gender groups skews the sample. The sample was not reflective of the general student population, and the findings in the study may reflect more the variance of different sub-populations of students rather than the population as a whole.

While this study adds to the literature on the diverse populations, there are also some limitations in examining social identity categories such as race and gender, as they are socially constructed phenomena. A great deal of diversity can exist within each of these groups, and people are made up of multiple identities (Jones \& McEwen, 2000). Examining concepts such as race and gender do not capture the true complexity of human identity and can lead to broad assumptions for a large, diverse group.

In addition to the challenges of capturing the complexity of the individuals in the study, there is also challenge in capturing the complexity of different campus involvement and other experiences in a survey. There is a range of different types of programs that may fall into one variable used in this study. For example, there may be different types of community service experiences, leadership programs, or athletic teams in which students may participate. A broad category may not capture significant aspects of those experiences that may influence how one views leadership. Additionally, students likely have different criteria for gauging their amount of involvement in 
something; how one student understands involvement in an activity much of the time might be different than how another students understands his or her involvement.

Finally, this study is delimited in its scope. This study only provides one angle from which to view students' leadership development: students' own definitions of leadership. This study does not even attempt to explore the different ways that students engage in or practice leadership.

\section{Implications of the Study}

The findings discussed above can inform a number of implications for institutional practice. Some key implications are discussed in this section. Due in part to the small effect size and/ or low significance of some of these findings, many of these implications are broader in scope and suggest additional examination of college campuses and students as opposed to suggesting specific program or policy changes. Much more information is needed before such specific suggestions should be considered.

As was seen in this study and in the larger literature on leadership, there are multiple ways of understanding the concept of leadership and many of these ways are contradictory or have different assumptions on how one engages in leadership and the outcome of leadership. For example, leadership as directing has different assumptions about the role of the leader and the other people in the relationship than understanding leadership as inspiring or collaborating.

Although there was evidence that more contemporary and post-industrial understandings of leadership were present among some college students, the findings from this study suggest that overall, students tended to have more hierarchical and leadercentric understandings of leadership than collaborative understandings of leadership. As 
colleges and universities continue to strive to develop students who are leaders and capable of leading and affecting change (Association of American Colleges and Universities, 2011; Astin \& Astin, 2000), it is imperative that institutional leaders clarify what values around leadership they seek to develop in their students. To accompany this, administrators should examine the programs and student involvement opportunities on their campuses and examine what assumptions and values about leadership they are teaching, promoting, and modeling. Administrators can also engage in conversations with students on campus to better understand how they tend to understand the concept of leadership and what institutional structures or experiences have influenced this. If there is a widespread institutional commitment to leadership, administrators and faculty members might consider developing an agreed-upon set of assumptions or values of leadership that they can promote and use to purposefully design their programs and courses.

This purposeful defining and potential reframing of the concept of leadership on college campuses could help create an environment that supports students' understandings of leadership to be more aligned with institutional goals and contemporary understandings of leadership. Since there is evidence that students' understandings of leadership can be developmental, reframing likely alone will not shift students' understandings, but it is a step toward creating an environment that reflects desired outcomes and understandings of leadership. Promoting values such as collaboration, teamwork, empowering others, and organizational success might also provide an environment from which students can move through the leadership identity development transition from leader identified to leadership differentiated. 
The reframing of leadership on campus to be less about hierarchy and power and more about collaboration and affecting positive change may be more inclusive of women and students of color. In this study and others women were found to view leadership as involving more collaboration and making a positive difference. While literature demonstrates that communities of color tend to be more communal and collaborative, findings from this study suggested that very few significant differences emerged with how students viewed leadership based on race; this could suggest that although students of color tend to have more collaborative approaches and understandings of leadership, this is not reflected in how they think about leadership. This reframing of leadership might make the concept of leadership more accessible to both students of color and women on campus, challenging the more traditional notions of leadership as being associated with power and White men.

Men, though, should not be excluded from the focus of leadership on campuses. The findings from this study around gender suggested that women tended to have understandings of leadership more aligned with contemporary, relational, and postindustrial understandings of leadership than men. This finding suggests that particular attention on promoting leadership as collaborative and involving positive change may be more pertinent for men. Programs and organizations targeting men, such as men's retreats, athletic teams, or fraternities, may be arenas conducive to promoting more contemporary ways of understanding leadership, challenging the more traditional and hierarchical concepts of leadership.

The findings from this study on the environmental variables can help administrators and faculty better address the leadership themes that they hope to develop 
in their graduates. The environmental variables examined in this research provide a number of avenues for potential implications and further examination. There are environmental variables both positively and negatively associated with leadership themes that may be considered desirable or undesirable for an institution. Additionally, for a number of leadership themes, many of the environmental variables were not significant predictors.

Examining the environmental variables that were positively associated with the leadership themes that are more contemporary and may be more in line with institutional outcomes (e.g., collaborate, support, modeling, and shared goal) can provide insight for practice. For example, on-campus employment is a positive predictor for the collaborate theme, participation in community service is a positive predictor for the modeling theme, and participation in socio-cultural conversations is a positive predictor for the leadership theme of shared goal. If these leadership themes reflect aspects of leadership that are in line with an institution's goals or mission, administrators should consider examining opportunities for students to further engage in the significant environmental variables found in the study (in this case, community service, on-campus employment, and sociocultural conversations).

Administrators could also draw implications for practice through examining environmental variables that are either associated with leadership themes that may be viewed as less desirable or negatively associated with desirable leadership themes. For example, the environmental variable of holding a formal leadership role was negatively associated with the shared goal theme. While we cannot discern from this data if students who are less likely to view leadership as involving a shared goal self-select into 
leadership roles or if leadership roles contribute to students' views of leadership as not involving a shared goal, the findings in this study nevertheless suggest that students holding formal leadership roles are less likely than their peers not holding formal leadership roles to view leadership as involving a shared goal. This finding can be viewed as potentially problematic and contradictory to institutional goals, student activities offices, and contemporary leadership models. This is a phenomenon that administrators and faculty should examine and address on their campuses. Some things to consider might be: What training and development opportunities are available to students who hold formal leadership roles and what is included in these trainings? What type of advising are student leaders provided in their role, and how are advisors trained? How are student leaders encouraged to create goals- on their own or as a group? What are the expectations given to group members in terms of their roles and responsibilities within the organization? Are student leadership awards given to individual students for individual accomplishments or to organizations for group accomplishments? What other aspects of the campus environment promote or detract from the idea of shared goals?

Similar questions may be asked for other environmental variables that were negatively associated with leadership themes that reflect more contemporary understandings of leadership or positively associated with more hierarchical understandings of leadership. For example, participation in community service was a positive predictor for the direct theme. This finding and others warrant additional examination at the institution into how the concept of leadership is presented, promoted, and modeled in these experiences. 
A final implication for practice comes from examining the lack of significance of some of the environmental variables for the leadership themes that may be viewed as desirable leadership themes for an institution. For example, student organization involvement and involvement in student government are both environmental variables that were not positively associated with any of the outcomes and participation in leadership programs was only significant for one theme. Similarly, there were no environmental variables that were predictors of the positive difference theme since the model for that theme was not significant. Like the implications provided above, these findings suggest that administrators and faculty purposefully examine the programs, services, and opportunities available to students with particular attention to how leadership is presented, promoted, and modeled.

\section{Recommendations for Further Research}

This study serves as a first step for examining college students' understandings of leadership. Particularly since this was the first study of its kind, there are a number of directions in which this research can continue in order to further the research and increase the understanding of college students' leadership development as it relates to how they understand the concept of leadership. In fact, there are recommendations for future research with the current dataset that was used in this study. This current study examined the environmental variables that predict different leadership themes for college students as whole. This research can be expanded to examine the predictor variables for various subpopulations within the data, such as for women, Asian American students, students with positional leadership roles, student athletes, and students at two-year institutions, to name a few. These different sub-groups of students may experience college differently 
and some experiences may be more salient or significant for some students in terms of how they grow to view leadership. This additional research can help capture conditional effects and help educators better understand the experiences that are specific to different populations with which they more directly work.

Another recommendation for further study with this current dataset is examining the participants' leadership themes in conjunction with their self-assessed leadership outcomes, which in the case of the Multi-Institutional Study of Leadership are socially responsible leadership and leadership efficacy. Examination of students' understandings of leadership alongside their self-assessed leadership behaviors could help examine if there is a relationship between how students view leadership and how they engage in leadership. This research could answer such questions as: Are students who view leadership as involving a shared goal more likely to have higher scores on their selfassessed outcomes scores of common purpose? Are certain leadership themes more associated with higher levels of leadership efficacy than others?

While this study provides an examination of a large number of college students' understandings of leadership, there are limitations in the depth of understanding that was captured through the methods used. This study could only capture to a certain extent the diversity of people and experiences and how this relates to understandings of leadership; there is still much more to be understood. The research did suggest that there are in fact many different ways in which college students understand the concept of leadership, which can be further examined through a more in-depth, qualitative examination of students' understandings of the concept of leadership and influences to this understanding. This could be done through one-on-one interviews or examination of 
course papers or journals. Additionally, this study was limited in how the environmental variables were captured and measured, collapsing a potentially diverse range of environmental involvements into one broader category, such as intercollegiate sports encompassing both individual and team sports and leadership programs being based on various assumptions or models. Further examination of these environmental variables as they relate to students' understandings of leadership could encompass a more nuanced and finely drawn classification and examination of these variables, which could allow for stronger inferences to be made from the findings. This could be done through survey research or qualitative research.

A final direction for future research as a result of this study is a further examination of the four leader and follower/ group leadership themes (collaborate, inspire, influence, and direct). The findings from this study appear to support the research on leadership identity development with specific emphasis on the transition from leader identifiea to leadership differentiated. In the case of this study, many students' leadership definitions reflected multiple themes relating to leader and follower/ group relationships, and a number actually included the contrasting themes of collaborate and direct. This finding can be more purposefully examined with attention to the leadership identity development research and with specific attention to the key transition in the model. Additionally, the different pairings of the 10 leadership themes could be examined to further understand the leadership identity development stages and transitions. By expanding this research through a leadership identity development lens, additional insight into college student development theory more broadly may also emerge. 


\section{Conclusion}

Leadership development continues to be emphasized as an outcome and goal of the college experience (Astin \& Astin, 2000; Keeling, 2004). This study examined the ways in which college students understand and define the concept of leadership. Additionally, demographic and college environmental variables associated with different understandings of leadership were examined. This study sheds light on the varying understandings of leadership within the college student population, which overall tend to emphasize more hierarchical and leader-centric approaches to leadership, and the experiences that are associated with these different understandings of leadership.

Understanding these different ways that college students view leadership and the experiences that either predict or do not predict these different experiences is valuable information for college and university administrators and faculty members as they seek to enhance programs and meet the leadership development goals of the institution. This research suggests that administrators and faculty further examine the ways in which leadership is promoted, taught, celebrated, and modeled on their campuses and look specifically at the programs that seek to develop leadership in their students.

A recent article from the Chronicle for Higher Education discussed the importance of leadership training and development on college campuses; the author suggested that in order to best address the leadership needs of the students, "each institution needs to define leadership in a meaningful way before it can develop a meaningful curriculum for its students" (Greenwald, 2010, December 5). This article, along with the findings from this study, suggests that institutions must not only examine their individual programs, but also the state of leadership in the larger institutional context. 
This research contributes to the understanding of how students view leadership and what may contribute to these understandings. This information along with other current and future research on college student leadership can inform the intentional efforts of colleges and universities in the development of leadership capacity in its students. 


\section{REFERENCES}

Allen, K. E., \& Cherrey, C. (2000). Systemic leadership: Enriching the meaning of our work. Lanham, MD: University Press of America.

Allen, K. E., Stelzner, S. P., \& Wielkiewicz, R. M. (1998). The ecology of leadership: Adapting to the challenges of a changing world. The Journal of Leadership Studies, 5(2), 62-82.

American Indian Research and Policy Institute. (1997). Traditional American Indian leadership: A comparison with U.S. governance. Retrieved from http://www.airpi.org/research/tradlead.html

Antonakis, J., Cianciolo, A. T., \& Sternberg, R. J. (2004). Leadership: Past, present, future. In J. Antonakis, A. T. Cianciolo \& R. J. Sternberg (Eds.), The Nature of Leadership (pp. 3-15). Thousand Oaks, CA: Sage Publications.

Antonio, A. L. (2001). The role of interracial interaction in the development of leadership skills and cultural knowledge and understanding. Research in Higher Education, $42(5), 593-617$.

Arminio, J. L., Carter, S., Jones, S. E., Kruger, K., Lucas, N., Washington, J., et al. (2000). Leadership experiences of students of color. NASPA Journal, 37(3), 496510.

Association of American Colleges and Universities (2011). Association of American Colleges and Universities, from http://www.aacu.org

Astin, A. W. (1991). Assessment for excellence: The philosophy and practice of assessment and evaluation of higher education. New York, NY: Macmillan Publishing. 
Astin, A. W. (1997). What matters in college: Four critical years revisited. San Francisco, CA: Jossey-Bass.

Astin, A. W., \& Astin, H. S. (2000). Leadership reconsidered: Engaging higher education in social change. Battle Creek, MI: W.K. Kellogg Foundation.

Astin, A. W., \& Sax, L. J. (1998). How undergraduates are affected by service participation. Journal of College Student Development, 39(3), 251-263.

Avolio, B. J., \& Gardner, W. L. (2005). Authentic leadership development: Getting to the root of positive forms of leadership. The Leadership Quarterly, 16, 315-338.

Avolio, B. J., \& Gibbons, T. (1988). Developing transformational leaders: A life span approach. In J. Conger \& R. Kanugo (Eds.), Charismatic Leadership: The Elusive Factor in Organizational Effectiveness (pp. 276-308). San Francisco, CA: JosseyBass.

Balon, D. G. (2004). Racial, ethnic, and gender differences among entering college student attitudes toward leadership, culture, and leader self-identification: A focus on Asian Pacific Americans. Unpublished dissertation. College Park, MD: University of Maryland.

Bar-On, R. (1997). The Bar-On emotional quotient inventory (EQ-i): A test of emotional intelligence. Tronoto, Canada: Multi-Health Systems.

Barnett, R. (1988). Does higher education have aims? Journal of Philosophy of Education, 22(2), 239-250.

Barsh, J., Cranston, S., \& Lewis, G. (2009). How remarkable women lead: The breakthrough model for work and life. New York, NY: Crown Business. 
Bass, B. M. (1990). Bass \& Stogdill's handbook of leadership: Theory, research \& managerial applications (3rd ed.). New York, NY: The Free Press.

Bass, B. M. (1995). Concepts of leadership: The beginnings. In J. T. Wren (Ed.), The Leader's Companion (pp. 49-52). New York, NY: The Free Press.

Baxter Magolda, M. B. (1992). Cocurricular influences on college students' intellectual development. Journal of College Student Development, 33(3), 203-213.

Baxter Magolda, M. B. (1999). Creating contexts for learning and self-authorship: Constructive-developmental pedagogy. Nashville, TN: Vanderbilt University Press.

Baxter Magolda, M. B. (2001). Making their own way: Narratives for transforming higher education to promote self-development. Sterling, VA: Stylus.

Bordas, J. (2007). Salsa, soul, and spirit: Leadership for a multicultural age. San Francisco, CA: Berrett Koehler.

Boyatzis, R. (1998). Transforming qualitative information. Thousand Oaks, CA: SAGE Publications.

Burns, J. M. (1978). Leadership. New York, NY: Harper \& Row.

Chickering, A. W., \& Reisser, L. (1993). Education and identity (2 ed.). San Francisco, CA: Jossey-Bass.

Cilente, K. (2009). An overview of the social change model of leadership. In S. R. Komives \& W. Wagner (Eds.), Leadership for a better world: Understanding the social change model of leadership development (pp. 43-77). San Francisco, CA: Jossey-Bass.

Cohen, J. (1992). A power primer. Psychological Bulletin, 112(1), 155-159. 
Cohen, L., Manion, L., \& Morrison, K. (2007). Research methods in education (6th ed.). New York, NY: Routledge.

Cooper, D. L., Healy, M. A., \& Simpson, J. (1994). Student development through involvement: Specific changes over time. Journal of College Student Development, 35(2), 98-102.

Council for the Advancement of Standards in Higher Education (2009). CAS professional standards for higher education (7th ed.). Washington, DC: Author.

Cress, C. M., Astin, H. S., Zimmerman-Oster, K., \& Burkhardt, J. C. (2001). Developmental outcomes of college students' involvement in leadership activities. Journal of College Student Development, 42(1), 15-27.

Creswell, J. W. (2003). Research design: Qualitative, quantitative, and mixed methods approaches (2nd ed.). Thousand Oaks, CA: Sage Publications.

Creswell, J. W., \& Plano Clark, V. L. (2007). Designing and conducting mixed methods research. Thousand Oaks, CA: Sage Publications.

Daloz Parks, S. (2005). Leadership can be taught. Boston, MA: Harvard Business School Press.

Day, D. V. (2001). Leadership development: A review in context Leadership Quarterly, 11(4), 581-613.

Day, D. V., Harrison, M. M., \& Halpin, S. (2008). An integrative approach to leader development: Connecting adult development, identity, and expertise. New York, NY: Routledge.

DiPaolo, D. G. (2002). Voices of leadership. Ann Arbor, MI: University of Michigan. 
Dugan, J. P. (2008). Group involvement experiences in college: Identifying a thematic taxonomy. Unpublished dissertation. University of Maryland, College Park, MD.

Dugan, J. P. (2011). Research on college student leadership development. In S. R. Komives, J. P. Dugan, J. E. Owen, C. Slack \& W. Wagner (Eds.), The Handbook for Student Leadership Development (pp. 59-84). San Francisco, CA: JosseyBass.

Dugan, J. P., \& Haber, P. (2007). Examining the influences of formal leadership programs on student educational gains. Concepts \& Connections, 15(3), 7-10.

Dugan, J. P., \& Komives, S. R. (2007). Developing leadership capacity in college students: Findings from a national study. College Park, MD: National Clearinghouse for Leadership Programs.

Dugan, J. P., \& Komives, S. R. (2009). Elements of 2009 MSL methods. Unpublished research report. College Park, MD: National Clearinghouse for Leadership Programs.

Dugan, J. P., \& Komives, S. R. (2010). Influences on college students' capacities for socially responsible leadership. Journal of College Student Development, 51(5), $525-549$.

Dugan, J. P., Komives, S. R., \& Segar, T. C. (2008). College student capacity for socially responsible leadership: Understanding norms and influences of race, gender, and sexual orientation. NASPA Journal, 45(4), 475-500.

Field, A. (2009). Discovering statistics using SPSS (3rd ed.). Thousand Oaks, CA: SAGE. 
Fischer, D. V., Overland, M., \& Adams, L. (2010). Leadership attitudes and beliefs of incoming first-year college students. Journal of Leadership Education, 9(1), 1-16.

Gilligan, C. (1977). In a different voice: Women's conceptions of self and morality. Harvard Educaitonal Review, 47, 481-517.

Goethals, G. R., \& Sorenson, G. J. (2007). The quest for a general theory of leadership. Northampton, MA: Edward Elgar Publishing.

Goethals, G. R., Sorenson, G. J., \& Burns, J. M. (2004). Encylopedia of leadership. Thousand Oaks, CA: Sage Publications.

Goleman, D. (1995). Emotional intelligence. New York, NY: Bantam Books.

Gonyea, R. M. (2005). Self-reported data in institutional research: Review and recommendations. In P. D. Umbach (Ed.), Survey Research Emerging Issues: New Directions for Institutional Research no. 127. San Francisco, CA: JosseyBass.

Greenleaf, R. K. (1977). Servant leadership. Mahwah, NJ: Paulist Press.

Greenleaf, R. K. (2002). Servant leadership: A journey into the nature of legitimate power and greatness. Mahwah, NJ: Paulist Press.

Greenleaf, R. K. (2008). The servant as leader. Indianapolis, IN: The Robert K. Greenleaf Center.

Greenwald, R. (2010, December 5). Today's students need leadership training like never before. The Chronicle of Higher Education. Retrieved from http:/chronicle.com/article/Todays-Students-Need/125604/

Haber, P. (2006a). Cocurricular involvement, formal leadership roles, and leadership education: Experiences predicting college student socially responsible leadership 
outcomes. Unpublished master's thesis. University of Maryland, College Park, MD.

Haber, P. (2006b). Structure, design, and models of student leadership programs. In S. R. Komives, J. P. Dugan, J. E. Owen, C. Slack \& W. Wagner (Eds.), Handbook for Student Leadership Programs (pp. 29-51). College Park, MD: National Clearinghouse for Leadership Programs.

Haber, P. (2011). Formal leadership program models. In S. R. Komives, J. P. Dugan, J. E. Owen, C. Slack \& W. Wagner (Eds.), The Handbook for Student Leadership Programs (pp. 231-258). San Francisco, CA: Jossey-Bass.

Heifetz, R. A. (1994). Leadership without easy answers. Cambridge, MA: Harvard University Press.

Heifetz, R. A., Grashow, A., \& Linsky, M. (2009). The practice of adaptive leadership. Boston, MA: Harvard Business Press.

Higher Education Research Institute (1996). A social change model of leadership development (3rd ed.). Los Angeles, CA: Higher Education Research Institute.

Hinkle, D. E., Wiserma, W., \& Jurs, S. G. (2003). Applied statistics for the behavioral sciences (5th ed.). Boston, MA: Houghton Mifflin.

Hobbs, E., \& Spencer, S. (2002). Perceived change in leadership skills as a result of the Wilderness Education Association wilderness stewardship course. Paper presented at the Wilderness Education Association 2002 National Conference, Bradford Woods, IN.

Hosmer, D. W., \& Lemeshow, S. (2000). Applied logistic regression. New York, NY: Wiley. 
Javidan, M., House, R. J., \& Dorfman, P. W. (2004). A nontechnical summary of GLOBE findings. In R. J. House, P. J. Hanges, M. Javidan, P. W. Dorfman \& V. Gupta (Eds.), Culture, leadership, and organizations: The GLOBE study of 62 societies. Thousand Oaks, CA: Sage Publications.

Jones, S. R., \& McEwen, M. K. (2000). A conceptual model of multiple dimensions of identity. Journal of College Student Development, 41(4), 405-414.

Keeling, R. P. (2004). Learning reconsidered: A campus-wide focus on the student experience. Washington, DC: National Association of Personnel Administrators and the American College Personnel Association.

Kegan, R. (1994). In Over Our Heads: The Mental Demands of Modern Life. Cambridge, MA: Harvard University Press.

Kellerman, B. (2008). Followership: How followers are creating change and changing leaders. Boston, MA: Harvard Business Press.

Kelley, R. E. (1995). In praise of followers. In J. T. Wren (Ed.), The Leader's Companion (pp. 193-204). New York, NY: The Free Press.

Kezar, A. J., Carducci, R., \& Contreras-McGavin, M. (2006). Rethinking the " $L$ " world in higher education: The revolution in research on leadership. ASHE Higher Education Report (Vol. 31, no. 6). San Francisco, CA: Jossey-Bass.

Kezar, A. J., \& Moriarty, D. (2000). Expanding our understanding of student leadership development: A study exploring gender and ethnic identity. Journal of College Student Development, 4l(1), 55-69.

Klenke, K. (2008). Qualitative research in the study of leadership. Bingley, UK: Emerald Group. 
Komives, S. R. (2011). Advancing leadership education. In S. R. Komives, J. P. Dugan, J. E. Owen, C. Slack \& W. Wagner (Eds.), The Handbook for Student Leadership Development (pp. 1-34). San Francisco, CA: Jossey-Bass.

Komives, S. R., \& Dugan, J. P. (2010). Contemporary leadership theories. In R. A. Couto (Ed.), Political and civic leadership: A reference handbook (pp, 111-120). Thousand Oaks, CA: Sage.

Komives, S. R., Dugan, J. P., \& Owen, J. E. (2009). MSL 2009 school report. College Park, MD: National Clearinghouse for Leadership Programs.

Komives, S. R., Dugan, J. P., Owen, J. E., Slack, C., \& Wagner, W. (Eds.). (2006). Handbook for student leadership programs. College Park, MD: National Clearinghouse for Leadership Programs.

Komives, S. R., Dugan, J. P., Owen, J. E., Slack, C., \& Wagner, W. (Eds.). (2011). Handbook for student leadership development (2nd ed.). San Franciscso, CA: Jossey-Bass.

Komives, S. R., Longerbeam, S. D., Owen, J. E., Mainella, F., \& Osteen, L. (2006). A leadership identity development model: Applications from a grounded theory. Journal of College Student Development, 47(4), 401-418.

Komives, S. R., Lucas, N., \& McMahon, T. R. (2007). Exploring leadership: For college students who want to make a difference (2nd ed.). San Francisco, CA: JosseyBass.

Komives, S. R., Owen Casper, J., Longerbeam, S. D., Mainella, F., \& Osteen, L. (2004). Leadership identity development. Concepts \& Connections, 12(3), 1-6. 
Komives, S. R., Owen, J. E., Longerbeam, S. D., Mainella, F. C., \& Osteen, L. (2005). Developing a leadership identity: A grounded theory. Journal of College Student Development, 46(6), 593-611.

Komives, S. R., \& Wagner, W. (2009). Leadership for a better world: Understanding the social change model of leadership development. San Francisco, CA: Jossey-Bass.

Kouzes, J. M., \& Posner, B. Z. (1987). The leadership challenge. San Francisco, CA: Jossey-Bass.

Kouzes, J. M., \& Posner, B. Z. (2008). The leadership challenge (4th ed.). San Francisco: San Francisco, CA.

Krippendorff, K. (2004). Content analysis: An introduction to its methodology (2nd ed.). Thousand Oaks, CA: SAGE.

Kuh, G. D., \& Lund, J. P. (1994). What students gain from participating in student government. In M. C. Terrell \& M. J. Cuyjet (Eds.), Developing student government leadership (Vol. 66, pp. 5-17). San Francisco, CA: Jossey-Bass.

Lord, R. G., Brown, D. J., Harvey, J. L., \& Hall, R. J. (2001). Contextual contraints on prototype generation and their multilevel consequences for leadership perceptions. The Leadership Quarterly, 12, 311-338.

Lord, R. G., \& Hall, R. J. (2005). Identity, deep structure and the development of leadership skill. The Leadership Quarterly, 15, 591-615.

Martin, R. M. (1987). The meaning of language. Cambridge, MA: The MIT Press.

MedCalc (2010). Logistic regression, from http://www.medcalc.be/manual/logistic regression.php 
Meier, H. (2010). Perception of leadership of Alfred University students: An analysis of qualitative data from the multi-institutional survey of leadership. Unpublished senior thesis. Alfred University.

Merrill-Sands, D., Kickul, J., \& Ingols, C. (2005). Women pursuing leadership and power: Challenging the myth of the "opt out revolution". Center for Gender in Organizations Insights, 20, 1-4.

Morgan, G. (2006). Images of organization (updated ed.). Thousand Oaks, CA: Sage Publications.

Multi-Institutional Study of Leadership (MSL) (2009). Multi-Institutional Study of Leadership, from http://leadershipstudy.net/

National Center for Education Statistics (2009). Digest of education statistics, 2008 (Chapter 3). Retrieved from http://nces.ed.gov/pubsearch/pubsinfo.asp?pubid $=2009020$

National Clearinghouse for Leadership Programs (2008). National Clearinghouse for Leadership Programs Retrieved 29 November 2008, from http://nclp.umd.edu/

Northouse, P. G. (2007). Leadership: Theory and practice (4th ed.). Thousand Oaks, CA: Sage Publications.

Owen, J. E., \& Komives, S. R. (2007). Does credit matter? Examining the effects of curricular leadership programs. Concepts \& Connections, 15(3), 4-6.

Pallant, J. (2005). SPSS survival manual (2nd ed.). New York, NY: Open University Press.

Pascarella, E. T. (2006). How college affects students: Ten directions for future research. Journal of College Student Development, 47(5), 508-520. 
Pascarella, E. T., \& Terenzini, P. T. (2005). How college affects students: A third decade of research (Vol. 2). San Francisco, CA: Jossey-Bass.

Peduzzi, P., Concato, J., Kemper, E., Holford, T. R., \& Feinstein, A. R. (1996). A simulation study of the number of events per variable in logistic regression analysis. Journal of Clinical Epidemiology, 49(12), 1373-1379.

Perry, W. G. (1981). Cognitive and ethical growth: The making of meaning. In A. W. Chickering (Ed.), The Modern American College (pp. 76-116). San Francisco, CA: Jossey-Bass.

Pondy, L. R. (1989). Leadership is a language game. In H. J. Leavitt, L. R. Pondy \& D. M. Boje (Eds.), Readings in Managerial Psychology (4th ed.). Chicago, IL: The University of Chicago Press.

Posner, B. Z., \& Brodsky, B. (1993). The leadership practices of effective RAs. Journal of College Student Development, 34, 300-304.

Posner, B. Z., \& Brodsky, B. (1994). Leadership practices of effective student leaders: Gender makes no difference. NASPA Journal, 31(2), 113-120.

Posner, B. Z., \& Rosenberger, J. (1997). Effective orientation advisors are also leaders. NASPA Journal, 35(1), 46-56.

Renn, K. A., \& Bilodeau, B. L. (2004). Leadership identity development among lesbian, gay, bisexual, and transgender student leaders. NASPA Journal, 42(3), 342-367.

Renn, K. A., \& Shang, P. (Eds.). (2008). Biracial and multiracial students: New directions for student services. San Francisco, CA: Jossey-Bass.

Roberts, D. C. (2003). Crossing the boundaries in leadership program design. In C. Cherrey, J. J. Gardiner \& N. S. Huber (Eds.), Building Leadership Bridges 2003 
(pp. 137-149). College Park, MD: International Leadership Association \& Center for Creative Leadership.

Roberts, D. C. (2007). Deeper learning in leadership: Helping college students find the potential within. San Francisco, CA: Jossey Bass.

Rohs, F. R. (2002). Improving the evaluation of leadership programs: Control response shift. Journal of Leadership Education, 1(2), 50-61.

Romano, C. R. (1996). A qualitative study of women student leaders. Journal of College Student Development, 37(6), 676-683.

Rost, J. C. (1991). Leadership for the twenty-first century. Westport, CT: Praeger.

Salovey, P., \& Mayer, J. D. (1990). Emotional intelligence. Imagination, Cognition and Personality, 9(3), 676-683.

Schein, E. H. (2004). Organizational culture and leadership (3rd ed.). San Francisco, CA: Jossey-Bass.

Senge, P. M. (2006). The fifth discipline: The art \& practice of the learning organization. New York, NY: Doubleday Currency.

Senge, P. M., Scharmer, C. O., Jaworski, J., \& Flowers, B. S. (2004). Presence: Human purpose and the field of the future. New York, NY: Society for Organization Learning.

Shankman, M. L., \& Allen, S. J. (2008). Emotionally intelligent leadership: A guide for college students. San Francisco, CA: Jossey-Bass.

Shankman, M. L., Haber, P., Facca, T. M., \& Allen, S. J. (2010). Gender and leadership through the lens of emotionally intelligent leadership. Leadership Review, 10, 88103. 
Shertzer, J. E., \& Schuh, J. H. (2004). College student perceptions of leadership: Empowering and constraining beliefs. NASPA Journal, 42(1), 111-131.

Smith, J. L. (2009). A study of the leadership styles and beliefs of students at Athens State University. Unpublished dissertation. The University of Alabama.

Sorenson, G. J. (2007). An intellectual history of leadership: The role of James MacGregor

Burns. In R. Couto (Ed.), Reflections on Leadership (pp. 19-30). Lanham, MD: University Press of America.

Tabachnick, B. G., \& Fidell, L. S. (2001). Using multivariate statistics (4th ed.). Boston, MA: Allyn and Bacon.

The National Center for Higher Education Management Systems (2009). NCHEMS Report on HIgher Education Inequality, from http://www.higheredinfo.org/raceethnicity/

Thompson, M. D. (2006). Student leadership process development: An assessment of contributing college resources. Journal of College Student Development, 47(3), 343-350.

Torbert, B. (2004). Action inqiury: The secret of timely and transforming leadership. San Francisco, CA: Berrett-Koehler Publishers.

Tyree, T. M. (1998). Designing an instrument to measure socially responsible leadership using the social change model of leadership development. Unpublished dissertation. University of Maryand, College Park, MD.

Wabash College (2009). Wabash National Study 2006-2009, from http://www.liberalarts.wabash.edu/study-overview/ 
Wagner, W. (2011). Considerations of student development in leadership. In S. R. Komives, J. P. Dugan, J. E. Owen, C. Slack \& W. Wagner (Eds.), The Handbook for Student Leadership Programs (pp. 85-107). San Francisco, CA: Jossey-Bass.

Walpole, M. (2003). Socioeconomic status and college: How SES affects college experiences and outcomes. The Review of Higher Education, 27(1), 45-73.

Western, S. (2008). Leadership: A critical text. London, England: Sage.

Wheatley, M. J. (1994). Leadership and the new science: Learning about organization from an orderly universe (3rd ed.). San Francisco, CA: Berrett-Koehler Publishers.

Wheatley, M. J. (2006). Leadership and the new science: Discovering order in a chaotic world (3rd ed.). San Francisco, CA: Berrett-Koehler Publishers.

Whitney, R. (2010). Mission and leadership: DePaul and multi-institutional study of leadership. Paper presented at the International Leadership Association, Boston, MA.

Wielkiewicz, R. M. (2000). The leadership attitudes and beliefs scale: An instrument for evaluating college students' thinking about leadership and organizations. Journal of College Student Development, 41(3), 337-349.

Wielkiewicz, R. M. (2002). Validity of the leadership attitudes and beliefs scale:

Relationships with personality, communal orientation, and social desirability. Journal of College Student Development, 43(1), 108-118.

Zimmerman-Oster, K., \& Burkhardt, J. C. (1999). Leadership in the making: Impact and insights from leadership development programs in U.S. colleges and universities. Battle Creek, MI: W.K. Kellogg Foundation. 


\section{APPENDIX A: EMAIL INVITATION}

[Month, Day, Year]

Dear [Student]:

The [Institution Name] has been selected to participate in a national study which will focus on student leadership experiences in college. As an institution, we are very interested in developing leadership among our graduate and hope to learn more about our students' experiences through participation in this study.

You have been selected to participate in this national study! Your participation is VERY important and will contribute a great deal to understanding the college student experience at both [Institution Name] and within the context of higher education. This is an amazing opportunity for the [Institution Name] and we hope you are excited to participate.

Participation is easy and just by completing the survey you will automatically be eligible for numerous prizes including drawings for numerous $\$ 100$ gift cards as well as [other incentives listed here].

What does it mean to participate?

Participation in the study will involve completing and online survey/ questionnaire about your college involvements and your thoughts about leadership.

The survey should take approximately 20 minutes to complete.

Your response is completely confidential. Only the researcher will be able to attach your name to your response so please be candid and honest.

Participation is of course, totally voluntary.

We encourage you now to click on the link below and indicate your consent to participate in the survey. If you have any questions, please contact [Institutional Contact Name, Email and Phone Number]

Thank you for your participation!

CLICK HERE TO BEGIN

[link] 


\title{
APPENDIX B: INFORMED CONSENT FORM
}

\author{
Consent Form
}

\begin{tabular}{|c|c|}
\hline Project Title & Multi-institutional Study of Leadership (MSL) \\
\hline $\begin{array}{l}\text { Why is this research } \\
\text { being done? }\end{array}$ & $\begin{array}{l}\text { This is a research project being conducted by the National Clearinghouse for } \\
\text { Leadership Programs (NCLP) at Iname of institution]. The purpose of this research } \\
\text { project is to enhance knowledge regarding college student leadership } \\
\text { development as well as the influence of higher education on the development of } \\
\text { leadership capacities. }\end{array}$ \\
\hline $\begin{array}{l}\text { What will I be asked } \\
\text { to do? }\end{array}$ & $\begin{array}{l}\text { You have been selected to respond to an online survey about student leadership } \\
\text { development. This survey will take about } 20 \text { minutes and asks questions about } \\
\text { your experiences before and after you started colfege. For example, you will be } \\
\text { asked about campus and community involvement, mentors, your experiences in } \\
\text { engaging whth other students, and other topics. You may leave it at any time and } \\
\text { resume from your last completed response. You may also skip any questions that } \\
\text { you are not comfortable answering. }\end{array}$ \\
\hline $\begin{array}{l}\text { What are the risks of } \\
\text { this research? }\end{array}$ & There are no known risks associated with participating in this research project. \\
\hline $\begin{array}{l}\text { What are the } \\
\text { benefits of this } \\
\text { research? }\end{array}$ & $\begin{array}{l}\text { This research is not designed to help you personally, but the results may help the } \\
\text { investigator learn more about leadership development at [name of institution] } \\
\text { and across the country. We hope that, in the future, other people might benefit } \\
\text { from this study through improved understanding of college student leadership } \\
\text { development. }\end{array}$ \\
\hline $\begin{array}{l}\text { Do I have to be in } \\
\text { this research? May I } \\
\text { stop participating at } \\
\text { any time? }\end{array}$ & $\begin{array}{l}\text { Your participation in this research is completely voluntary. You may choose not to } \\
\text { take part at all. If you decide to participate in this research, you may stop } \\
\text { participating at any time. If you decide not to participate in this study or if you } \\
\text { stop participating at any time, you will not be penalized or lose any benefits to } \\
\text { which you otherwise qualify. }\end{array}$ \\
\hline $\begin{array}{l}\text { What about } \\
\text { confidentiallty? }\end{array}$ & $\begin{array}{l}\text { We will do our best to keep your personal information confidential. To help } \\
\text { protect your confidentiality, The Center for Student Studies (CSS), an independent } \\
\text { survey-research company, has been hired to maintain all study records. They will } \\
\text { use password-protected, 128-bit SSL-encrypted technology to receive, transmit, } \\
\text { and store data. } \\
\text { you have been assigned a randomly generated, one-time-use I0 number as a code } \\
\text { to access the survey, so that your responses will be separated from any } \\
\text { information that could possibly identify you. Your name will not be included on } \\
\text { the surveys and other collected data. Through the use of an identification key, } \\
\text { the researchers will be able to link your survey to your identity; only the } \\
\text { researcher will have access to the identification key. } \\
\text { The data from this study will be retained in a secure repository for future research } \\
\text { purposes. Records will be kept confidential to the extent provided by federal, } \\
\text { state, and local law. CSS will retain your contact information-in a separate, } \\
\text { secure file from data-in order to send you follow up emails if necessary. You may } \\
\text { be contacted in future years for a follow-up study. Upon completion of the study, } \\
\text { all names and e-mail addresses will be destroyed. }\end{array}$ \\
\hline & \\
\hline
\end{tabular}


APPENDIX C: PARTICIPANT DEMOGRAPHICS IN CURRENT STUDY AS

COMPARED TO RANDOM MSL SAMPLE

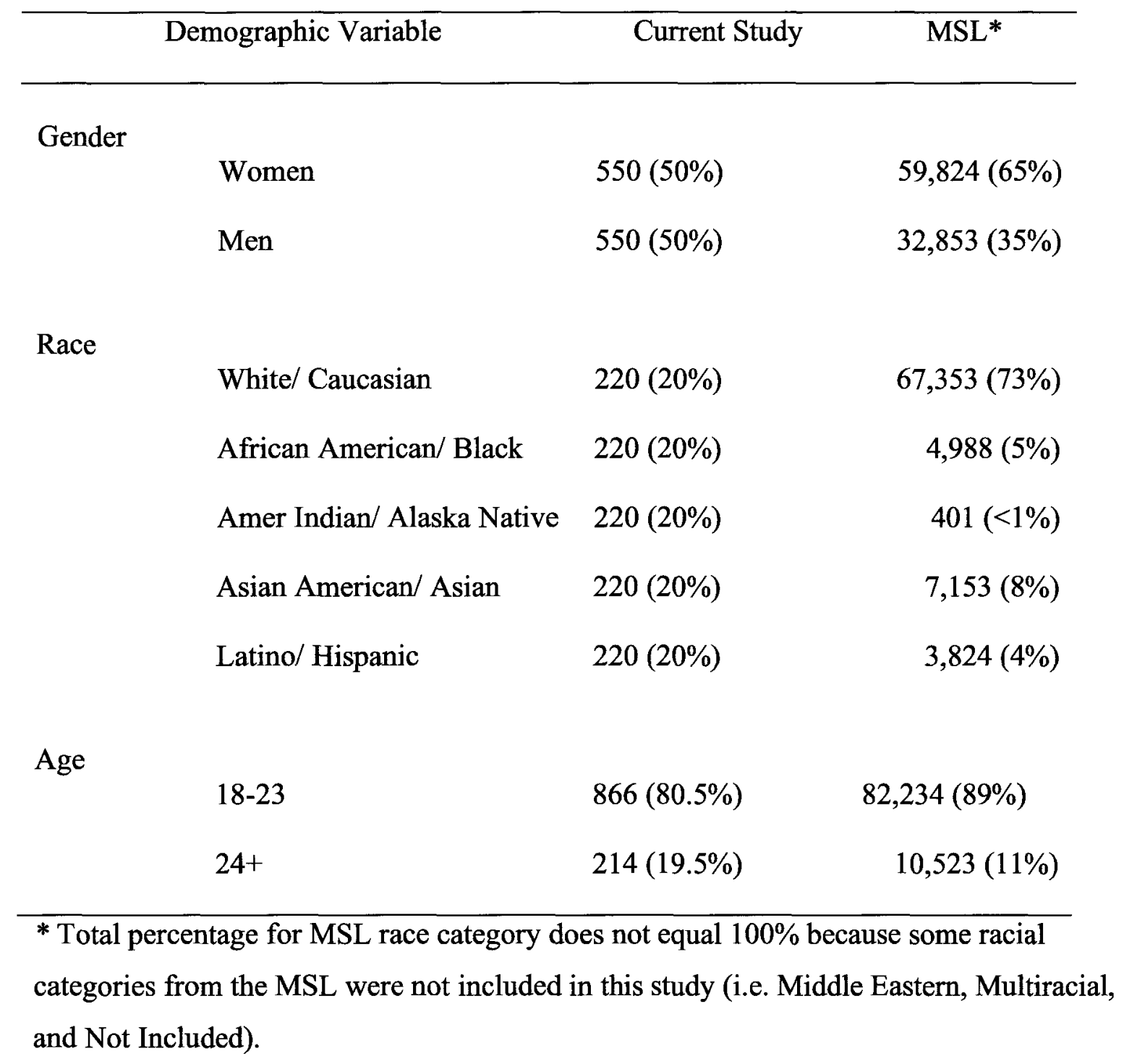




\section{APPENDIX D: THEME CODEBOOK AND INTERRATER INSTRUCTIONS}

\section{A Few Notes Before You Begin}

1. Please read each theme in its entirety before coding.

2. Look at the response/ definition as a whole and in the overall context of what was written when identifying themes. Just because a word is there that may fit into a theme, the overall meaning may not actually reflect that theme.

3. A definition can fall into many themes, even if they might seem contradictory (ex. task and relationship). You may assign multiple themes to one definition.

4. Sample key descriptors are provided- but this is not an exhaustive list. If you feel that other descriptors fit as well feel free to add them to this list.

5. I welcome any and all feedback on these themes. If you think any of them are too broad, not clear, or missing please let me know!

6. When you apply themes to the definitions in the Excel spreadsheet you can put the number " 1 " in that cell. There is an example provided.

7. If you feel that none of the themes are applicable or not substantial enough, you may select the theme "Unusable". 


\begin{tabular}{|c|c|c|c|c|}
\hline Label & $\begin{array}{l}\text { Definition of } \\
\text { Theme }\end{array}$ & $\begin{array}{l}\text { Key } \\
\text { Descriptors }\end{array}$ & $\begin{array}{l}\text { Exclusions or } \\
\text { Qualifications for } \\
\text { Identifying Themes }\end{array}$ & $\begin{array}{l}\text { Example of } \\
\text { Positive Cases } \\
\text { of the Theme }\end{array}$ \\
\hline $\begin{array}{l}\text { 1. } \\
\text { Collaborate/ } \\
\text { Work } \\
\text { Together }\end{array}$ & $\begin{array}{l}\text { This theme } \\
\text { involves people } \\
\text { working together } \\
\text { through } \\
\text { collaboration, } \\
\text { including others' } \\
\text { ideas, and } \\
\text { knowing that one } \\
\text { must follow as } \\
\text { well as lead. } \\
\text { While there may } \\
\text { still be mention } \\
\text { of leader and } \\
\text { follower as } \\
\text { distinct roles, the } \\
\text { nature of } \\
\text { interaction } \\
\text { involves } \\
\text { collaboration. }\end{array}$ & $\begin{array}{ll} & \text { Collaborati } \\
\text { ng } \\
\text { - } & \text { Working } \\
\text { together } \\
\text { - Sharing } \\
\text { tasks and } \\
\text { responsibili } \\
\text { ties } \\
\text { - Following } \\
\text { as well as } \\
\text { leading }\end{array}$ & $\begin{array}{l}\text { Although shared goal } \\
\text { can suggest a } \\
\text { collaboration, it is } \\
\text { only included in this } \\
\text { theme if there is a } \\
\text { direct inclusion of } \\
\text { working together or } \\
\text { collaborating. There } \\
\text { is a separate category } \\
\text { for shared goal. }\end{array}$ & $\begin{array}{l}\text { It means } \\
\text { leading the } \\
\text { team to } \\
\text { perform as } \\
\text { best they can, } \\
\text { taking into } \\
\text { account each } \\
\text { individual } \\
\text { members } \\
\text { assets and } \\
\text { what they can } \\
\text { contribute to } \\
\text { the group. } \\
\\
\text { Leadership is } \\
\text { the act of } \\
\text { bringing } \\
\text { people together } \\
\text { to work on a } \\
\text { common goal. }\end{array}$ \\
\hline $\begin{array}{l}\text { 2. Inspire/ } \\
\text { Motivate }\end{array}$ & $\begin{array}{l}\text { This theme } \\
\text { involves an } \\
\text { emphasis on the } \\
\text { interaction } \\
\text { between a leader } \\
\text { and others in the } \\
\text { group through } \\
\text { getting people } \\
\text { involved, } \\
\text { activated, and } \\
\text { engaged in the } \\
\text { process. This } \\
\text { goes beyond } \\
\text { being in charge } \\
\text { of people or } \\
\text { influencing } \\
\text { them. There is } \\
\text { some evidence } \\
\text { of motivating, } \\
\text { empowering, or } \\
\text { inspiring others. }\end{array}$ & $\begin{array}{ll}\text { - } & \text { Inspire } \\
\text { - } & \text { Motivate } \\
\text { - } & \text { Empower } \\
\text { - Teach }\end{array}$ & $\begin{array}{l}\text { Interaction that is } \\
\text { more top-down within } \\
\text { activating and } \\
\text { engaging people, such } \\
\text { as guiding, leading, or } \\
\text { influencing, are not } \\
\text { included in this theme } \\
\text { and instead are in } \\
\text { theme three. } \\
\text { This theme is different } \\
\text { from theme five in } \\
\text { that this is focusing on } \\
\text { motivating or even } \\
\text { supporting a group; } \\
\text { theme five focuses on } \\
\text { helping, supporting, } \\
\text { or mentoring an } \\
\text { individual, related } \\
\text { more to that person } \\
\text { than a the leadership } \\
\text { process or outcome. }\end{array}$ & $\begin{array}{l}\text { Leadership } \\
\text { means to be } \\
\text { able to inspire } \\
\text { others, and to } \\
\text { be able to put } \\
\text { ideas into } \\
\text { motion. } \\
\text { Leadership is } \\
\text { the ability to } \\
\text { motivate } \\
\text { others towards } \\
\text { a common goal. }\end{array}$ \\
\hline
\end{tabular}




\begin{tabular}{|c|c|c|c|c|}
\hline Label (cont.) & $\begin{array}{l}\text { Definition of } \\
\text { Theme }\end{array}$ & Key Descriptors & $\begin{array}{l}\text { Exclusions or } \\
\text { Qualifications } \\
\text { for Identifying } \\
\text { Themes }\end{array}$ & $\begin{array}{l}\text { Example of } \\
\text { Positive Cases of } \\
\text { the Theme }\end{array}$ \\
\hline $\begin{array}{l}\text { 3. Influence/ } \\
\text { Guide/ Lead/ } \\
\text { Others } \\
\text { Follow You }\end{array}$ & $\begin{array}{l}\text { This theme } \\
\text { involves } \\
\text { mention of a } \\
\text { leader and other } \\
\text { people or a } \\
\text { group in a } \\
\text { transactional or } \\
\text { top-down } \\
\text { manner, } \\
\text { whereby the } \\
\text { leader leads, } \\
\text { influences, or } \\
\text { guides others. } \\
\text { The emphasis is } \\
\text { on having others } \\
\text { follow a leader. } \\
\text { There is not a } \\
\text { negative or } \\
\text { controlling } \\
\text { focus in this } \\
\text { theme. }\end{array}$ & $\begin{array}{ll} & \text { Influence } \\
\text { - } & \text { Lead } \\
\text { - } & \text { Guide [a } \\
& \text { group] } \\
\text { - } & \text { Others follow } \\
& \text { you } \\
\text { - } & \text { Provide } \\
& \text { direction }\end{array}$ & $\begin{array}{l}\text { A focus on } \\
\text { controlling or } \\
\text { directing others } \\
\text { is not included } \\
\text { in this theme- } \\
\text { that would be in } \\
\text { the fourth } \\
\text { theme. A focus } \\
\text { on providing } \\
\text { direction, } \\
\text { though, would } \\
\text { be included in } \\
\text { this theme. }\end{array}$ & $\begin{array}{l}\text { Taking the initiative } \\
\text { to try to help others } \\
\text { and provide } \\
\text { direction when } \\
\text { needed and wanted } \\
\text { to help add to the } \\
\text { greater good. } \\
\text { Leadership means } \\
\text { that you can actually } \\
\text { lead a group of } \\
\text { people into } \\
\text { accomplishing a } \\
\text { goal or task. }\end{array}$ \\
\hline $\begin{array}{l}\text { 4. Direct/ } \\
\text { Control/In } \\
\text { Charge }\end{array}$ & $\begin{array}{l}\text { This theme } \\
\text { involves } \\
\text { mention of other } \\
\text { people or a } \\
\text { group in a } \\
\text { strictly } \\
\text { transactional or } \\
\text { top- down } \\
\text { manner, which } \\
\text { may or may not } \\
\text { have a negative } \\
\text { connotation or } \\
\text { focus. The } \\
\text { emphasis is on } \\
\text { controlling, } \\
\text { directing, } \\
\text { exerting } \\
\text { authority or } \\
\text { using power. }\end{array}$ & $\begin{array}{ll}\text { - } & \text { Directing/ } \\
\text { Dictating } \\
\text { - } & \text { Being in } \\
\text { charge } \\
\text { - Taking charge } \\
\text { of a person, } \\
\text { group, or } \\
\text { situation } \\
\text { - Having control } \\
\text { - Power } \\
\text { - Emphasis on } \\
\text { role, authority }\end{array}$ & $\begin{array}{l}\text { As is discussed } \\
\text { above for theme } \\
\text { three, providing } \\
\text { direction is } \\
\text { associated with } \\
\text { theme three, } \\
\text { while directing } \\
\text { someone is } \\
\text { associated with } \\
\text { theme four. }\end{array}$ & $\begin{array}{l}\text { Leadership means } \\
\text { that there is some } \\
\text { form of } \\
\text { authority/or leader } \\
\text { that takes charge of } \\
\text { whatever a task may } \\
\text { be. } \\
\text { Leadership is the } \\
\text { ability and action of } \\
\text { directing others } \\
\text { towards a common } \\
\text { goal or purpose. }\end{array}$ \\
\hline
\end{tabular}




\begin{tabular}{|c|c|c|c|c|}
\hline Label (cont.) & $\begin{array}{l}\text { Definition of } \\
\text { Theme }\end{array}$ & Key Descriptors & $\begin{array}{l}\text { Exclusions or } \\
\text { Qualifications } \\
\text { for Identifying } \\
\text { Themes }\end{array}$ & $\begin{array}{l}\text { Example of } \\
\text { Positive Cases of } \\
\text { the Theme }\end{array}$ \\
\hline $\begin{array}{l}\text { 5. Providing } \\
\text { Support/ } \\
\text { Bring Out } \\
\text { the Best in } \\
\text { Others }\end{array}$ & $\begin{array}{l}\text { This theme } \\
\text { focuses on the } \\
\text { leader helping, } \\
\text { supporting or } \\
\text { giving advice to } \\
\text { an individual. It } \\
\text { also relates to } \\
\text { putting others } \\
\text { needs before } \\
\text { one's own and } \\
\text { helping people } \\
\text { be their best. }\end{array}$ & $\begin{array}{ll}\text { - } & \text { Helping } \\
\text { - } & \text { Giving advice } \\
\text { - } & \text { Supporting } \\
\text { - } & \text { Mentoring } \\
\text { - } & \text { Caring for } \\
\text { people } \\
\text { - Providing } \\
\text { guidance [to an } \\
\text { individual] } \\
\text { - Put others } \\
\text { before you } \\
\text { - Well-being of } \\
\text { others } \\
\text { - Serve others }\end{array}$ & $\begin{array}{l}\text { This theme does } \\
\text { not include } \\
\text { guiding others } \\
\text { if it is talking } \\
\text { about guiding } \\
\text { others or a } \\
\text { group toward a } \\
\text { goal - but it } \\
\text { could include } \\
\text { guiding if it's } \\
\text { about providing } \\
\text { advice or } \\
\text { personal } \\
\text { support. }\end{array}$ & $\begin{array}{l}\text { Being able to give } \\
\text { thoughtful advice } \\
\text { to others. } \\
\text { Leadership is to take } \\
\text { charge and help } \\
\text { others get through } \\
\text { situations. To be a } \\
\text { guide and a mentor } \\
\text { to others. To put } \\
\text { others before } \\
\text { yourself. }\end{array}$ \\
\hline $\begin{array}{l}\text { 6. Modeling } \\
\text { Behavior/ } \\
\text { Set Example }\end{array}$ & $\begin{array}{l}\text { This theme } \\
\text { involves } \\
\text { someone setting } \\
\text { a positive } \\
\text { example or } \\
\text { being a role } \\
\text { model in their } \\
\text { actions or } \\
\text { overall sense of } \\
\text { being. It also } \\
\text { relates to } \\
\text { leading with } \\
\text { morality and } \\
\text { ethics. }\end{array}$ & $\begin{array}{ll}\text { - } & \text { Look up to } \\
\text { - } & \text { Modeling } \\
\text { - } & \text { Role Model } \\
\text { - } & \text { Set Example } \\
\text { - } & \text { Positive } \\
& \text { Example } \\
\text { - } & \text { Moral, ethics } \\
\text { - } & \text { Lead through } \\
& \text { actions (not } \\
& \text { just words) }\end{array}$ & $\begin{array}{l}\text { This theme } \\
\text { involves } \\
\text { explicit mention } \\
\text { of someone } \\
\text { being a role } \\
\text { model or } \\
\text { positive } \\
\text { example, not } \\
\text { just mention of } \\
\text { positive or } \\
\text { admirable } \\
\text { qualities (which } \\
\text { instead is in } \\
\text { theme five). }\end{array}$ & $\begin{array}{l}\text { A true leader is } \\
\text { someone who } \\
\text { influences and } \\
\text { directs others by } \\
\text { their actions. It is } \\
\text { someone who sets } \\
\text { the example for } \\
\text { others to follow. } \\
\text { Leadership means } \\
\text { being able to take on } \\
\text { a position that } \\
\text { represents my } \\
\text { beliefs, integrity, } \\
\text { and morals that will } \\
\text { enhance my } \\
\text { community and } \\
\text { surrounding } \\
\text { community. }\end{array}$ \\
\hline
\end{tabular}




\begin{tabular}{|c|c|c|c|c|}
\hline Label (cont.) & $\begin{array}{l}\text { Definition of } \\
\text { Theme }\end{array}$ & Key Descriptors & $\begin{array}{l}\text { Exclusions or } \\
\text { Qualifications } \\
\text { for Identifying } \\
\text { Themes }\end{array}$ & $\begin{array}{l}\text { Example of } \\
\text { Positive Cases of } \\
\text { the Theme }\end{array}$ \\
\hline $\begin{array}{l}7 . \\
\text { Admirable } \\
\text { Personal } \\
\text { Qualities }\end{array}$ & $\begin{array}{l}\text { This theme } \\
\text { involves } \\
\text { mention of } \\
\text { positive or } \\
\text { admirable } \\
\text { personal } \\
\text { qualities that an } \\
\text { individual has or } \\
\text { demonstrates. }\end{array}$ & $\begin{array}{ll}\text { - } & \text { Respected } \\
\text { - } & \text { Likeability } \\
\text { - } & \text { Passion } \\
\text { - } & \text { Problem } \\
& \text { solving ability } \\
\text { - } & \text { Intelligent } \\
\text { - } & \text { Charisma } \\
\text { - } & \text { Ambition } \\
\text { - } & \text { Confidence } \\
\text { - } & \text { Wisdom } \\
\text { - } & \text { Success } \\
\text { - } & \text { Strength } \\
\text { - } & \text { Stands out }\end{array}$ & $\begin{array}{l}\text { This theme } \\
\text { must focus on } \\
\text { some specific, } \\
\text { positive quality } \\
\text { or ability that } \\
\text { an individual } \\
\text { has that makes } \\
\text { them } \\
\text { exceptional or } \\
\text { makes them a } \\
\text { leader. }\end{array}$ & $\begin{array}{l}\text { Leadership is } \\
\text { someone standing } \\
\text { out and taking a } \\
\text { stand for something. } \\
\text { Leadership is } \\
\text { decision that a } \\
\text { person makes to take } \\
\text { upon themselves to } \\
\text { succeed through } \\
\text { their } \\
\text { determination. } \\
\text { To me, leadership } \\
\text { describes a person } \\
\text { that is self- } \\
\text { motivated, has set } \\
\text { goals, good } \\
\text { influence, great } \\
\text { spirit and a great } \\
\text { leader. }\end{array}$ \\
\hline $\begin{array}{l}\text { 8. Positive } \\
\text { Difference/ } \\
\text { Community } \\
\text { Focus }\end{array}$ & $\begin{array}{l}\text { This theme } \\
\text { involves } \\
\text { leadership for a } \\
\text { greater good, } \\
\text { making a } \\
\text { positive } \\
\text { difference, } \\
\text { caring about the } \\
\text { larger } \\
\text { community, or } \\
\text { affecting } \\
\text { something } \\
\text { beyond the } \\
\text { group or } \\
\text { individual. }\end{array}$ & $\begin{array}{ll}\text { - } & \text { Make a } \\
\text { - } & \text { Pifference } \\
\text { Positive } \\
\text { - } & \text { Commorence } \\
\text { - } & \text { Community } \\
\text { Focus } \\
\text { - } \quad \text { Greater Good } \\
\text { - } \quad \text { Making things } \\
\text { Better } \\
\text { - Caring about } \\
\text { the Larger } \\
\text { Community/ } \\
\text { Bigger Picture } \\
\text { - Responsibility } \\
\text { to a Cause or } \\
\text { Purpose } \\
\text { Best Interest }\end{array}$ & $\begin{array}{l}\text { Although they } \\
\text { may be } \\
\text { combined or } \\
\text { thought of as } \\
\text { very similar, } \\
\text { this theme is } \\
\text { different from } \\
\text { shared goal in } \\
\text { theme nine. } \\
\text { The emphasis } \\
\text { here is that the } \\
\text { purpose of the } \\
\text { leadership } \\
\text { process is } \\
\text { enhancing } \\
\text { something or } \\
\text { focusing on a } \\
\text { larger } \\
\text { community }\end{array}$ & $\begin{array}{l}\text { To be outspoken and } \\
\text { a person who } \\
\text { makes a difference. } \\
\text { Leadership means } \\
\text { having ambition, the } \\
\text { drive to have a } \\
\text { purpose in your } \\
\text { personal space, in } \\
\text { your living area, } \\
\text { your community, } \\
\text { and your world. } \\
\text { A leader is someone } \\
\text { who can embody the } \\
\text { message of the } \\
\text { group, engage others } \\
\text { and inspire respect } \\
\text { within the } \\
\text { community. }\end{array}$ \\
\hline
\end{tabular}




\begin{tabular}{|c|c|c|c|c|}
\hline Label (cont.) & $\begin{array}{l}\text { Definition of } \\
\text { Theme }\end{array}$ & Key Descriptors & $\begin{array}{l}\text { Exclusions or } \\
\text { Qualifications } \\
\text { for Identifying } \\
\text { Themes }\end{array}$ & $\begin{array}{l}\text { Example of } \\
\text { Positive Cases of } \\
\text { the Theme }\end{array}$ \\
\hline $\begin{array}{l}\text { 9. Shared } \\
\text { Goal }\end{array}$ & $\begin{array}{l}\text { This theme } \\
\text { involves } \\
\text { recognition of a } \\
\text { common or } \\
\text { shared goal or } \\
\text { purpose within a } \\
\text { group. }\end{array}$ & $\begin{array}{ll}\text { Common/ } \\
\text { Shared Goal } \\
\text { - Common/ } \\
\text { Shared } \\
\text { Purpose } \\
\text { - Agreed upon } \\
\text { goal or } \\
\text { direction }\end{array}$ & $\begin{array}{l}\text { This focus on } \\
\text { Shared Goal } \\
\text { trumps that of } \\
\text { goal attainment } \\
\text { in theme ten. If } \\
\text { there is a } \\
\text { mention of a } \\
\text { shared goal, this } \\
\text { theme is } \\
\text { appropriate. If } \\
\text { there is also a } \\
\text { strong focus on } \\
\text { task } \\
\text { accomplishment } \\
\text { then both } \\
\text { themes nine and } \\
\text { ten are applied. }\end{array}$ & $\begin{array}{l}\text { Leadership is to } \\
\text { motivate a group of } \\
\text { people with a } \\
\text { common goal to } \\
\text { complete a certain } \\
\text { task. } \\
\text { Ability to take } \\
\text { others in a direction } \\
\text { agreed upon by the } \\
\text { entire group. }\end{array}$ \\
\hline $\begin{array}{l}\text { 10. Task/ } \\
\text { Goal/ Action }\end{array}$ & $\begin{array}{l}\text { This theme } \\
\text { involves } \\
\text { accomplishing a } \\
\text { goal or engaging } \\
\text { in a task or } \\
\text { action. It can } \\
\text { also involve } \\
\text { stepping up and } \\
\text { taking initiative. }\end{array}$ & $\begin{array}{ll}\text { - } & \text { Complete a } \\
\text { task } \\
\text { - } & \text { Accomplish a } \\
\text { Goal } \\
\text { - } & \text { Take action } \\
\text { - } & \text { Take initiative } \\
\text { (on } \\
\text { accomplishing } \\
\text { a task) } \\
\text { - Step up } \\
\text { - Get things } \\
\text { done } \\
\text { - Output or } \\
\text { outcome } \\
\text { Objective }\end{array}$ & $\begin{array}{l}\text { If there is a } \\
\text { focus on Shared } \\
\text { Goal, theme } \\
\text { nine should be } \\
\text { applied. }\end{array}$ & $\begin{array}{l}\text { Pulling together a } \\
\text { group and getting } \\
\text { stuff done. } \\
\text { Knowing when it is } \\
\text { appropriate to take } \\
\text { initiative in taking } \\
\text { charge } \\
\text { Leadership is the } \\
\text { ability influence } \\
\text { others to } \\
\text { accomplish an } \\
\text { objective. }\end{array}$ \\
\hline
\end{tabular}




\section{APPENDIX E: INTERCORRELATIONS OF PREDICTOR VARIABLES FOR}

\section{LOGISTIC REGRESSION ANALYSES}

\begin{tabular}{|c|c|c|c|c|c|c|c|}
\hline & 1 & 2 & 3 & 4 & 5 & 6 & 7 \\
\hline 1. Gender & $\ldots$ & & & & & & \\
\hline 2. Race & .00 & 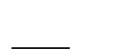 & & & & & \\
\hline 3. Age & -.01 & $-.08 *$ & - & & & & \\
\hline $\begin{array}{l}\text { 4. Parent's Formal } \\
\text { Education }\end{array}$ & $.08 * *$ & $-.21 * * *$ & $-.21 * * *$ & 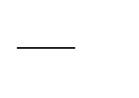 & & & \\
\hline $\begin{array}{l}\text { 5. Community } \\
\text { Service }\end{array}$ & -.04 & -.02 & .05 & -.01 & $\underline{-}$ & & \\
\hline $\begin{array}{l}\text { 6. Socio-Cultural } \\
\text { Conversations }\end{array}$ & -.01 & .02 & -.11 & .12 & .19 & $\ldots$ & \\
\hline $\begin{array}{l}\text { 7. Off-Campus } \\
\text { Work }\end{array}$ & -.02 & .00 & $.32 * * *$ & $-.18^{* * *}$ & -.03 & $-.10^{* *}$ & 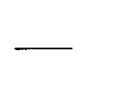 \\
\hline $\begin{array}{l}\text { 8. On-Campus } \\
\text { Work }\end{array}$ & -.02 & .04 & -.04 & -.02 & $.10^{* * *}$ & .05 & $-.25 * * *$ \\
\hline $\begin{array}{l}\text { 9. College Org } \\
\text { Involvement }\end{array}$ & .02 & $-.08 * *$ & $-.21 * * *$ & $.15^{* * *}$ & $.41 * * *$ & $.24 * * *$ & $-.21 * * *$ \\
\hline 10. Leadership Role & .03 & $-.07 *$ & $-.14 * * *$ & $.12^{* * *}$ & $.39 * * *$ & $.16^{* * *}$ & $-.13 * * *$ \\
\hline $\begin{array}{l}\text { 11. Community } \\
\text { Org Involvement }\end{array}$ & -.06 & -.05 & $.26 * * *$ & -.06 & $.32 * * *$ & $.08 * *$ & $.19 * * *$ \\
\hline $\begin{array}{l}\text { 12. Leadership } \\
\text { Program }\end{array}$ & .00 & .01 & $-.08 * *$ & .05 & $.33 * * *$ & $.16^{* * *}$ & $-.08 * *$ \\
\hline $\begin{array}{l}\text { 13. Social Greek } \\
\text { Org }\end{array}$ & -.05 & .02 & $.09 * *$ & -.06 & $-.16^{* * *}$ & .05 & .02 \\
\hline $\begin{array}{l}\text { 14. Sports- } \\
\text { Intercollegiate }\end{array}$ & $-.14 * * *$ & $.13 * * *$ & .04 & -.06 & $-.09 * *$ & .00 & .03 \\
\hline $\begin{array}{l}\text { 15. Student } \\
\text { Government }\end{array}$ & .02 & .06 & .04 & -.02 & $-.20 * * *$ & $-.14 * * *$ & $.09 * *$ \\
\hline
\end{tabular}




\begin{tabular}{|c|c|c|c|c|c|c|c|}
\hline & 8 & 9 & 10 & 11 & 12 & 13 & 14 \\
\hline $\begin{array}{l}\text { 8. On-Campus } \\
\text { Work }\end{array}$ & - & & & & & & \\
\hline $\begin{array}{l}\text { 9. College Org } \\
\text { Involvement }\end{array}$ & $.16^{* * *}$ & - & & & & & \\
\hline 10. Leadership Role & $.13 * * *$ & $.66^{* * *}$ & - & & & & \\
\hline $\begin{array}{l}\text { 11. Community } \\
\text { Org Involvement }\end{array}$ & .01 & $.13 * * *$ & $.17^{* * *}$ & - & & & \\
\hline $\begin{array}{l}\text { 12. Leadership } \\
\text { Program }\end{array}$ & $.16^{* * *}$ & $.38 * * *$ & $.44^{* * *}$ & $.13^{* * *}$ & - & & \\
\hline $\begin{array}{l}\text { 13. Social Greek } \\
\text { Org }\end{array}$ & .02 & -.23 & -.21 & .05 & -.15 & 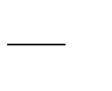 & \\
\hline $\begin{array}{l}\text { 14. Sports- } \\
\text { Intercollegiate }\end{array}$ & -.01 & $-.09 * *$ & $-.11 * * *$ & .04 & .03 & .03 & $\ldots$ \\
\hline $\begin{array}{l}\text { 15. Student } \\
\text { Government }\end{array}$ & $-.15^{* * *}$ & $-.30 * * *$ & $-.36^{* * *}$ & $-.09 * *$ & $-.25 * * *$ & $.09 * *$ & .05 \\
\hline
\end{tabular}

